Q

41 L86A25 




\section{Digitized by the Internet Archive in 2007 with funding from Microsoft Corporation}




\title{
THE CELEBRATION OF THE
}

\section{TWO HUNDRED AND FIFTIETH}

\author{
ANNIVERSARY
}

OF THE

\section{ROYAL SOCIETY OF LONDON}

\author{
JULY 15-19, 1912
}

\section{LONDON}

PRINTED FOR THE ROYAL SOCIETY

AT THE OXFORD UNIVERSITY PRESS

AND SOLD BY HUMPHREY MILFORD, AMEN CORNER, E.C.

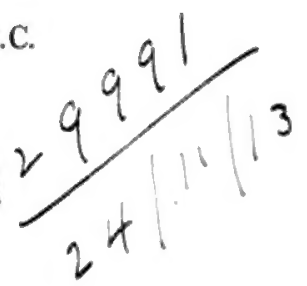


OXFORD: HORACE HART

PRINTER TO THE UNIVERSITy

$Q$
41

$186 A 25$ 


\section{CONTENTS}

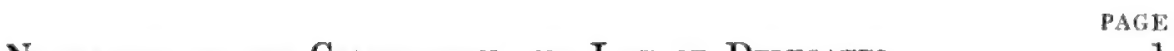

Narrative of the Celebration and List of Delegates . • • 1

Adpress by the Dean of Westminster . . . . . . 5

Address by the President of the Royal Sochety . . . . 8

Latin Speeches by the Public Orators of the Universitiles of Oxford and Cambridge in presenting Delegates for Honorary

DEgrees . . . . . . . . . . 24

Addresses of Felicitatiox . . . . . . . . . . 31

Telegrams and Letters . . . . . . . . . . 123

INDEX . . . . . . . . . . . . . 125 


\section{THE ROYAL SOCIETY}

\section{CELEBRATION OF THE 250TH ANNIVERSARY}

Ov the 15th of July 1662 a Charter granted by King Charles II passed the Great Seal incorporating, under the name of 'The Royal Society', a company of eminent and enthusiastic men who for some years had been prosecuting the study of Natural Science, or, as it was then termed, Experimental Philosophy. This date has accordingly been reckoned to be that of the birth of the Society as an organized association. The approach of the 250th return of the day suggested that the event was one which might appropriately be marked by some special form of commemoration. Hence, early in the year 1911 the President and Council of the Society determined to make it the occasion of a Celebration which should be held at a time as near as might be found convenient to that of the Society's birthday on 15th July 1912.

As an appropriate permanent memorial of the occasion two volumes were undertaken to be prepared and published-(1) a new edition of the 'Record' of the Society and (2) a facsimile reproduction of the pages of signatures of the Fellows in the Charterbook, from that of the Royal Founder down to those entered in the summer of 1912.

The 'Record ', as revised, re-arranged, and enlarged, is intended to give an account of the foundation and early history of the Society with the text of all its Charters, its Statutes with their variations down to the present time, the Society's various Trusts, lists of its Benefactors, its Presidents and Officers and its Medallists and Lecturers, with an account of its Library, Portraits, Busts, and Medals, likewise full details regarding the existing Committees and the various work of the Society. The Chrono- 
logical Register of the Fellows has been thoroughly revised and for the first time made complete.

'The facsimile reproduction of the Signatures has been successfully accomplished by the University Press, Oxford, and has been published in a folio volume with the title, "The Signatures in the First Journal-book and the Charter-book of the Royal Society.' This interesting volume contains the autographs of the Fellows from the first founders down to the present day, and is probably the most extensive existing collection of the signatures of distinguished leaders in science during the last two centuries and a half. Besides the pages of the Charter-book, the volume also comprises facsimiles of three pages of the first Journalbook of the Society, on which, under date 5th December 1660, are inscribed the autograph signatures of the original company of men of science and their friends and well-wishers who resolved to form themselves into an organized Society, and who, some nineteen months later, were incorporated by the King as 'The Royal Society'. One of the chief difficulties in the preparation of this facsimile volume arose in the decipherment of many of the signatures and the compilation of an alphabetical List which should give accurately the dates of admission into the Society, with the page of the Charter-book on which each signature would be found. But in the end every signature was identified, and the volume together with the 'Record' were both ready for distribution by the 13th of July, on which day the President and Treasurer had the honour of presenting a copy of each volume to His Majesty King George $\mathbf{V}$, who was graciously pleased to accept them and to express his interest in the forthcoming Celebration. Copies of these volumes were subsequently sent to the Universities, Academies, and other Institutions that were represented at the Anniversary.

The invitations to be present in London for the purpose of attending the Society's Celebration began to be issued in January 1912. Each Foreign Member and a number of eminent foreign men of science who were not Members were specially invited, and the Universities, Academies, and other learned Institutions in the United Kingdom, in the British Dominions beyond the Sea, and in all the civilized countries of the world, were each asked to 



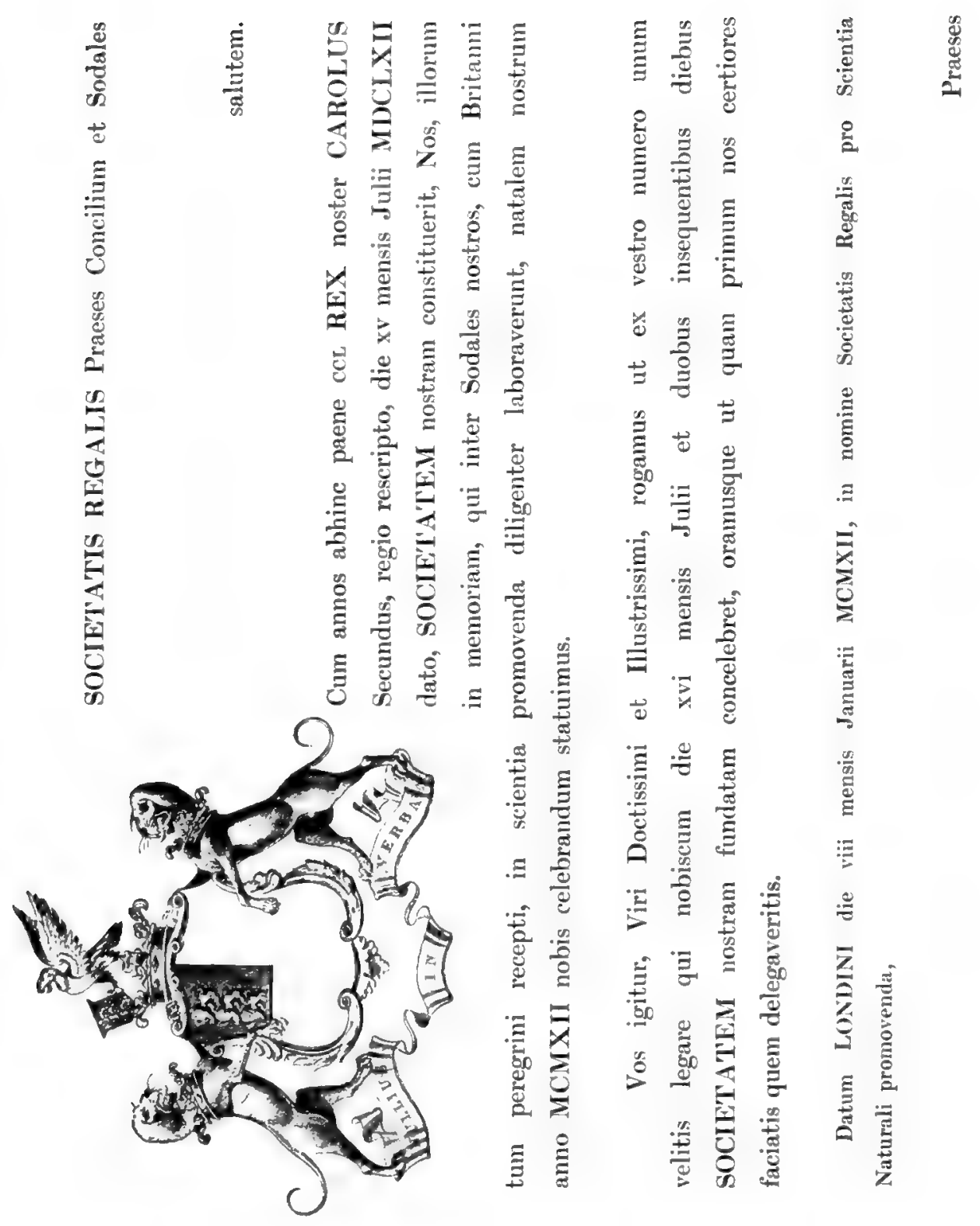


send a delegate. The illuminated Invitation was in Latin and in the accompanying form, with the requisite verbal variations in the last paragraph when addressed to individual persons.

It was arranged that the various functions should extend from the evening of Monday, July 15th, to the evening of Thursday, 18th. The following Diary was printed and placed in the hands of the Fellows and visitors before the proceedings began :

$$
\text { Monday, JULY 15Th. }
$$

Evening Reception of the Delegates in the Rooms of the Royal Society, Burlington House, Piccadilly, 8.30 to 11 p.m. The Enquiry Office will be open from 9 a.m. to 7 p.m. this day, and on application there, Delegates and Fellows will obtain all the tickets required for the various functions of the Celebration.

\section{Tuesday, July $16 \mathrm{rH}$.}

Commemorative Service in Westminster Abbey; 12 noon.

Formal Reception of the Delegates and Presentation of Addresses in the Great Library of the Royal Society, 2.30 p.m.

Banquet in the Guildhall of the City of London, 6.30 for 7 p.m.

$$
\text { Wednesday, JuLY } 17_{\mathrm{TH}} \text {. }
$$

Visits in the morning to Places of Interest in and near London.

Garden Party given by Her Grace the Duchess of Northumberland, at Syon House, on the Thames (4 to 7 o'clock).

Conversazione at the Royal Society, 9 o'clock.

$$
\text { Thursday, July 18тh. }
$$

Visits in the morning to Places of Interest in and near London.

Garden Party at Windsor given by Their Majesties the King and Queen.

In the evening Dinner Parties; particulars of which will await Delegates and

Fellows at Burlington House from the morning of Monday, July 15th, onward.

The formal Celebration was held in the Rooms of the Royal Society in Burlington House. For the convenience of those attending it, an Enquiry Office and Post Office were fitted up in the adjoining meeting-room of the Geological Society, which that Society had kindly lent for the occasion, and where all the 
cards of invitation, tickets, and other documents connected with the Celebration were obtainable.

A number of the Clubs in the west end of London elected Foreign and Colonial Delegates Honorary Members during the time of the commemoration. A Committee of Ladies was formed for the purpose of providing entertainment for ladies accompanying delegates, at such times as they would not be present at the functions of the Society. The meeting-room of the Royal Society was set apart for the use of these ladies. 'The Ladies' Committee took care that some of their number should always be in attendance in that room at specified hours in order to render every assistance in their power. By wearing different coloured badges they indicated which of them spoke French, German, or Italian. They organized visits to the Royal Gardens, Kew, and to places of interest in London, and some of their number accompanied the excursionists.

A Register was kept in which every Delegate was requested to sign his name. This collection of autographs forms an interesting record which will be preserved among the Society's archives.

The Royal Society's invitation met with a cordial reception all over the globe. The great majority of the Universities, Academies, and other scientific Institutions sent delegates who presented congratulatory addresses. In cases where delegation was not attempted the addresses arrived by post together with many telegrams of felicitation. The following is a brief narrative of the proceedings throughout the Anniversary:

\section{Monday, July 15Th, 1912.}

This being the birthday of the Royal Society the President, Council, and Fellows assembled in the evening in their Library for the purpose of informally welcoming such of the Delegates as had already arrived in London, and settling with them some of the arrangements for the more formal reception to be held on the following day. A large proportion of visitors were present, though some were unable to reach London in time for this meeting. 


\section{Tuesday July 16Th.}

By arrangement with the Dean and Chapter, a short commemorative service was held at noon in the ancient Abbey of Westminster. Assembling in the historic Jerusalem Chamber, the President and Council of the Royal Society, in academic dress and preceded by the Society's Mace, followed in procession the Dean and clergy to the places reserved for them. Seats were set apart for the general body of the Fellows, for the Foreign Members, and for the Delegates and ladies who had accompanied them. The music was arranged and conducted by the organist of the Abbey, Sir Frederick Bridge, C.V.O., Mus.Doc. Towards the close of the service a short address was given by the Dean, the Right Reverend Bishop Ryle, C.V.O., D.D., who, at the request of the Society, has permitted it to be printed here.

\section{Address by the Dean of Westminster.}

1 Esdras iv. 38, 40, 41. Truth abideth, and is strong for ever; she liveth and conquereth for evermore. ... Blessed be the God of truth.... And all the people then shouted, and said, Great is truth, and strong above all things.

'Magna est veritas, et praevalet.'

'There have been times even within the memory of some who are gathered within these walls, when a welcome such as we have desired to give in this Abbey to the Members of the Royal Society on the occasion of its 250th Anniversary, would have received but a faint echo from the religious world of this country.

'The perturbation which took possession of men's minds last century at the period of the most startling of the discoveries in Natural Science was wont to betray itself too often in ill-considered words of fear, impatience, and indignation. Nor need we wonder. To quote the words of John Fiske: "The men of the present day who have kept pace with the scientific movement are separated from the men whose education ended in 1830 by an immeasurably wider gulf than ever before divided one progressive generation of men from their predecessors." Misunderstanding, apprehension, and friction were the result. 
'We look back with regret upon any occasion when the cause of truth on any of its many sides has been compromised by the attitude of its defenders; or when the spirit of charity and toleration has been forgotten in the wretched atmosphere of controversy.

'Times are changed. I believe I may claim to speak in the name of the whole world of contemporary Christian thought, when in this Abbey I give expression to the gratitude which, as a rule, we clergy have little opportunity to render, for the amazing enrichment of human thought which has resulted from the patient researches of Natural Science during the past two hundred and fifty, and in particular during the past eighty, years. We thank God for the great and glorious work that has been done by the men of science; for the widening of human thought; for the elevation communicated to the methods and ideals of study. "Science," as has finely been said by an eminent religious teacher in our own day"science is truly a revelation.... Instead of the round world which cannot be moved, every star that twinkles in the sky becomes a fiery sun whirling through the deeps of space. Instead of the six days of creation, we look down vistas of time to which a thousand years are no more than a watch in the night. Instead of repeated acts of creation, we see a mighty chain of life stretching upwards from the sea-weeds and the sponges to-where shall we put a limit to all-enduring patience and all-sovereign goodness?" 1

'With all humility we express our grateful obligation for the benefits which for a quarter of a millennium have been rendered in this country by the Royal Society. In no small measure it has been due to the weight of wise opinion created by its studies and observations, that the intellectual life of the people has emerged so far as it has from the influence of the Middle Ages. The work of the Royal Society has tended to elevate and purify thought. It is untrammelled by party politics. Its studies overleap the barriers of race and language. They make for the peace of the world, as well as for the well-being of every class. They continually contribute to the promotion of Unity. 'Truth is one; and however feebly our words may express it, yet we are convinced

1 Gwatkin, Knowledge of God, ii. 275. 
that the discoveries of Science discharge a truly prophetic office in making known to mankind the facts of the Universe, in which we believe we may read the record of the Will of the Supreme Mind. And in deepest humility we express our conviction that the God whose laws are discerned in evolution, gravitation, and the conservation of energy is $\mathrm{He}$ whose laws will be no less clearly discerned in love, forgiveness, and redemption, in the spiritual existence and in the gift of immortality.

'We stand, as it were, bareheaded, while you proclaim to a solemnized and attentive world the wonderful mysteries of the Universe. You have added sanctity to the knowledge of phenomena; you have laid deep and lasting the foundations of accurate research; you have quickened intellectual life with the enthusiasm for the investigation of truth. You bid us not stand, but go forward.

'In conclusion, let me remind you, while I bring to an end this word of welcome to our Abbey, that we revere in this place the great names which are famous on your roll of distinction, and which are no less famous among the memorials committed to our keeping. Newton and Darwin, Herschel and Adams, Humphry Davy and Woodward, Buckland, Lyell and Joule, William Spottiswoode and Stokes and Kelvin, how varied, how illustrious is this galaxy of men, so simple in their lives, so potent in their influence! It is not for me to speak. But I suppose we should not be wrong to assume that even with the light which the work of these great men has shed upon the pathway of the progress of mankind, we have only so far travelled a little way out of darkness. What may we not in all humility pray for and expect from the discoveries of Natural Science in the next two hundred and fifty years?

'That in the future, as in the past, the work of your Society may be blessed to the increase of human knowledge, for the good of our fellow creatures, and in the maintenance of just and charitable opinion among all classes of the community, is, I am sure, the earnest prayer of every man who has the fear of God in his heart.

" If Reason may not command," said Whichcote, some two hundred and fifty years ago, "it will condemn." And it is 
through the pre-eminent influence of the men of the Royal Society in the field of Natural Science, that we believe that Reason, as the noblest gift of God to man, will assert its unfailing and beneficent sway, never ceasing to be touched with the passionate search for the secrets of truth and ever fired with the love of our fellow creatures, and animated with the generous hope of benefiting them through the application of scientific discovery. Magna est veritas, et praevalet.'

In the afternoon at $\mathbf{2 . 3 0}$ the formal Reception of the Delegates took place in the Great Library of the Royal Society, which was completely filled. The Delegates were grouped according to the countries they represented, these countries being taken in alphabetical order. After the visitors had been marshalled to the seats reserved for each country the proceedings began with an address from the President, Sir Archibald Geikie, who spoke as follows :

\section{Addiess of the President.}

' On behalf of the Royal Society, I desire to express our warm appreciation of the sympathetic response which has been made by so many Universities, Academies, and learned Institutions in all parts of the world, and by so many distinguished men of science, to our invitation to celebrate with us on this occasion the 250th birthday of the Society. No more striking proof than is presented by this assembly could be given of the reality and cordiality of that spirit of frank and loyal co-operation which unites into one great brotherhood the students of science in every land and in every language. We welcome you, Gentlemen, with our whole heart. We appreciate most sincerely the honour which has been conferred on the Royal Society by your presence here to-day. We greet the Delegates who bring to us the felicitations of some of the oldest centres of culture in Europe, which had become famous some centuries before our own Society was born. Not less fully do we rejoice to meet the Delegates from the younger Institutions in our own and other lands, who have come from British dominions beyond the seas, from furthest $A$ sia and Africa, and in such numbers from the Great Republic across the Atlantic where the lamp of science now burns with so bright a radiance and in so many 
centres of growing activity. While it is a proud satisfaction to receive among our guests to-day leaders in science whose names have become honoured household words in all parts of the globe. the gratification is not less to find, among your number, scholars who represent the older literary learning, who have been deputed to convey to us the congratulations of the time-honoured Universities which they adorn. To one and all we return our grateful thanks for your presence here at our Celebration. We sincerely desire that the few festal days which you are to spend with us may be in every way enjoyable to you, so that your impressions of your visit to London on this occasion may become a pleasant memory which you will care to cherish in the days to come.

' 'Two hundred and fifty years seem in some respects no long span of time in the course of human history, but the two hundred and fifty years across which we look back to-day have been in the history of science a period of momentous importance, crowded with incident, and full of marvellous achievement. When in the earlier decades of the seventeenth century Francis Bacon was so cogently insisting on the necessity of studying Nature by the careful observation of facts and the testing of conclusions by experiment, he made but slight practical impression in England. The seed which he sowed did not spring into life until after he had passed away. About the middle of the century, howerer, the spirit of eager curiosity and inquiry with regard to the world wherein we live, which spread over all civilized countries, reached England also. Nature was still, as it had been from the earliest days of mankind, a vast unknown region, full on erery hand of mystery and wonder. Even the most everyday phenomena presented to thoughtful minds problems for which no satisfactory solution had been found. The earnest desire to seek an explanation of some of these familiar phenomena at last induced a remarkable group of men in this country to organize themselves systematically for the prosecution of that experimental philosophy which Bacon had so longed to see pursued. 'The time, however, was not propitious, for it was one of political turmoil and civil war in England. 'The studious men who desired to pursue these researches sought refuge from the social strife in the quiet investigation of Nature. They met weekly in London, where they 
discussed many and diverse questions in physical and biological science, devising and carrying into execution numerous experiments by which they tried to ascertain the nature and connexion of some of the fundamental processes in the economy of this world. When the civil commotions drove them from their meeting-place in London, some of the more active and enthusiastic among their number sought the shelter of Oxford, where, under the hospitable roof of W adham College, they were able to continue their inquiries.

'The restoration of the Monarchy in the early summer of the year 1660 , which led to the re-establishment of settled order in the country, allowed the resumption of scientific meetings in the autumn of that year. With the brighter prospects of peace before them, the philosophers assembled once more in the picturesque Gresham College in the city of London, and for the better accomplishment of their aims they determined to form themselves into a definite Society with a regular organization and a common fund from which the cost of experiments could be defrayed. Had they restricted the membership of their proposed Society to men of science, properly so called, their number would hardly have exceeded two score. But with commendable foresight they took advantage of the prevalent spirit of curiosity regarding the secrets of Nature, and gathered round them a company of three times their own number comprising prominent representatives of the Church, of Law, of Medicine, of Politics, and of the Public Services. Their adherents included also men of letters, and it is specially noteworthy that among these were the foremost poets in the England of that day-John Dryden, Edmund Waller, John Denham, Abraham Cowley, William Hammond, and Thomas Stanley. This brilliant assemblage of the intellect and learning of the time soon attracted the notice and the active sympathy of King Charles II, who himself had his full share of the widespread contagion of curiosity and inquiry. $\mathrm{He}$ attended some of the meetings of the infant Society, and on the 15th July 1662 granted to it a Charter of Incorporation with the name of "The Royal Society" and the definite constitution under which it is still governed. That date was thus regarded as the birthday of the Society which, after the lapse of two centuries and a half, we are met to-day to celebrate. 
"The career of the Royal Society is fully recorded in its various publications. Its "Philosophical Transactions" and "Proceedings", and likewise the separate works which it has issued, form a chronicle from which the successive stages in the progress of modem science can be followed. The enumeration of only a few of the names which appear in these volumes shows that the Society has counted among its Fellows some of the great leaders in all branches of Natural Knowledge. Starting its career with a notable group of physicists and mathematicians, among whom were Robert Boyle and John Wilkins, it ere long welcomed Isaac Newton into its ranks, published his immortal "Principia", and annually elected him as its President for nearly a quarter of a century. The physical sciences have all along been strongly represented here. It seems but yesterday that James Clerk Maxwell's voice was heard in these rooms and that Stokes and Kelvin sat in the presidential chair. That the succession of leaders is still well maintained, the presence here to-day of Lord Rayleigh, Sir William Crookes, Sir Joseph Thomson, Sir Joseph Larmor, and many others amply proves. Nor have the biological sciences been less prominent in the work of the Society. From the early days of John Ray down to those of Charles Darwin, Hooker, Huxley and Lister, every branch of biology has been illustrated and advanced by our Fellows.

'As Science knows no restriction of country or' language, the Royal Society has from its earliest beginning cultivated friendly relations with fellow workers in research all over the world. The first list of original members includes the honoured name of the physicist and astronomer Huygens, some of whose gifts to us we still possess; and from that time till now the Society has been proud to inscribe on the roll of its Foreign Members the names of the most illustrious exponents of science in each generation. It has been glad also to recognize distinction by the award of its medals far beyond the bounds of the British Dominions. At the same time the Academies and Universities of other lands have ever shown a generous recognition of the labours of the Fellows of the Royal Society, honouring them by electing them into their membership or by conferring upon them academic degrees. This confraternity of the commonwealth of science reaches to-day the climax of its manifestation in our experience, when we receive 
delegates from so many countries who by their presence here express the sympathy and goodwill of the various institutions which they represent. To these institutions, venerable and youthful, a formal expression of our grateful appreciation will in due course be transmitted. In the meantime I will conclude these opening remarks by again thanking you for your presence here to-day and bidding you a cordial welcome to the halls of the Royal Society.'

The presentation of Addresses from the various Institutions represented then began. The delegations, as arranged in the alphabetical order of the countries represented by them, are given in the following list. As it would have been impossible that the Addresses should be read at the meeting, one delegate from each country was selected who should briefly express the friendly feelings of his compatriots. The Addresses themselves will be found in extenso from p. 31 to p. 122 of this volume. 


\section{List of Delegates attending the Celebration.}

\section{EUROPE.}

Austria-Hungary.

Imperial Academy of Sciences, Vienna

Bohemian Karl-Ferdinand Univer- Prof. Dr. Frantisek Vejdovský, Rector. sity, Prague

Imperial Academy of Sciences, Cra- Prof. Dr. Leo Marchlewski. cow

Royal Hungarian University, Buda- Prof. Izidor Fröhlich, Rector. pest

\section{Belgium.}

University of Louvain - . - Prof. A. de Hemptinne.

Royal Academy of Sciences, Brussels Prof. Louis Dollo.

\section{Denmark.}

University of Copenhagen - . Prof. Hector F. E. Jungersen.

Royal Danish Society of Science, Prof. Eug. Warming.

Copenhagen

\section{France.}

University of Paris - . . Prof.Émile Picard, Membre de l'Institut. Academy of Sciences, Institute of Mons. Gabriel Lippmann, President.

France, Paris - Prof. Charles Barrois, Membre de l'Institut.

Observatory, Paris . . . Mons. Henri Deslandres, Membre de l'Institut.

Mons. A. Haller, Membre de l'Institut.

French Society of Physics, Paris - Mons. E. B. Baillaud, Membre de l'Institut,

Botanical Society of France, Paris . Mons. Philippe de Vilmorin.

Chemical Society of France, Paris . Mons. Hanriot, President.

University of Bordeaux. - . Prof. A. Pitres.

National Academy of Bordeaux - Prof. A. Pitres.

University of Clermont-Ferrand - Prof. Pellet.

University of Lille . Prof. A. Schatz.

University of Nancy - . . M. Ch. Adam, Rector.

University of Toulouse . - . Prof. Jules Drach. 
Europe-continued.

Germany.

University of Berlin

- Prof. Dr. W. Waldeyer.

Prof. Dr. W. Nernst.

University of Bonn - . . Prof. Dr. H. Kayser.

University of Breslau - . . Prof. Dr. Adolf Kneser, Rector.

University of Erlangen - . . Prof. Dr. Varnhagen.

University of Freiburg-im-Breisgau Prof. Dr. Oskar Bolza.

University of Giessen - . Prof. Dr. Walter König.

University of Göttingen - . Prof. Dr. Woldemar Voigt, Rector.

University of Greifswald . . Dr, Otto Jaekel.

University of Halle - . . Prof. Dr. J. Veit.

University of Heidelberg . - Prof. Dr. G. Quincke.

University of Königsberg - . Prof. Dr. G. Winter.

University of Leipzig - . Prof. Dr. Eduard Sievers.

Prof. Dr. W. Ostwald.

University of Marburg . - . Prof. Dr. Eugen Korschelt.

University of Munich . - . Prof. Dr. von Groth.

University of Münster - . - Prof. Dr. Karl Busz.

University of Rostock - . - Prof. Dr. Rudolf Hübner, Rector.

University of Strasburg - . Prof. Dr. J. Ficker.

University of Tübingen . - Prof. Dr. H. von Vöchting.

Royal Prussian Academy of Sciences, Prof. Dr. H. Rubens. Berlin

Royal Society of Sciences, Göttingen Prof. Dr. O. Wallach.

Royal Bavarian Academy of Sciences, Prof. Dr. von Groth. Munich

GREece.

University of Athens - - . Prof. Andrew Andreadìs.

ITALY.

University of Rome - . . Prof. Vito Volterra.

University of Bologna . . .

University of Palermo . . . Prof. Giovanni Guccia.

University of Pisa.

University of Padua

Royal Academy dei Lincei, Rome .

Royal Academy della Crusca, Florence

Royal Lombard Institute of Science Prof. Vito Volterra. and Letters, Milan 
EURoPE-continued.

Royal Society of Naples . Sir Archibald Geikie, K.C.B., P.R.S.

Zoological Station, Naples • . Prof. Reinhard Dohrn.

Royal Academy of Sciences, Turin . Lord Rayleigh, O.M., F.R.S.

Monaco.

Oceanographical Institute - Mr. J. Y. Buchanan, F.R.S.

\section{Nethertands.}

University of Amsterdam - . Prof. C. Winkler, Rector Magnificus.

University of Groningen - Prof. G. C. Nijhoff, Rector.

University of Leyden - . - Dr. F. Pijper, Rector.

University of Utrecht . - . Dr. A. A. Nyland, Rector Magnificus.

Royal Academy of Sciences, Am- Prof. P. Zeeman, Secretary.

sterdam

Dutch Society of Sciences, Haarlem . Dr. J. P. Lotsy, Perpetual Secretary.

Batavian Society of Experimental Dr. R. H. van Dorsten, Secretary.

Philosophy, Rotterdam

Norway.

Royal University of Norway, Chris- Prof. Waldemar Brögger. tiania

Academy of Sciences, Christiania - Prof. H. Mohn, President.

\section{Portugal.}

Academy of Sciences, Lisbon - . Mr. Edgar Prestage.

Russia.

Imperial Academy of Sciences, St. Dr. O. Backlund.

Petersburg

University of Moscow

University of Dorpat (Juriew)

University of Warsaw
Prince Boris Galitzin.

Prof. I. P. Pawlow.

- Prof. A. P. Goubaroff.

- Prof. Alexander Ivanovic Jarockij.

- Prof. P. I. Mitrophanow.

\section{Finland。}

University of Finland, Helsingfors . Prof. Anders Donner, Rector.

Finnish Society of Sciences, Helsing- Prof. J. J. Sederholm.

fors

Spain.

Royal Academy of Sciences, Madrid Prof. Rodriguez Carracido. 
Elrope-continued.

SWEDEN.

University of Lund - . - Prof. C. W. L. Charlier.

University of Stockholm . . Baron Gerard de Geer, Pro-Rector.

University of Upsala . . . Prof. Allvar Gullstrand.

Royal Swedish Academy of Sciences, Count K. A. H. Miorner, Vice-President. Stockholm

\section{SwITZERLaNd.}

University of Berne . . Prof. Th. Studer.

University of Geneva - . - Prof. E. Naville.

Helvetic Society of Natural Sciences,

Berne

Federal 'Technical High School, Prof. P. Weiss. Ziirich

EGYPL.

University of Egypt, Cairo - . H.H. Prince Ahmed Fouad Pacha, President-Rector.

Gordon College, Khartoum . . Dr. James Currie, Principal.

JAPAN.

Imperial University, Tokio - . Prof. R. Fujisawa.

Imperial University, Kyoto - . Prof. Jisaburo Yokobori.

\section{UNITED STATES OF AMERICA.}

University of California . - . Prof. H. C. Plummer.

University of Chicago - . - Prof. E. B. Frost.

Clark University, Worcester . - Prof. Arthur G. Webster.

Columbia University, New York . Dr. N. Murray Butler, President.

Cornell University, Ithaca, N.Y. - Prof. J. H. Comstock.

Harvard University - . . Prof. B. O. Peirce.

Johns Hopkins University, Balti- Prof. W. Bullock Clark. more

Leland Stanford Junior University, Prof. Vernon L. Kellogg. California

University of Michigan . - . Prof. William H. Hobbs.

University of Minnesota, Minnea- Dr. Arthur Hamilton. polis

University of Pennsylvania, Phila- Dr. Edgar F. Smith, Provost. delphia

University of Princeton, New Jersey Prof. John G. Hibben, President. 


\section{UntTed States of America-continued.}

University of Wisconsin - . Prof. Charles K. Leith.

Yale University - • . - Dr. Arthur Twining Hadley, President.

American Academy of Arts and Prof. Edwin H. Hall. Sciences, Boston

Connecticut Academy of Sciences Prof. Ernest W. Brown, F.R.S. and Arts

American Mathematical Society, Prof. H. B. Fine, President. New York

American Philosophical Society, Prof. W. B. Scott, Vice-President. Philadelphia

Franklin Institute, Philadelphia . Major G. O. Squier.

California Academy of Sciences, Mr. Joseph D. Grant. San Fransisco

Carnegie Institution, Washington . Dr. R. S. Woodward, President.

National Academy of Sciences, Dr. Amold Hague, Secretary. Washington

Smithsonian Institution, Washing- Dr. Arnold Hague. ton

Washington Academy of Sciences . Dr. L. O. Howard.

MEXICO.

National University of Mexico - Dr. G. C. Martinez.

\section{BRITISH DOMINIONS BEYOND THE SEAS}

Australia.

University of Adelaide - - Prof. H. Lamb, F.R.S.

University of Melbourne - . Prof. Henry Laurie.

University of Sydney, New South Prof. T. P. Anderson Stuart. Wales

Royal Society of Tasmania, Hobart Royal Society of Victoria, Melbourne

Royal Society of New South Wales, Mr. Charles Hedley. Sydney

Dr. Gregory Sprott.

Mr. J. R. Hogg.

Canada.

McGill University, Montreal . Lord Strathcona, Chancellor. Dr. W. Peterson, Principal.

University of Toronto - - . Mr. R. A. Falconer, President.

Queen's University, Kingston, On- Prof. John Watson. tario 


\section{British Dominions beYond the SEAs-continued.}

University of New Brunswick, Dr. C. C. Jones, Chancellor.

Fredericton, N.B.

University of Manitoba, Winnipeg Prof. Swale Vincent.

University of Ottawa - . . The Rev. Dr. Roy, Rector.

Royal Society of Canada, Ottawa . Sir Gilbert Parker, M.P.

Nova Scotian Institute of Science, Prof. J. G. MacGregor, F.R.S.

Halifax, N.S.

\section{INDIA.}

H.H. Maharaj Rana Sir Bhawani

Singh, Bahadur of Jhalawar,

K.C.S.I., Rajputana

University of Allahabad - Rai Bahadur G. N. Chakravati.

University of Bombay - . - Dr. F. G. Selby, late Vice-Chancellor.

University of Calcutta . - . Prof. P. C. Ray.

University of Madras . . . Dr. A. C. Mitchell.

Asiatic Society of Bengal, Calcutta Mr. G. H. Tipper, Hon. Secretary.

Mohammedan Anglo-Oriental Col- Sir Theodore Morison, K.C.I.E.

lege of Aligarh

Indian Institute of Science ․ - Dr. M. W. Travers, F.R.S., Director.

South Arrica.

University of the Cape of Good Hope Prof. A. H. MacKenzie.

Natal University College, Pieter- The Hon. J. C. Dove Wilson. maritzburg

Royal Society of South Africa - Sir David Gill, K.C.B., F.R.S.

\section{BRITISH ISLES}

\section{England and Wales.}

University of Oxford - . - Dr. C. B. Heberden, Vice-Chancellor. "Wadham College Rev. P. A. Wright-Henderson, D.D., Warden.

University of Cambridge - . Lord Rayleigh,O.M., F.R.S., Chancellor.

University of London . . . Dr. Wilmot Parker Herringham, ViceChancellor.

University of Birmingham . Sir Oliver Lodge, F.R.S., Principal.

University of Bristol Prof. Lloyd Morgan, F.R.S.

University of Durham (Armstrong Sir George H. Philipson, Vice-ChanCollege) cellor.

University of Leeds _ . . Mr. M. E. Sadler, Pro-Chancellor. 


\section{BRITTSH IsLEs-continued.}

University of Liverpool . - Prof. W. A. Herdman, F.R.S.

University of Manchester . . Sir Alfred Hopkinson, Vice-Chancellor,

University of Sheffield - . - Prof. W. M. Hicks, F.R.S., Acting Vice-Chancellor:

University of Wales . . . Sir H. Reichel Vice-Chancellor.

Royal College of Physicians . . Sir Thomas Barlow, Bart., F.R.S., President.

Royal College of Surgeons Sir Rickman J. Godlee, Bart., President.

London Society of Antiquaries . Sir Charles H. Read, President.

$"$ British Academy . . Dr. A. W. Ward, President.

" British Museum . . The Rt. Hon. The Speaker.

Sir F. G. Kenyon, K.C.B., Director.

Dr. L. Fletcher, F.R.S., Director of Natural History Museum.

" Chemical Society - . Prof. P. F. Frankland, F.R.S., President.

" Entomological Society . The Rev. F. D. Morice, President.

" Geological Society - . Dr. A. Strahan, F.R.S., President.

" Geological Survey of Great Dr. J. J. H. Teall, F.R.S., Director. Britain

Institute of Chemistry - Prof. R. Meldola, F.R.S., President.

"Institution of Civil Engi- Mr. R. Elliott-Cuoper, Vice-President. neers

Institution of Electrical Mr. S. Z. de Ferranti, President. Engineers

Institution of Mechanical Mr. E. B. Ellington, President. Engineers

Iron and Steel Institute - Mr. Arthur Cooper, President.

" Linnean Society - .- Prof. E. B. Poulton, F.R.S.

" Lister Institute of Pre- The Rt. Hon. Sir H. E. Roscoe, F.R.S., ventive Medicine Chairman.

Mathematical Society - Dr. H. F. Baker, F.R.S., President.

" Mercers' Company . . Mr. Horace Cullen, Master.

" Mineralogical Society . Prof. W. J. Lewis, F.R.S.

" Pharmaceutical Society . Mr. C. B. Allen, President.

" Physical Society . . Prof. Arthur Schuster, F.R.S., President.

" Royal Academy of Aits . Sir Edward Poynter, Bart., President.

9 Royal Agricultural Society

; Royal Anthropological Institute

» Royal Army Medical College Lord Middleton, President.

Mr. Alfred P. Maudslay, President.

Col. B. Skinner, Commandant.

" Royal Astronomical Society

Mr. F. W. Dyson, F.R.S., President. 
British IsLes-continued.

London Royal Geographical Society

" Royal Horticultural Society

" Royal Institute of British Architects

" Royal Institution of Great Britain

$" \quad$ Royal Meteorological Society

, Royal Microscopical Society

" Royal Society of Arts

" Royal Society of Medicine

" Royal Statistical Society

" Royal United Service Institution

" Zoological Society . . The Duke of Bedford, K.G., F.R.S., President.

British Association for the Advancement of Science

Cambridge Philosophical Society

Major Leonard Darwin, Vice-President. Sir Trevor Lawrence, Bart., President. Mr. Reginald Blomfield, President.

Dr. Donald W. C. Hood.

Dr. H. N. Dickson, President.

Mr. H. G. Plimmer, F.R.S., President. Lord Sanderson, G.C.B., Chairman. Sir Henry Morris, Bart., President. Lord George Hamilton, G.C.S.I.

Col. Sir Lonsdale Hale. Sir William Ramsay, K.C.B., F.R.S., President.

Sir George Darwin, K.C.B., F.R.S., President.

Royal Cornwall Polytechnic Society, Lord St. Levan.

Falmouth

Royal Observatory, Greenwich - Rear-Admiral H. E. Purey-Cust, Hydrographer to the Navy.

Manchester Literary and Philo- Prof. F. E. Weiss, President. sophical Society

Ordnance Survey, Southampton

Ashmolean Society of Oxford

National Physical Laboratory

Society of Chemical Industry
- Col. C. F. Close, Director-General.

- Dr. A. A. Rambaut, F.R.S., President.

- Dr. Rudolph Messel, F.R.S., President.
- Mr. R. Kaye Gray.

Scotland.

University of Aberdeen - - . Rev. Dr. G. Adam Smith, Principal.

University of Edinburgh . Prof. James Geikie, F.R.S.

University of Glasgow . . . . Sir Donald MacAlister, K.C.B., ViceChancellor.

University of St. Andrews - . Prof. J. C. Irvine.

Royal Society of Edinburgh . Prof. A. Crum Brown, F.R.S.

Royal Philosophical Society of Prof. John Glaister, President. Glasgow 
Brttish Isles-contimued.

IRELAND.

University of Dublin (Trinity Prof. J. Joly, F.R.S. College)

Royal Irish Academy, Dublin

Royal Dublin Society . . . Sir Ho

Prof. J. A. McClelland, F.R.S., Secretary.

Queen's University of Belfast . - Prof. J. Symington, F.R.S.

National University of Ireland, Dr. Alexander Anderson.

\section{Dublin}

On the evening of July 16th the 250th anniversary of the Royal Society was celebrated by a Dinner held in the ancient Guildhall of London, which was attended by 490 guests. Besides the representative Delegates whose names are given in the foregoing list (p. 13) the company included a large number of the Fellows of the Society, several members of the Government, the Ambassadors of France, Italy, and Japan, the Archbishops of Canterbury and York, Cardinal Bourne, the Dean of Westminster, the Moderator of the Church of Scotland, the Lord Chief Justice of England, the Master of the Rolls, the Lord Justice Clerk of Scotland, and representatives of literature, art, and science. After the usual loyal toasts the toast of 'The Royal Society' was given by Mr. Asquith, the Prime Minister, and was responded to by the President. The 'Universities at Home and Abroad' were proposed by Viscount Morley, Lord President of the Council, and responses were given by Professor Émile Picard, of the Institute of France, Professor Waldeyer, of the University of Berlin, and Professor Winkler, Rector of the University of Amsterdam. The toast of the "Learned Societies in the Old World and the New' was proposed by His Grace the Archbishop of Canterbury, and was replied to by the Marchese E. Paterno di Sessa, of the Accademia dei Lincei, Rome, Prince Boris Galitzin, of the Imperial Academy of St. Petersburg, and Dr. R. S. Woodward, President of the Carnegie Institution, Washington. The last toast, that of the 'City of London', was proposed by Dr. Peterson, Principal of McGill University, Montreal; and, in the unavoidable absence of the Lord Mayor of London, a reply was made by the Right Honourable Sir T. Vezey Strong, the previous Lord Mayor. 


\section{Wednesday, JUly 17'TH.}

The morning of this day was set apart for visits to places of interest in London, such as Lambeth Palace, Westminster Abbey, the British Museum, Bloomsbury, the Natural History Museum, South Kensington, and the Victoria and Albert Museum. Arrangements were made by which the several parties of visitors were conducted over these and other institutions, and the chief features of each were pointed out by the resident officials.

In the afternoon the Duke and Duchess of Northumberland gave a Garden Party at Syon House, their residence on the Thames, to which the Delegates and Fellows of the Royal Society with their ladies were invited. As the weather was brilliantly fine, a large company assembled in the picturesque grounds and enjoyed the summer beauty of an English park.

In the evening a Conversazione was held in the rooms of the Royal Society at Burlington House, which was numerously attended. Among the objects of interest presented on the occasion attention was specially directed to the large collection of portraits hung on the walls of the tea-room and meeting-room. In the short handbook which was supplied to the company a brief account of each picture was given. The portraits are valuable not only as likenesses of eminent men who have been connected with the Royal Society, but not a few of them also as works of art. On the walls of the tea-room hang contemporary portraits of Francis Bacon, Isaac Newton, Robert Boyle, John Wallis, John Wilkins, Christopher Wren, John Flamsteed, Edmund Halley, John Locke, and other early Fellows of the Society. The meeting-room contains portraits of more recent Presidents. Among the exhibits shown on this occasion were the apparatus devised by Mr. C. T. R. Wilson for making visible the tracks of ionizing particles of vapour condensed upon the ions set free along the paths; and also some Cloud-photographs showing the nature of the ionization produced by different kinds of rays. Sir William Crookes exhibited his historical collection of Radiometers and Otheoscopes. Mr. C. V. Boys showed his instrument for experimenting with rotating soap-films. Some of the historical relics in the possession of the Society were likewise displayed, including Robert Boyle's air-pump, Huygens' aerial or tubeless 
telescope, Newton's original account of his Reflecting Telescope, dated January 1672, and some instruments that belonged respectively to Christopher Wren, Joseph Priestley, Captain James Cook, and Charles Darwin.

\section{Thursday, July 18Th.}

The arrangements for the morning were similar to those of the morning of the previous day. In the afternoon, the President, Council, and Delegates went by railway to Windsor, where, by the King's command, they were first conducted to St. George's Chapel and thence through the State apartments of the Castle, where the visitors had an opportunity of seeing the treasures of art collected by successive sovereigns of England. The whole company was marshalled on the terrace overlooking the gardens, the same geographical arrangement of the Delegates being maintained as at the presentation of addresses in Burlington House. The King and Queen then came down to the terrace, and the President, Treasurer, and Secretaries of the Royal Society were presented to their Majesties by the Lord Chamberlain. The Delegates were then presented in succession to their Majesties by the President. After the ceremony of presentation, the company joined the large Garden Party which their Majesties had invited to Windsor on the occasion, and the King and Queen, conversing with their guests on the way, passed to the Royal Tent.

As the whole Celebration was to end on the evening of this day arrangements were made for a series of farewell dinners, smaller and less formal than the large banquet in the Guildhall, when the hospitality could be mingled with more general friendly intercourse. A number of the Fellows gave parties, at which Delegates and the ladies accompanying them could see a little of English homes. The other Delegates were entertained by the Royal Society Club, a dining club connected with the Society for some two hundred years. At these various parties much pleasant conversation took place, the friendships which had been begun on the previous days were further strengthened, and the Fellows of the Royal Society bade their guests farewell with the assurance that the Celebration had passed off as successfully as could have been desired. 
The various functions arranged by the Royal Society were now completed, but reference should be made to the sympathetic action of the Universities of Oxford and Cambridge in organizing an additional day and inviting a considerable number of Foreign and Colonial Delegates, together with a few Fellows of the Society, to partake of the hospitality of these two ancient seats of learning. On the morning of Friday, the 19th, two parties, about equal in number, left London for Oxford and Cambridge respectively. At Oxford the guests took luncheon at All Souls College, with the Chancellor of the University, Lord Curzon, and the $W$ arden and Fellows as hosts. A garden-party in the afternoon at Wadham was full of interest in connexion with the association of this College with the early history of the Royal Society. The Warden gave the visitors a brief address in the Lodge wherein the meetings of the early founders of the Society were held when, owing to the political troubles of the middle of the seventeenth century, they could no longer be held in London. At Cambridge similar hospitality was shown to the guests by the Master and Fellows of St. John's College.

At both Universities Honorary Degrees were conferred on a few of the more distinguished men who had attended the Celebration of the Royal Society. As a permanent and interesting record of the visits of this day, the Latin éloges pronounced by the Public Orator of each University are here given. Those at Oxford (by Mr. A. D. Godley) were as follow:

\section{OXFORD}

Jons Oscar Backlund, Central Observatory, Poulkovo.

Hodie eos hospitio excipimus qui Regiam illam Societatem ducentos et quinquaginta annos peractos celebrantem votis et gratulationibus salutatum venerunt: quos igitur fautrix et altrix naturalis scientiae Universitas Oxoniensis oblata facultate quoad potest titulis exoptat ornare. Ex his primus ad vos accedit qui antiquissimam omnium scientiam profitetur. Hic origine Suecanus postea in Russiam invitatus migravit: ibi et aliarum turrium astris observandis exstructarum et praecipue eius quae est apud Pulkowenses curam suscepit. Quod si quid de studiis eius loqui audere possum, haec nomine certe eos referre videntur qui longe aliam illi quidem scientiam e caeli motibus olim deduxerunt: est enim mathematicus et mathematicas praesertim rationes 
astronomiae adhibet. His artibus Enckiani illius cometae cursum et velocitatem est emensus : propter quod insignissimo praemio Astronomica nostra Societas hominem doctissimum ornavit. Nunc vero habet illud quoque meritorum testimonium, quod Academiarum illius concilii, quod mox Petropoli conventurum esse audimus, Praeses est nuper electus. Praesento ergo vobis Јohannem Oskar Backlind, Turris Speculatoriae Principalis inter Pulkowenses Curatorem, ut admittatur ad gradum Doctoris in Scientia, honoris causa.

\section{Waldemar C. Brögger, University of Christiania.}

Eum ad vos duco qui ut geologicae scientiae nullum fere non genus tetigit, ita in rupium praecipue et saxorum structura atque elementis scrutandis mirabilem peritiam atque eruditionem praestitit. Namque patriae suae litorum et montium formas inspiciendo ea se cognitione imbuit ut priscarum illarum terrae marisque mutationum velut imaginem exprimere potuerit: quod qui scripta eius legerit, is glaciei paulatim recedentis tractus et Oceani modo prolatos modo coartatos fines velut oculis praesens aspicere videatur. Quid quaeritis ? nihil nisi eruditissime idem et disertissime exposuit : novas rerum leges tulit et probavit: quamque alii in singulis geologiae partibus diligentiam exercent hic toti illi scientiae adhibuit. Propter illud autem vix minorem laudem mereri videtur, quod his studiis non otio et securitate a ceteris curis remotum se dedit, sed curiae suae consiliis et regendae Universitatis negotiis distractum atque occupatum.

Itaque cum nemo huius temporis in ea quam profitetur scientia cum maiore laude sit versatus, -id quod insigne illud Wollastonianum nuper ei a doctis viris collatum testatur,-praesento vobis Waldemardm Christophorum BRögger, Mineralogiae et Geologiae Professorem in Universitate Christianiensi, Rectorem eiusdem Universitatis, ut admittatur ad gradum Doctoris in Scientia, honoris causa.

\section{William B. Scotr, University of Princeton.}

Quod in antiquiore orbis terrarum parte a viris magni nominis iam est factum hic quem videtis in America cuius reipublicae civis est primus effecit. Nam cum alii geologistae aliis scientiae suae partibus se dederint, hic illuc potissimum incubuit ut quaenam fuerint ea saecla animantum exquireret quae terras nondum in speciem quam videmus informatas colebant: vestigia eorum e remotissima antiquitate conservata et inclusas ipsis rupibus reliquias enucleavit et in lucem produxit: unde nos modo monstrorum magnitudinem miramur modo notorum hodie animalium fontem atque originem agnoscimus. Quibus rebus inveniendis multum laboris suscepit: immo in ipsa Patagonia, qua terrarum regione nihil potest esse ab humanitate seiunctius, tres continuos habitavit annos. Nemo tenebras et crepuscula mundi latiore visu amplexus est, nemo reperta in rationum formam prudentius composuit. Haec ut 
doctorum virorum consensu ita praccipue Geologicae nostrae Societatis iudicio comprobantur: namque ea singulari honore et praemio ingeniosissimum hominem nuper ornavit. Quare praesento vobis Wildelmum Berryman ScotT, Geologiae et Palaeontologiae Professorem Blairianum in Universitate Princetonensi, ut admittatur ad gradum Doctoris in Scientia, honoris causa.

Wratel Waldeyer, University of Berlin.

Quid est dignius quod ab academicis honoretur quam continuus vitae cursus uno tenore scientiae finibus proferendis deditus? Hic enim quem videtis ex ineunte aevo in anatomiae studio elaboravit, cuius rei est hodie professor: annum agimus quinquagesinum ex quo primum reperta sua litteris mandare coeperat: neque postea ullus est secutus quin idem commentariis et libellis edendis industriam suam atque eruditionem indicaret. In quo temporis spatio permagnam rerum varietatem scribendo tractavit: modo ovorum partum et generationem animalium, modo oculos et visus rationem studiis et investigationibus amplexus est : vix ullam denique quaestionem quae modo ad corporis humani structuram pertineret intactam reliquit. Neque a doctis hominibus tantum haec laudantur, sed et omnibus profuerunt: multum enim qui medendi artem profitentur sunt huius lucubrationibus et consiliis adiuti. Praesento ergo vobis Willelmum Waldeyer, Imperatoris Germanici in Medicina consiliarium, Anatomiae Professorem et Anatomici Collegii in Universitate Berolinensi rectorem, ut admittatur ad gradum Doctoris in Scientia, honoris causa.

Peter Zeeman, University of Amsterdam.

Hominem ingeniosissimum et multum experimentis ausum vobis praesento. Et quoniaim in hoc doctorum virorum consessu loqui posse mihi videor liberius, quae praecipua fuerit eius famae causa paucis (advertite) docebo. Nam cum ignis ardentis lumen per vitrum lineis distinctum ita transmitti sciatis ut non omnes lineae sed secundum eius rei qua utitur naturam aliae alias immisso lumine fulgeant: hic si vim magnetoëlectricam igni adhibueris commixtos una omnes spectri quod vocant colores in singulis lineis apparere experiendo demonstravit. Hoc repertum maximi momenti ab iis haberi quibus cura est primordia rerum quali natura praedita constent investigare, omnes necesse est agnoscant. Itaque cum hic non modo in lucis ratione elaboraverit verum etiam ad mundi totius naturae cognitionem multum contulisse videatur, magnum inter omnes physicistas nomen et laudem consecutus est: neque est quisquam dignior quem titulo aliquo hoc praesertim die ornemus. Praesento igitur vobis Perrum Zekman, Physicae Professorem in Universitate Amstelodamensi, ut admittatur ad gradum Doctoris in Scientia, honoris causa. ${ }^{2}$

1 Dr. Gabriel Lippmann, For. Memb. R. S., President of the Academy of Sciences of Paris, was to have been included among those who received Honorary Degrees, but the sudden death of Professor Poincaré recalled him at once to France. 


\section{CAMBRIDGE}

The following are the speeches delivered by the Public Orator (Sir John Sandys) in welcoming the Delegates, on their visit to Cambridge, and in presenting to the Chancellor (Lord Rayleigh) the several recipients of honorary Degrees :

In ipso limine laudationum nostrarum, Societatis Regalis tot hospites illustres, post sacra saecularia feliciter acta, Cantabrigiam hodie invisentes, Academiae totius nomine iubemus salvere. Unumquemque igitur vestrum salutat et Baconis et Newtoni et aliorum in scientia naturali aut olim aut nunc insignium virorum Universitas. Dum tot scientiarum inter se diversarum cultores illustres e tot orbis terrarum partibus ad litora nostra atque adeo Academiae nostrae ad nemora hodie advectos intuemur, denuo nobis rata esse videntur vetera illa prophetae verba:- 'plurimi pertransibunt, et multiplex erit scientia.' Tot advenarum illustrium e numero placuit Senatui nostro nonnullos, gentium inter se diversarum legatos, scientiarum inter se diversarum antistites, velut exempli causa, titulo nostro decorare, qui honos, vestrum omnium praesentia illustratus, vestrum omnium, ut speramus, benevolentia comprobabitur.

Edwin B. Frost, University of Chicago.

Dignissime domine, domine Cancellarie, et tota Academia-

Primum omnium respublica maxima trans oceanum Atlanticum nobis coniunctissima quasi nuntium quendam sidereum ad nos misit, qui lacus maximi in litore astrophysica (ut aiunt) praeclare profitetur, lacus minimi in margine speculae astronomicae celeberrimae praepositus. Ibi, astronomi praeclari, Societatis Regalis haud ita pridem Praesidis, vestigia secutus, stellas, quae inerrantes vocantur, diligenter observavit, et spectri (ut dicitur) auxilio, earum motus aut recedentes aut appropinquantes accurate computavit. Idem, cum collegis optimis consociatus, stellas duplices atque etiam multiplices plurimas detexit; siderum denique illorum praesertim, quorum in aëre helium inesse comprobatum est, primus tarditatem quandam motus demonstravit. Astronomo autem nostro, viro impigro, viro acerrimo, tarditatem mentis nemo exprobrabit. Etenim, talium virorum auxilio, 'caelum ipsum petimus,' non iam 'stultitia',', sed sapientia ; atque, ut philosophi cuiusdam Romani verbis utar, 'cogitatio nostra caeli munimenta perrumpit.' 3 Duco ad vos scientiae astrophysicae professorem illustrem, Edwin Brant Frost.

1 Liber Danielis prophetue, xii. 4.

${ }^{2}$ Hor. Carm. i. 3, 38. SSeneca, De Otio, v. 6. 
Marquis E. Paternò di Sessa, University of Rome.

Ex Italia ad nos advectus est regni Italici Britannis amicissimi senator, coronae Italicae eques clarissimus, qui, Palermi natus, Romae per annos quadraginta scientiam chemicam experimentis suis luculenter illustravit. Peritis notum est hunc virum olim benzenii potissimum progeniem explorasse, - benzenii, quod matris haud pulchrae filiam, filiarum autem suavium et pulchrarum matrem nominaverim. Notum est eundem postea corpora ex fluorino, elemento illo impigro, composita, penitus investigasse; in aliis denique elementis, bromio praesertim et phosphoro liquido, particularum pondera accuratius examinasse. Ceterum haec omnia scientiae ad mysteria intima pertinent, non a nobis vixdum initiatis divulganda. Etenim e scriptoribus Romanis unus ait, 'omnium rerum sunt quaedam in alto secreta '; 1 alter autem, 'facilius natura intellegitur quam enarratur.' ${ }^{2}$ Duco ad vos scientiae chemicae professorem admodum nobilem, Marchionem Emanuelem Paternò di SEssa.

Ivan Petrovitch Pawlow, Imperial Academy of Sciences of St. Petersburg, Foreign Member of the Royal Society.

Russorum ex imperio maximo, a nobis remoto sed studiorum communium in vinculis vicino, ad nos venit physiologiae professor Petroburgensis, qui ciborum digerendorum rationem universam exploravit, his studiis officinam quandam dedicavit, physiologiae studiosorum scholam florentissimam fundavit. Ut alia omittam, quam pulchre ostendit sucos illos, qui cibo concoquendo inserviunt, non modo mentis motu vario etiam ipsos moveri et mutari, sed etiam unicuique ciborum generi esse accommodatos, atque omnibus elementis noxiis adversari et in contrariam partem fortiter contendere. Mentis quidem certamen Prudentii in carmine quodam heroico narratum vidimus; corporis autem certamen, mentisque et corporis societatem intimam ab hoc viro celebratam audivimus. Talium virorum ex studiis Cornelii Celsi praecepto illi melius obtemperare possumus: ante omnia corporis sui naturam quisque norit. $^{3}$ Duco ad vos physiologiae professorem egregium, Ivan Petrovitch Pawlow.

Charles E. Picard, of the Institute of France, Foreign Member of the Royal Society.

Francogallorum respublica nobis vicina, et vinculis indies artioribus nobiscum coniuncta, hospitem ad nos misit mathematicum insignem, mathematici insignis (olim cum studii eiusdem antesignanis Cantabrigiensibus consociati ${ }^{4}$ )

1 Plin. N. H. xvii. 29. 2 Seneca, Epp. 121, \$11.

'Celsus, De Medicina, ì. 3, 'ante omnia norit quisque naturam sui corporis.'

- Charles Hermite was associated with Sylvester, Ferrers, Stokes, and Cayley as one of the editors of the Quarterly Journal of Mathematics from 1857 to 1878. 
et generum et operum eius editorem praestantissimum. Reipublicae autem illi hodie propterea praesertim gratulamur, quod talium virorum consilium, populi totius cum fructu, totiens expetit. Primum, abhinc annos quattuor et viginti, praemium ex eadem studiorum provincia reportavit, quam in Scandinavia Abelius primus illustraverat. Idem, scientiarum Academiae Parisiensi nuper praepositus, quamquam argumentorum in genere quodam abstruso versatur, stili lucidi lumine libros suos omnes illustravit. Testis est opus praeclarum de scientiae statu hodierno ad sensum popularem accommodatum; testes sunt Analytica illa, etiam a iuventute Britannica libenter perlecta; testes etiam illae de methodi analyticae historia Angliae novae in Universitate quadam nova nuper habitae orationes. Ergo in uno eodemque viro et mathematici illustris et oratoris optimi habetis exemplar. Duco ad vos studiorum analyticorum professorem eloquentem, Carolum Aemilum Picard.

\section{Heinrich Rubens, University of Berlin.}

Germanorum ex imperio maximo, nobis utinam in perpetuum coniunctissimo, ad nos perlatus est scientiae physicae in Universitate Berolinensi professor, qui, luce cotidiana non contentus, etiam lucem illam, quae oculorum aciem fugit, assidue exploravit. Lucem quidem universam ex undis constare electricis, rationibus exquisitis ductus, Maxwellius noster olim praedixit; idque et sui ipsius et aliorum experimentis postea prorsus comprobatum est. Hic autem, rem ipsam denuo aggressus, placitis Maxwellianis maxime congruus, lucis undas longas est dimensus, illis quidem multo longiores quae erant antea cognitae, sed illis aliquanto breviores quas vis electrica per artem adhibita generare potuit. Sed, inter has duas undarum varietates penitus exploratas, iam restat intervallum perbreve, quo sine dubio (fortasse per hospitem nostrum) propediem expleto, Maxwellii nostri doctrina universa erit patefacta, et, inter tot rerum naturae miracula, etiam lucis leges melius cognoscentur. Dixit olim Miltonus noster, 'Lux sacra,-salve, prima progenies Dei '; ${ }^{1}$ et tu, salve, lucis legum explorator indefesse. Duco ad vos scientiae physicae professorem praeclarum, Regis sui consilio privato adscriptum, Henricus Runess.

\section{J. E. B. W ARming, University of Copenhagen.}

Regnum Danicum, Scandinaviae pars eximia, cum Britannia vinculis teneris sed eisdem firmissimis conjuncta, misit scientiae botanicae professorem emeritum, qui inter suos horto praefuit admirabilem in modum disposito et ordinato. Idem non modo doctrinae botanicae orbem totum in libro quodam eximio perlustravit, sed etiam, in aliis litterarum monumentis, partes eius nonnullas aut ad Americam Australem aut ad zonae torridae miracula aut ad Floram Arctoam pertinentes subtilius perscrutatus est. In illa vero scientiae

1 Paradise Lost, iii. 1, 'Hail, holy Light! offspring of Heav'n first-born.' 
tam pulchrae provincia, quae oecologia nuncupatur, viarum novarum explorator exstitit. Unde factum est, ut haec studiorum provincia, non modo in regno Danico, sed etiam inter Francogallos, inter Germanos, in Helvetia, in Britannia, inter populos denique mari Atlantico a nobis divisos, cultoribus indies pluribus pateat. Non minus autem quam haec potissimum pars scientiarum naturalium, talium rerum scientia tota munus sibi vindicavit locorum spatiis universum atque adeo orbi terrarum toti conterminum. Ergo.hospitibus nostris omnibus, e tot orbis terrarum partibus ad nos hodie allatis, Historiae Naturalis auctoris eruditissimi verba licet sibi confidenter arrogare: 'Non unius terrae sed totius Naturae interpretes sumus." ${ }^{2}$ Coronam nostram supremam accipit Florae sacerdos venerabilis, Eugenius Warming.

${ }^{1}$ Plin. N. H. xviii. 214. 


\title{
I. THE ADDRESSES ${ }^{1}$
}

\author{
EUROPE
}

\section{AUSTRIA-HUNGARY}

\section{Imperial Academy of Sciences, Vienna}

Hochgeehrte Geseldschaft! Gerechter Stolz erfüllt unsere Seele, wenn wir die Errungenschaften auf dem Gebiete der Naturwissenschaften betrachten. Von den geheimnisvollen Vorgängen in der Natur liegt ein grosser Teil enthïllt vor unseren Augen. Wir verstehen nicht nur die grossartigen Vorgänge, die der Himmel uns darbietet, wir können sogar die Bewegungen der unsichtbaren Atome beschreiben. Bis zu den Grenzen der Sichtbarkeit können wir noch das organische Leben verfolgen, das so lange ungestört das Dasein der Menschen gefährdete. Unzählige praktische Erfindungen waren die Folge der wissenschaftlichen Errungenschaften, Erfindungen, welche für das Behagen, aber auch für die Gesundheit der Menschen von höchstem Wert sind, Erfindungen, mit denen wir Raum und Zeit besiegen. Die Erforschung der Natur war aber auch ein grosser Gewinn für die moralische Hebung des Menschengeschlechtes, sie allein war es, die die Menge aus dunklem Aberglauben befreite, die solchen Verirrungen wie Astrologie, Alchemie usf. ein Ende setzte. Allergrössten Dank sind wir daher den Männern schuldig, die durch ihre Forschungen dieses Emporblühen der Wissenschaft erzielten. Aber wenn es auch seit jeher nicht an hervorleuchtenden Geistern fehlte, die Kometen gleich Licht in die Finsternis strahlten: die neue Richtung brach sich erst Bahn durch vereintes Streben. Als beim Untergang der Scholastik in den Menschen allmählich die Erkenntnis aufdämmerte, dass das Studium der Natur vor allem geeignet ist, unseren Geist zu befreien, da zog gerade in England die neue Richtung zahlreiche Schüler an, die, indem sie in dem Forschen nach Wahrheit den besten Trost fuir die Wirren ihrer Zeit fanden, sich zu regelmässiger gemeinsamer Arbeit verbanden und alle Teile der Naturwissenschaft in Angriff nahmen. Das Ansehen und die Zahl dieser Männer, im Anfange noch die 'Invisibles', stieg rasch, indem ihre Mitbürger den Wert ihrer Studien für den Fortschritt der Menschheit erkannten. Königliche Gnade erhob diese Gesellschaft 1662 zur Royal Society, ein Akt, welcher der ganzen Welt Vorteil brachte, indem die Royal Socicty nummehr

\footnotetext{
1 These are arranged in the same geographical order as the List of Delegates, pp. 13-21.
} 
durch 250 Jahre unermüdlich immer neue Früchte des Wissens zur Reife brachte. Ihre Schriften enthalten die Bausteine unseres gesamten heutigen Wissens, durch welche sie selbst und darnach die bewundernden Schwesterakademien die Naturwissenschaften auf ihren heutigen Stand bringen konnten. Eine der jüngsten Akademien, die dem Stern der Royal Society bewundernd folgt, die kaiserliche Akademie der Wissenschaften in Wien, wünscht der Royal Society zu der 250. Wiederkehr ihres Stiftungstages, dass sie in aller Zukunft ihres Bestandes sich erfreuen und fortfahren möge, eine Leuchte für die Menschheit zu sein.

Wien, am 30. Juni 1912.

Das Präsidium der Kaiserlichen Akademie der Wissenschaften :

E. VON BÖHM-BAWERK, Präsident. VIKTOR VON LANG, Vizepräsident. FRIEDRICH BECKE, Generalsekretär. JOSEF VON KARABACEK, Sekretär.

\section{University of Agram}

Ampeissimae Regali Societati Londini. Inter academias liberalium artium, quae in rerum cognitione et scientiae pervestigatione vigent, Societas Vestra principatum obtinet secundisque rerum proventibus antiquitus traditis ea incrementa cepit, in quibus perquam raro alia collegia gloriari possint. Inde ab ipsis cultus atque humanitatis quasi incunabulis clari et docti viri Britannorum gentis societatem privatam constituerunt, quae postea tutela regis Caroli II Regalis nuncupata est, ut non una aliqua in re elaboraret, sed omnia, praecipue philosophiam, scientiae pervestigatione comprehenderet. Gravitate et auctoritate sua iam a primordiis domi ad magnum et honoratum ministerium indicis litterati et consiliarii rerum publicarum curatorum producta est, foris vero editiones eius ab omnibus hominibus, qui in artibus versantur, honorem consequuntur. Raro fit ut aliqua litterarum societas per tam longum tempus sit industria singulari, sicut Vestra, cui uni omnium ducentesimum quinquagesimum diem natalem celebrare contigit. Qua ex re concludi potest Societatem Vestram munere atque officio feliciter functam esse, nam aliter sentire de societate, cui usus erat cum luminibus doctrinae, ut cum clarissimo Newton et cum viris doctis Halley, Simpson, Cavendish, Wollaston, Priestley, Herschel, Davy et multis aliis, haud licet. Quamobrem omnes viri docti de his sollemnibus gaudent, imprimis vero Croatarum Universitas Zagrabiensis ex intimo corde amplissimae Regali Societati gratulatur, optatque ut in scientiae pervestigatione et in posterum fortuna prospera 
utatur et quam maximos progressus in studiis faciat. Senatus acadenicus regiae litterarum Universitatis Francisco-Iosephinae.

Zagrabiae, die 9 Iulii 191 .

\author{
Rector: DR. JULIUS DOMAC. \\ Ab epistulis: FRANCISCUS PEVALEK.
}

\title{
Imperial Academy of Sciences, Cracow
}

REgIA Societas, quae ducentos quinquaginta iam annos stat tanquam columna ignea omnibus sive apud Britannos praeclaros sive apud reliquas gentes scientiarum studiosis : quotiescunque difficiliores tractabant quaestiones, indefesso praelucebat ardore, ut per tenebras et dubia pervenirent ad veritatis contemplationem. Inter tot nationes, tot doctorum collegia et instituta, quae gratissimam celeberrimae Societatis memoriam conservant, propter cousilia monitaque in scientiis colendis saepissime ab ea impertita, etiam antiquum regnum Poloniae cum scholis suis et Academiis locum sibi debitum obtinet. Itaque decet et convenit ut hoc die glorioso, communi laetitiae destinato, quándo Regia Societas cum superbia bene merita retrorsum per duo saecula cum dimidio respiciet labores suos ac studia, etiam vox illius regionis andiatur quae protulit Copernicum, utque iungatur choro mundano gratulatorum. Neque mirum videbitur, si muneri gratulandi celeberrimae Societati nomine nationis Polonae totque generationum studiosorum ac doctorum incumbat detque operam Academia Scientiarum Cracoviensis, non interruptae traditionis haeres legitima et vera. Namque ruina libertatis politicae non inhibuit neque interrupit apud Polonos studiorum progressum, erectio vero Imperialis Academiae Scientiarum Cracoviensis, fundatae a Sua Maiestate, Imperatore Austriae Francisco Iosepho I, novam et firmam addidit disciplinam et temperantiam antiquis studiis, quae fere numquam cessavere durante regno Poloniae. Iam quadraginta istis annis, qui praeterierunt ab eius institutione, Academia Cracoviensis, imprimis vero eius Classis mathematico-physica multis re vera iungebatur vinculis Illustrissimae Regiae Societati tum quoad methodum indagationum melius ediscendam tum ad clarius determinandum inceptorum operum finem ultimum. Cuius rei testimoniis abundant tantum, quantum sat est, Academiae Cracoviensis Annales; beneficia vero familiaris consuetudinis, concessa nostris Academicis a nonnullis perquam illustribus membris Regiae Societatis his ultimis decenniis quantum et quale fuerit, vere non poterit aestimari, nisi mutuum litterarum commercium aliquando in medium proferatur. Itaque gratis animis multiplices has relationes agnoscentes et revocantes Praeses ac Socii Imperialis Academiae Scientiarum Cracoviensis, debitam manifestantes venerationem suam hac occasione laetissima oblata et considerantes magnificam Societatis Regiae historiam tum praeteritam tum praesentem, ex totis cordibus augurantur ut historia futura non minus sit splendida utque novae scientiae humanae 
provinciae inveniantur omnibusque pateant utque Regia Societas per multa adhuc saecula futura remaneat Britannis gloriosa ac splendens corona, aliis nationibus auxiliatrix et adiutrix omnis generis studiorum, tandem fraternitatis mutuae populorum exemplum vivificans, ut omnes se diligant et adiuvent in Christo, qui est scientiarum fons vivus, numquam exhaustus.

Cracoviae, die XII Iulii A.D. MCMXII.

BOLESLAW ULANOWSKI, Secretarius generalis. FRIDERICUS ZOLL Sen., Vice Praesidis. WLADYSLAW NATANSON, Secretarius, Classis mathematico-physica.

EDWARD JANCZEWSKI, Director, Classis mathematico-physica.

\section{UNiversity of Lemberg}

Rector et Sexates Universitatis Poloniae Leopoliexsis Societati Regire Londinensi et vetustate et auctoritate primae inter Academias Scientiarum in toto terrarum orbe salutem summaeque venerationis testimonium mittunt. Inde ab illo Isaaco Newtonio et hodie collegium Vestrum magno numero virorum praestantissimorum ornatur, qui cum non unius populi, sed generis humani sint praeceptores, Societas Regia quasi sol quidam doctrinarum exstitit, cuius radii usque ad extremos cultus humanitatisque fines descendunt. Ex eis quidem finibus orientalibus, sed ex terra quae Nicolao Copernico filio suo gloriatur, accipite, Viri Illustrissimi, sollemnia semisaecularia quinta Societatis Vestrae celebrantes, plurimam salutem nec non optima omina, ut opera Vestra eodem atque adhuc modo etiam in tempus futurum uberrimos fructus messemque opimam generi ferat humano.

Leopoli (Lemberg) in Austria, Galicia, die 1 Iulii, Anno 1912.

L. FINKEL, h.t. Rector.

\section{Boheman Karl-Ferdinand University, Prague}

Rektor a Senát Č́eské University Karlo-Ferdinandovy v Praze připojují se radostně $\mathrm{k}$ slavnosti významného dne, jímž Královská Společnost v Londýně oslavuje 250leté výročí svého založení. l'ř̀i té př́iležitosti vzpomínaji nehynoucích zásluh, jež si Královská Společnost o rozkvět věd získala. Ona prvá postavila se $\mathbf{v}$ čelo hnutí, jímž obrozeno badání ve všech oborech věd př́rodních a $\mathbf{v}$ tomto smèru razila dráhy od prvého svého vzniku aždo doby dnešní. $\quad \mathrm{V}$ době, $k d y \mathrm{v}$ čechách nepř́zní osudu a pohromami válečnými dohrobeny veškeré mnohoslibné počátky ku pěstění nauk, stálajiž Královská 
Společnost $\mathrm{v}$ čele ruchu vědeckého a dala podnět $\mathrm{k}$ zakládáni jiných sesterských institucí Evropských. I vzpomenouti dlužno oněch prvých hlubokých myslitelư, již postupem doby mystiku $z$ vědy odstraňovali, jakož i nepřehledné řady oněch slavných badatelư, kteři v čele Královské Společnosti exaktním a biologickým naukám nové směry vědecké práce určovali. Na dnešním pokroku a na praktických vymoženostech věd přírodních má Královská Společnost největš́ podíl! Majice tedy stále na paměti veliké ony zásluhy, jež si Královská Společnost o rozkvět věd a tudiǔ i o prospěch lidstva získala, osvědčují rektor a senát české university Královské Společnosti pocity své hluboké úcty a vážnosti, jakož i své upř́mné blahopřání ku trvalým výsledkům blahodámé jeji činnosti.

v Praze, dne 1. Července 1912.

J. ČELAKOVSKÝ, $V$ 。 rektor.

KAREE KADLEC, t. č. Děkan fakulty prárnické.

Rector et Senatus Caes. Reg. Universitatis Litteranum Caroleae Ferdinandeae Pragensis Bohemicae Societati Regiae Londinensi. Ducentesima quinquagesima natalicia Societatis vestrae quod sollemniter celebratis, gaudemus eaque sollemnia votis optimis prosequimur. Simul pia memoria illud recolimus, quantopere Societas vestra de cultu ac flore scientiarum, ex quo condita est, meruerit. Nam illa prima tamquam dux eorum procedebat, quorum opera studium in omnibus scientiarum naturalium generibus renatum est, atque ita novas cogitandi vias per omne aevi sui spatium muniebat. Quando temporum iniquitate bellicisque casibus omnia ferme felicia scientias colendi initia in Bohemia extincta sunt, agmen virorum in doctrinis elaborantium Societas vestra iam ducebat, effecitque ut aliae similes per Europae terras conderentur societates. Atque in animum revocandi videntur cum primi illi viri docti ingeniosi, qui procedente tempore superstitiones e doctrinarum rationibus propellerent, tum innumerabiles illi rerum investigatores clarissimi, qui Societati vestrae praepositi exactis quae dicuntur et biologicis disciplinis velut novas vias docti laboris demonstrabant. Quod tantum ad hanc aetatem naturales scientiae profecerunt quodque tantum fructum usus earum tulit hominibus, haec maxima ex parte Societatis vestrae laus est existimanda. Dum igitur memoria tenemus, quantopere Societas vestra de scientiarum incremento et flore meruerit generisque humani commoda auxerit provexerit, verecunde ac pie eam colimus suspicimus, quodque talia tamque utilia et semper duratura effecit, sincere laetamur totoque animo vobis congratulamur.

Dabamus Pragae, capite regni Bohemiae, kalendis Iuliis anni MCMXII.

$J$ J ČELAKOVSKÝ, $h$. $t$. rector.

CAROLUS KADLEC, $h$. $t$. decanus facult. iuridicae. 


\section{Royal Hungarian University, Budapest}

Rector et Senatus Regiae Scientiarum Universitatis Hungaricae Bunapestinensis Magnifico Praesidi Societatis Regalis Londinensis pro Scientia Naturali promovenda S. P. D. Magnifice Domine, E litteris Vestris ad nos perhumaniter datis maximo cum gaudio Vos die decima sexta et duabus insequentibus diebus mensis Iulii a. c. Societatis Vestrae, a Carolo Secundo rege Vestro constitutae, feliciter peracti anni ducentesimi quinquagesimi sollemnia celebraturos esse legimus. Gratias Vobis agimus, viri praestantissimi, quod laeto cum hoc nuntio ad has Ferias saeculares nos quoque benignissime familiarissimeque invitatos esse volueritis. His festis per legatum nostrum publice missum Dominum Dr ${ }^{\text {вm }}$ Isidorum Fröhuch, Consiliarium Aulicum Reg. Hung., Rectorem huius temporis Universitatis Nostrae Magnificum gratulationes nostras, caritatem votaque testamur, ex animi sententia optantes ut per sequentia quoque saecula Societas Vestra floreat et crescat. Haec vero charta sigillo Universitatis munita in tabulario Societatis Vestrae deposita, perenni sit documento, quam sincere voluerit particeps esse gens nostra Hungarica inter populos celeberrimos culturae humanae diebus festis humanitatis et quam ardenter Vobis omnia bona faustaque precata sit.

Dabamus Budapestini in Capite Regni Hungariae, die trigesima mensis Iunii a. D. millesimo nongentesimo duodecimo.

Dr. ISIDORUS FRO̊HLICH, $\boldsymbol{h} . \boldsymbol{t}$. Rector.

Dr. ANTONIUS MARGITARY, Regis Consil., Senatus Notarius.

\section{BELGIUM}

\section{UNIVERSITY OF LOUVAIN}

A Monsieur le Président et a Messieurs les Membres de la Société Royale de Londres.--Messieurs, L'Université Catholique de Louvain, qui garde le souvenir reconnaissant de la participation des Sociétés savantes à ses propres fêtes jubilaires, est heureuse aujourd'hui d'offrir, à son tour, à la Société Royale de Londres, ses vives félicitations à l'occasion de la célébrution solennelle du $250^{\text {me }}$ anniversaire de sa fondation. Il n'est pas une Institution scientifique qui puisse se glorifier d'un passé plus brillant et plus fécond. Dans le domaine des sciences physiques et mathématiques comme dans celui de la biologie, la Société Royale s'est dignement acquittée de la mission que lui confia son Auguste Fondateur: elle a été un puissant facteur du progrès des sciences naturelles. Elle s'est acquis de la sorte un droit incontestable aux suffrages 
de tous les Corps savants. L'Université de Louvain forme les voux les plus ardents pour la prospérité toujours croissante de cette illustre Société: Vivat! Crescat! Floreat! Au nom du Conseil Rectoral,

Le Recteur, P. LADEUZE.

Le Socrétaire, J. VAN BIERVLIET.

Louvain, le 27 Juin 1912.

\section{Royal Academy of Sciences, Brussels}

A ta Société Royale de Londres.-Monsieur le Président, Sir Archibald GeImIE, Associé de l'Académie royale de Belgique, Vous voulez bien porter à la connaissance de l'Académie royale de Belgique que la Société royale de Londres, fondée, en 1645, par un groupe de savants, en vue du progrès de la science dans le Royaume-Uni, constituée en association dès 1660, et investie le 15 juillet 1662, par le Roi Charles II, d'une Charte de corporation, célébrera le 16 juillet de l'année actuelle son deux cent cinquantième anniversaire. Vouz invitez, en même temps, on ne peut plus confraternellement, l'Académie royale de Belgique à cette commémoration d'une si haute importance pour la science, en général, de tous les pays qui s'occupent de la culture des connaissances humaines en tête desquelles sont l'Astronomie et votre immortel Newton. L'Académie royale de Belgique est on ne peut plus flattée de cette gracieuse invitation de la Société royale pour laquelle elle professe la plus grande admiration, non seulement pour ses membres si illustres, mais aussi pour les travaux dont ils ont enrichi la science européenne pendant les deux siècles et demi écoulés de votre célèbre Société. Ce n'est pas d'hier, illustre Confrère, que nous apprécions la haute valeur scientifique de la Société royale et sa valeur morale. Lors de son rétablissement par le Roi Guillaume I ${ }^{\text {r }}$, en 1816, le premier soin de l'Académie royale de Belgique fut de demander à la Société royale de Londres l'échange de ses publications avec vos célèbres Philosophical Transactions. La collection que nous possédons de ces Transactions remonte à l'année 1777\%; elle constitue le plus beau joyau de notre bibliothèque, au même titre que les publications de l'Académie des sciences de Paris. C'est un trésor inestimable qui fait constamment l'admiration des savants qui y ont recours pour leurs travaux. Ils sont légion les membres de la Société royale que l'Académie royale de Belgique a eu l'honneur de compter comme associés depuis 1816. Et leurs noms sont déjà entourés parmi nous, comme en Angleterre, de l'auréole de la gloire: Charles Babbage, Sir John William Herschel, Pierre Barlow, Sir James South, Sir Edward Sabine, John Barrat, John Taylor, Robert Brown, Sir David Brewster, Michael Faraday, Sir Richard Owen, Sir Charles Wheatstone, Sir George Biddell Airy, Sir Roderick Impey Murchison, Sir Charles Lyell, 
Thomas Davidson, Charles Robert Darwin, Joseph Dalton Hooker, Andrew Crombie Ramsay, Thomas Henry Huxley, Lord Kelvin, John Tyndall, James Prescott Joule, Sir Joseph Prestwich, Arthur Cayley, James Joseph Sylvester, Sir William Henry Flower. D'autre part, c'est un réel honneur pour nous de voir encore figurer dans nos rangs Sir George-Howard Darwin, Sir James Dewar, Sir Edwin Ray Lankester, Sir John Murray et vous même, Sir Archibald Geikie, le si distingué président actuel de la Société royale. Il nous est impossible, Sir, dans le cadre de cette Adresse de félicitations, de citer tous les travaux de votre Société, même les plus célèbres. Et cependant l'Académie royale de Belgique aurait été si heureuse d'en parler, surtout de ceux qui, depuis le commencement du xvII ${ }^{\mathrm{m} \theta}$ siècle, ont fait progresser les sciences d'une manière si prodigieuse. D'aussi célèbres souvenirs et un aussi mémorable passé, dont la Belgique, comme toute l'Europe scientifique, a profité, sont le plus sûr garant d'un avenir qui sera aussi illustre pour la Société royale de Londres. L'Académie royale de Belgique souhaite à la Société royale d'acquérir encore de nouveaux titres à la reconnaissance de l'humanité. Puisse-t-elle, à tout jamais, pour le bien de celle-ci, continuer à tenir avec l'Académie des sciences de Paris le sceptre de la science qui constitue le flambeau de la vérité. Quant à Lord Lister, l'Académie, au nom de toute la Belgique, s'associe au deuil de l'Angleterre au sujet de la mort de l'illustre chirurgien. Telle est l'expression des sentiments de l'Académie royale de Belgique, que l'un de ses membres, $\mathbf{M}$. Dollo, s'est engagé à vous apporter de notre part.

Bruxelles, le 16 juillet 1912.

Le Secrétaire perpétuel, Le Chevalier EDMOND MARCHAL.

\section{DENMARK}

\section{University of Copenhagen}

Universitas Hauniensis Regali Societati S. P. D. Duo iam saecula et dimidium Regalis Societas ita egit, ut egregium illud dictum, quod vexillo suo inscripsit, semper summa cum fide exsequeretur. Eo tempore exorta, quo nihil fere praeter ecclesiam in lumine erat, praecipueque Naturalium Rerum Scientia crassa superstitionis caligine obfuscabatur, hoc sibi proposuit, ut novam et veram philosophiam naturalem in lucem duceret, experiendi arte fultam et ingenua inquirendi ratione procedentem. Libera, a nullius gratia pendens, nullo auxilio externo munita, incrementum sensu cepit et robur, dum socii, scientiam ipsius causa ardentibus animis amantes, infatigabili studendi vigore provehuntur veritatemque ex tenebris nebulisque eliciunt, minime eo deterriti, quod labores, quibus operam suam impendebant, saepius 
spes suas fallere nullumque profectum promittere videbantur. Procedente tempore non raro apparuit, ea quoque, quae primo aspectu vana et sterilia esse videbantur, uberes et inexhaustos fontes aperuisse. Quod vere dictum est, Anglorum nationem non victoriis terras expugnando coloniasque late per orbem condendo potius quam naturam suae terrae sibi subiciendo magnam et illustrem factam esse, quodque nulla cuiquam relinquitur dubitatio quin accrescens Rerum Naturalium Scientia toti generi humano immane quantum profuerit, Regalis Societas merito gloriari potest, tam hanc patriae laudem quam illas communis hominum vitae utilitates magnam partem viris deberi quos in sociorum numero habuerit. Ingenuo et grato animo eorum beneficiorum memoriam retinens, quae bonarum artium studia huic Societati debent quae ipsa princeps condita postea multis aliis eiusdem generis societatibus originem dedit et normam, Universitas Hauniensis Regali Societati CCL annos gloriose exactos gratulatur, sperans fore ut futura eius tempora digna praeteritis saeculis luce fulgeant.

FRANCISCUS BUHL, $h$. a. Rector Universitatis.

\section{Royal Danish Society of Science, Copenhagen}

Tr. Royal Society i London. Grundlæggelsen af Royal Society for 250 Aar siden var en Begivenhed, som ogsaa nu med allerstörste Paaskönnelse maa mindes af enhver, som glæeder sig over den Höjde, hvortil Nutidens Naturvidenskab har hævet sig. Ved dets Stiftelse lagdes nemlig Grunden til store Lære: Bygninger, som siden den Tid ere voksede op, og som ere i Stand til at bære kommende Tiders rige Arbejder. Uforglemmelige i Videnskabens Historie ere de hver par sit Omraade fremragende Mænd, der samledes först i en mere privat Kreds og dernæst i det af dem grundlagte Selskab for at foretage naturvidenskabelige Forsüg i et Omfang og med en Planmæssighed, som ikke var kendt $\mathrm{i}$ tidligere Tider. $-\mathrm{Om}$ den store Betydning af det Samarbejde mellem indenlandske og udenlandske Medlemmer, som Royal Society straks bragte tilveje, vidner den Brevveksling, som med det som Mellemled förtes mellem Newton og Leibniz, og som indeholder de vigtigste Dokumenter vedrörende Infinitesimalregningens Tilbliven. Endelig var det under dette Selskabs Auspicier, at Newton nogle Aar senere, kraftig tilskyndet af dets ävrige Medlemmer, udgav sine Principia. Disse faa Træk vise den Hovedandel, som Royal Society i sine förste Decennier havde i Grundlæggelsen af den moderne Mathematik, Fysik og Astronomi; men tidlig udstraktes dets initiativrige og frugtbringende Virksomhed ligeledes til de andre Omraader af Naturvidenskaben, og ogsaa efter Udskillelsen af Selskaber med mere specielle Formaal er Royal Society vedblevet at være Centralorganet for den britiske Nations naturvidenskabelige Arbejde, der har haft og bestandig har en saa fremragende Andel i de store Fremskridt paa alle Naturvidenskabens 
Omraader. Som Repræsentant for det mere beskedne Arbejde i de samme Retninger, som göres af en langt mindre, men beslægtet Nation, tager det Kongelige Danske Videnskabernes Selskab levende Del baade i den almindelige Tak for alt det, som er ydet og den Dag i Dag bliver ydet gjennem Royal Society, og i Önsket om en Fremtid, der svarer til dets Fortid og Nutid.

I det Kongelige Danske Videnskabernes Selskab, Juli 1912.

\section{Prosident VILH. THOMSEN. \\ Sekretor H. G. ZEUTHEN.}

\section{FRANCE}

\section{University of Paris}

L'Universtié de Paris aU Président, au Conseil et aux membres de la Sociérté Royale de Londres.-L'Université de Paris est heureuse de se faire représenter aux fêtes données par la Société Royale de Londres à l'occasion du deux cent cinquantième anniversaire de sa fondation. Ce fut un jour mémorable que celui où le roi Charles II transforma en Société Royale le club où se réunissaient chaque semaine quelques curieux de la méthode expérimentale. Le programme de votre Charte était de développer la nouvelle philosophie, comme on disait alors, c'est-à-dire la connaissance de la nature au moyen de l'expérience. Votre Société est toujours restée fidèle à son premier but, et l'histoire de la Science montre avec quel éclat vous avez contribué au développement de ce que vous appelez encore aujourd'hui la philosophie naturelle. On ne peut se reporter aux premiers temps de votre fondation sans évoquer le souvenir de celui qui fut pendant vingt-quatre ans votre président, et dont un de vos poètes a dit éloquemment que c'est un honneur pour le genre humain qu'un tel homme ait existé. Toute louange pâlit à côté du nom d'Isaac Newton. Il n'est pas une branche des sciences physicomathématiques et des sciences naturelles qui n’ait été enrichie par les travaux des membres de votre Compagnie. John Dalton et Humphry Davy comptent parmi les fondateurs de la chimie moderne, et les découvertes de Faraday et de Maxwell en électricité ont eu d'immenses conséquences. Toute une philosophie se rattache au nom de Charles Darwin, dont les admirables et patientes observations ont mis en évidence d'importants facteurs de l'évolution des êtres vivants. Dans le grand labeur jamais terminé, par lequel s'édifie peu à peu la Science, chaque nation apporte sa mentalité particulière. Vos savants restent toujours soucieux des détails et des applications. Quel bel exemple a donné un grand physicien, comme Lord Kelvin, dont l'esprit puissant, capable des spéculations les plus élevées sur la thermodynamique et la théorie des atomes- 
tourbillons, s'attachait en même temps aux questions pratiques de la navigation et de la télégraphie transatlantique! Il fut aussi des vôtres, l'illustre Lord Lister qui, en s'inspirant des doctrines pastoriennes, a créé une méthode de pansement bouleversant la chirurgie, et s'est ainsi placé parmi les bienfaiteurs de l'humanité. La Science est dans une perpétuelle évolution. Les faits et les principes qui paraissent les mieux établis restent toujours sujets à revision. Mais, pour les reviser, il faut parfois une singulière audace. Elle ne vous a pas manqué. Près d'ici, des gaz nouveaux, l'argon et ses congénères, ont été extraits de l'air atmosphérique tant de fois analysé par les plus illustres chimistes. C'est dans un laboratoire anglais que fut repris récemment l'antique problème de la transmutation des éléments et que la transformation du radium en hélium a été établie; ce souvenir, où sont associées la science anglaise et la science française, est particulièrement cher à l'Université de Paris. La part aussi est considérable qui revient aux savants de votre pays dans les vues nouvelles sur les théories électroniques de la matière. Depuis deux cent cinquante ans, l'influence de la Société Royale n'a cessé de grandir. Ses Proceedings et ses Transactions comptent parmi les journaux scientifiques les plus renommés et vont porter au loin le témoignage de votre activité. Quelle gratitude tous les savants ne doivent-ils pas à la Société Royale pour son Catalogue of Scientific Papers pendant le $\mathrm{xIx}^{\theta}$ siècle, entreprise immense, devenue internationale pour le siècle actuel, mais dont vous avez conservé la haute direction. C'est encore à votre initiative qu'est due la création de l'Association internationale des Académies; grâce à vous, le projet, digne du chancelier Bacon, d'une Académie Universelle ouverte à toutes les nations est devenu une réalité. Vous vous êtes toujours préoccupés du rôle social que doivent jouer les Sociétés savantes. Il n'est pas en Angleterre une grande entreprise, ayant un caractère scientifique, sur laquelle vous n'ayez été consultés, ou dont vous n'ayez suggéré la création. Qu'il nous suffise de rappeler, pour des temps récents, le Laboratoire national de Physique, dû à l'initiative de votre Conseil, et qui reste placé sous son contrôle direct. Un passé si brillant répond de l'avenir de la Société Royale. L'Université de Paris lui apporte cordialement ses félicitations pour tant d'ouvres accomplies. Puissent toujours ses membres, rassemblés pour l'avancement de la connaissance de la nature, suivant les termes de votre Charte deux fois et demie séculaire, continuer à travailler pour le progrès des sciences et la gloire de l'Angleterre.

Paris, le 16 juillet 1912.

Le Vice-Recteur, Président du Conseil de IUniversité de Paris, L. LIAHD.

Le Professeur délégué de IUniversité de Paris, EM. PICARD. 


\section{Académie des Sciences de l'Institut, Paris}

Messievrs et chers Confrères,-Parmi les voeux que vous recevez de tous côtés, à l'occasion de la célébration de votre deux cent cinquantième Anniversaire, vous distinguerez, nous en sommes assurés, ceux que l'ACADEme DEs Scinnces dr. Paris nous a chargés de vous présenter en son nom. Vous connaissez de longue date les sentiments qui nous animent, l'affection que nous vous portons, l'admiration profonde que nous éprouvons pour vos travaux. Ces sentiments remontent à nos premières origines. Notre Académie et votre illustre Société ont eu des destinées à peu près pareilles. L'une et l'autre ont été établies par les amis de la science, longtemps avant d'être reconnues par le gouvernement de leur pays. Dès le début du xviI ${ }^{\ominus}$ siècle, nos savants de Paris avaient pris l'habitude de se réunir périodiquement, pour se proposer des problèmes de mathématiques, pour faire des expériences, pour discuter les grandes questions scientifiques que suscitèrent les découvertes de Képler et de Galilée. Vers la même époque, vos philosophes, vos savants, dont plusieurs vinrent nous rendre visite, se réunissaient à Londres et à Oxford pour s'occuper, comme les nôtres, d'expériences et de recherches scientifiques. Lorsque ces assemblées qui se tenaient dans l'un et l'autre pays commencèrent à $\mathrm{y}$ être connues, elles ne tardèrent pas à recevoir l'investiture officielle. Charles II vous donnait votre première Charte en 1662. Quatre ans après, en 1666, notre Académie recevait la sienne des mains de Louis XIV et de Colbert, 'ce ministre porté de lui-même aux grands desseins', en même temps qu'était décidée la création de l'Observatoire de Paris. Nos commencements se ressemblent à plusieurs égards. Par exemple, dans cette première partie de leur carrière, nos Académies ont, l'une et l'autre, compté parmi leurs membres d'éminents médecins. Il est vrai que les travaux de Newton n'ont pas tardé à illuminer vos débuts d'un éclat incomparable; notre Académie peut revendiquer du moins l'honneur d'avoir poursuivi et complété l'œuvre de ce grand homme. D'Alembert, Clairaut, Laplace, Lagrange figureront dignement à côté des successeurs que vous avez donnés à Newton dans l'achèvement de la plus glorieuse conquête qu'ait jamais faite l'esprit humain. Cette union féconde de nos recherches s'est maintenue jusqu'à nos jours. Lorsque, vers la fin du $x{ }^{1}{ }^{8}$ siècle, Lavoisier a jeté les bases de la Chimie moderne, ses travaux ont été étroitement mêlés à ceux de Priestley et de Cavendish. Au siècle qui vient de finir, et pour ne parler que de ceux qui ne sont plus, la postérité réunira dans une admiration commune les noms de quelques-uns de nos confrères, et ceux à jamais illustres d'Herschel, de Dalton, de Faraday, de Darwin, de Lord Kelvin, de Sylvester, de Cayley, 
d'Adams, de Maxwell, d'Huggins, de Lord Lister. Quelque incomplite qu'elle puisse être, cette énumération montre bien que, tout en conservant l'empreinte de Newton, tout en vous attachant à cultiver cette science maîtresse à laquelle il a donné le beau nom de philosophie naturelle, vous n'avez négligé aucune branche du savoir" humain. La méthode qui vous a guidés peut être aisément définie en quelques mots: Nullius in verba, telle a été la devise que la Société royale a toujours appliquée dans les travaux que, depuis sa fondation, Elle n'a cessé d'accomplir pour le développement et l'accroissement des sciences de la Nature. En répandant ainsi, en faisant connaitre par vos propres recherches et par les directions que vous donnez, cette méthode scientifique que le Chancelier Bacon avait préconisée avec tant de force et d'autorité, que Newton avait illustrée dans ses Principia et dans son Optique, vous avez rempli avec éclat la partie essentielle de la tâche qui, de tout temps, a été dévolue aux Sociétés Savantes; mais votre action s'est étendue plus loin encore et vous nous avez donné, sur d'autres points, des exemples que tous doivent s'efforcer d'imiter. Rattachés à votre gouvernement par des liens quelque peu lâches, qui vous assurent une indépendance ì peu près complète, vous avez tenu néanmoins à lui rendre tous les services qu'un grand pays peut attendre d'une Société Savante. Vous lui prêtez votre concours pour la distribution des subventions aux recherches scientifiques, pour la direction de l'Observatoire de Greenwich, du Laboratoire national de physique, pour l'étude des maladies tropicales qui se rencontrent dans votre Empire, le plus vaste que le monde ait jamais connu; vous provoquez, vous sollicitez sa coopération pour les expéditions maritimes et scientifiques, pour les découvertes géographiques, pour l'étude des tremblements de terre, de l'Océan dans ses profondeurs, et pour bien d'autres objets que nous renonçons à énumérer. Tant de travaux, tant de préoccupations sont loin d'épuiser votre activité; et l'on vous a toujours trouvés animés d'un esprit large et vraiment libéral, prêts à̀ susciter et à faire vivre ces associations internationales qui sont appelées à prendre une place de plus en plus bienfaisante dans le développement et dans la vie de l'humanité. Naguère, vous coopériez avec nous à la création de l'Association internationale des Académies ; vous avez voulu diriger vous-mêmes une des entreprises les plus difficiles qui aient jamais été tentées: nous voulons parler du Catalogue international de littérature scientifique, qui a été déjà, et qui sera plus encore dans l'avenir, si utile, si nécessaire aux chercheurs de tous les pays. Les services que vous avez ainsi rendus à votre pays, à la science et à l'humanité méritent le respect et l'admiration que vous apportent aujourd'hui tant de voix autorisées, auxquelles nous sommes heureux de joindre les nôtres. Puissiez-vous prospérer longtemps encore pour servir d'exemple à nos Sociétés Savantes, pour offrir à votre pays et aux savants de toutes les nations une moisson de plus en plus ample de ces découvertes qui sont marquées au coin de toutes les qualités, du génie de votre race! tel est le vœu bien cordial et bien sincère que vous 
présentent en ce jour vos confrères, permettez-nous de dire vos amis, de l'Académie des Sciences de Paris.

Le 15 juillet $191 \%$.

GABRIEL LIPPMANN, Président.

FÉLIX GUYON, Vice-Président.

GASTON DARBOUX, Secrétaire perpétuel pour les

Sciences mathématiques.

PHILIPPE VAN TIEGHEM, Secrétaire perpétuel pour les Sciences physiques.

\section{Obseryatory, Paris}

Le Directeur de l'Orservatoire de Paris à Monsieur ie President de la Soclété Royale de Londres.-Monsieur le Président, -En miinvitant à assister à vos fêtes, vous avez voulu honorer l'Observatoire de Paris, dont trois directeurs, J.-D. Cassini, Arago, Le Verrier, ont été associés étrangers de la Société Royale. Parmi les grands noms qui, dans tous les ordres des sciences, ont illustré votre Société, ceux des astronomes, avec Bradley, Newton, Herschel et tant d'autres, brillent aux tout premiers rangs. L'Observatoire de Paris est heureux de leur rendre hommage, et d'exprimer à la Société Royale, avec ses remercîments pour l'honneur qui lui est fait, sa profonde admiration.

\section{B. BAILlAUD, Directeur de TObservatoire de Paris.}

\section{French Society of Physics, Paris}

La Société Française de Physique à la Socreté Royale de Londres à l'occasion du deux cent cinquantième anniversaire de sa fondation.-A Monsieur le Président de la Société Royale de Londres.-Monsieur le Président,-La Société Française de Physique vous exprime ses bien vives félicitations à l'occasion de la célébration du deux cent cinquantième anniversaire de la fondation de la Société Royale de Londres. Ces deux siècles et demi de fécond labeur, que nous célébrons aujourd'hui, ont magnifiquement accru, par leurs riches moissons de découvertes, le patrimoine universel de la Vérité et de la Science. Votre illustre Compagnie a eu l'heureuse pensée de convier les Sociétés savantes étrangères à cette solennelle commémoration de tant de souvenirs glorieux. La Société Française de Physique est heureuse de répondre à votre cordiale invitation, dont elle sent tout le prix, et de venir apporter à la Société Royale de Londres son tribut d'hommages et de respectueuse admiration.

Paris, 1912.

B. BAILllaUd, Président.

CH.-ED. GUILLAUME, Vice-president. HENRI ABRAHAM, Secrétaire général. 


\section{Botanical Society of France, Paris}

A ia Royal Society, Londres.-La Société Botanique de France est heureuse d'exprimer à la Royal Society ses plus chaleureuses félicitations à l'occasion de son $250^{\text {ème }}$ Anniversaire et elle est particulièrement flattée et reconnaissante d'avoir été invitée à prendre part aux Cérémonies Jubilaires. Pleine d'admiration pour l'ouvre scientifique de la Savante Société Anglaise Elle forme le vou que l'avenir lui réserve une riche moisson d'importants travaux et de glorieux lauriers.

Le Président de la Société Botanique de France, R. ZEILLER.

15 Juillet 1912.

\section{University of Bordeaux}

Universitatis Burdigalensis Consilum Societati Regali Londinensi pro Screntia naturali promovenda Salutem.-Per vos, Viri doctissimi et illustrissimi, liceat nobis-quod iam non semel fecimus-declarare quanta iamdudum admiratione opera prosequamur sodalium vestrorum qui tantopere ad promovendam scientiam contulerunt et conferunt. Rogamus iidem benigne vota nostra accipiatis optantium ut in posterum non minoribus beneficiis humanitatem donetis, ideoque in aeternum crescat et augeatur decus clarissimae vestrae Societatis.

Datum Burdigalae, die $\boldsymbol{X}$ mensis Iulii MCMXII in nomine Universitatis Consilii.

A. PITRES, delegatus.

\section{National Academy of Bordeaux}

L'Academie nationale des Sciences, Beldes-Lertres et Arts de Bordeaux adresse à la Société Royale de Londres à l'occasion du $250^{\circ}$ anniversaire de sa fondation son salut confraternel et son vœu cordial de prospérité. Londres et Bordeaux sont unis, depuis près de deux mille ans, par des liens qu'ont noués des intérêts économiques communs, qu'ont resserrés des affinités naturelles et des sympathies inaltérables. Dès l'époque romaine Bordeaux fut le point de départ de la voie qui mène de France en Grande-Bretagne et dont Londres est le point d'arrivée. Au Moyen Age, pendant trois siècles, les deux cités eurent des destinées semblables. Le même roi d'Angleterre, duc d'Aquitaine, qui signa la Grande Charte, donna aux Bordelais ces franchises communales dont ils gardent pieusement la tradition. La prospérité commerciale, née des échanges entre Londres et Bordeaux, a pour jamais garanti à notre ville son prestige de métropole du Sud-Ouest de la France. Cet 
amour des libertés municipales et cette solidarité économique sont les deux traits caractéristiques de l'histoire de Bordeaux. Au xvir siècle un nouveau lien, d'une autre nature, fut noué. Cinquante ans après Londres, Bordeaux voulut avoir sa Société royale, vouée, elle aussi, à l'étude et au progrès des sciences de la nature. Des relations très nobles, dont nos registres conservent la trace, s'établirent entre la jeune Académie bordelaise et son éminente sœur aînée. L'honneur en revient au membre le plus illustre de notre Compagnie, à l'immortel penseur qui révéla à la France la beauté de la constitution anglaise, au grand Montesquieu. A la veille de célébrer le deuxième centenaire de sa fondation, l'Académie de Bordeaux est fière de rappeler ces souvenirs. Puissent-ils resserrer, d'une façon plus étroite encore, les liens séculaires de nos deux cités, affermir la cordiale entente de nos deux nations, gage de la paix du monde!

Bordeaux, 8 Juillet 1912.

Le Président de l'Académie nationale des Sciences, Belles-Lettres et Arts de Bordeaux, PAUL COURTEAULT.

\section{University of Clermont-Ferrand}

Praesidi Concilio et Sodalibus amplissimae Societatis Regalis Lonini consistentrs Universitas Claromontensis S. P. D.-Accepimus, Viri Doctissimi et Illustrissimi, gratoque legimus animo litteras quibus nos certiores facitis vos natalem vestrum hoc ipso mense Iulio celebraturos esse; vobisque hosce ducentos quinquaginta peractos feliciter annos libentissime gratulamur. Nemo est enim, inter eos qui scientiae Naturali promovendae student, qui nesciat quantum per illud grande temporis spatium in rerum natura inquirenda, scrutanda, investiganda profeceritis, quantoque doctrinae emolumento per vos aucti fuerint homines. Unum igitur e nostro numero, uti amicissime rogavistis, Professorem Augustum Pelcet, delegavimus, qui vobiscum Societatem vestram fundatam concelebret, nostraeque erga vos benivolentiae testis locuples festis diebus proximis intersit.

Dabamus Claromonte, Kal. Iuliis a. MDCCCCXII.

A. COVILLE, Rector, Concilii Universitatis Praeses.

\section{UNiversity OF NANCY}

Université de Nancy.-Monsieur le Président,-Un navire, à pleines voiles, franchissant la barrière des deux colonnes d'Hercule, dont l'antiquité avait dit qu'on n'irait pas plus loin; au-dessous, cette inscription, empruntée à la Bible, Multi pertransibunt et augebitur Scientia, 'Beaucoup passeront, et 
le domaine de la Science sera augmentế: telle est l'image et telle est la devisc gravées au-devant du Novum Organum de Francis Bacon. Prophétiques paroles, qui devaient trouver leur pleine réalisation dans l'ueuvre accomplie par cette fille posthume de son génie, Ia Société Royale de Londres. Depuis deux siècles et demi, en effet, combien de savants ont passé, qui, après aroir exploré toutes les parties du vaste monde scientifique, ont rapporté de leurs voyages, comme un éloquent livre de bord, ces deux cent onze volumes de vos Philosophical Transactions! Et quelle gloire pour eux d'avoir, sous les plis du pavillon britannique, combattu le bon combat pour cet impérialisme de la Science, le plus grand et le plus bean de tous, le senl qui n'enregistre que des victoires, et dont bénéficient tous les peuples! Au dix-septième siècle déjà, un de nos esprits les plus curieux, qui sous un air frivole cachait le goût des choses sérieuses, un Français enfin, en était émerveillé, et s'interrompait dans une de ses Fables pour jeter cette réllexion:

... Les Anglais pensent profondément.

Creusant dans les sujets, et forts d'expériences,

Ils étendent partout l'empire des sciences.

Cet hommage que vous rendait ingénument notre La Fontaine, toute la France savante vous l'apporte aujourd'hui: non seulement Paris, la capitale, mais aussi les diverses régions françaises, et la nôtre en particulier: je veux dire la Lorraine. C'est la France de l'Est, sensible plus que toute autre à la gloire scientifique, parce que, plus que toute autre, elle a appris à la connaitre en de glorieux fils nés de son sol: au siècle dernier, les mathématiciens Poncelet et Hermite, l'un de Metz et l'autre du Pays messin, tous deux Lorrains, de cette Lorraine arrachée depuis lors à notre Patrie; avant eux, Gergonne, connu par ses Annales, et Liouville, par son Journal; après eux, le plus haut représentant actuel des mathématiques parmi nous, un fils de Nancy même, Henri Poincaré. C'est un grand honneur pour notre jeune Université de Nancy, de mêler sa voix à ce magnifique concert d'éloges qui retentissent de partout à la gloire de la Société Royale de Londres. Par le nombre et la valeur de vos travaux, par l'illustration de vos savants, qu'en Angleterre la faveur publique aussi bien que le pouvoir récompensent à l'envi, puissiez-vous toujours, comme vous avez fait jusqu'ici, poursuivre au cours des âges votre fécond labeur, pro Dignitate et Augmentis Scientiarum, disait encore Bacon 'Pour l'accroissement ou le progrès des Sciences, et aussi pour leur dignité!'

Nancy, 14 Juillet 191\%.

Le Recteur de CUniversité, CH. ADAM, Membre correspondant de IInstitut de France. 


\section{GERMANY}

'The Universities of Germany, instead of each preparing an Address, combined their felicitations upon a large bronze 'Tablet which, at the Reception of the Royal Society, was presented in their name by Professor 1)r. Woldemar Voigt, Rector of the University of Giottingen. Delegates were at the same time present from the Universities of Berlin, Bonn, Breslau, Erlangen, Freiburg-im-Breisgau, Giessen, Göttingen, Greifswald, Halle, Heidelberg, Königsberg, Leipzig, Marburg, Munich, Münster, Rostock, Strassburg, and 'Tubingen. The 'Tablet, which is shown in the accompanying illustration, now hangs on the wall of the Entrance-hall of the Society's apartments in Burlington House.

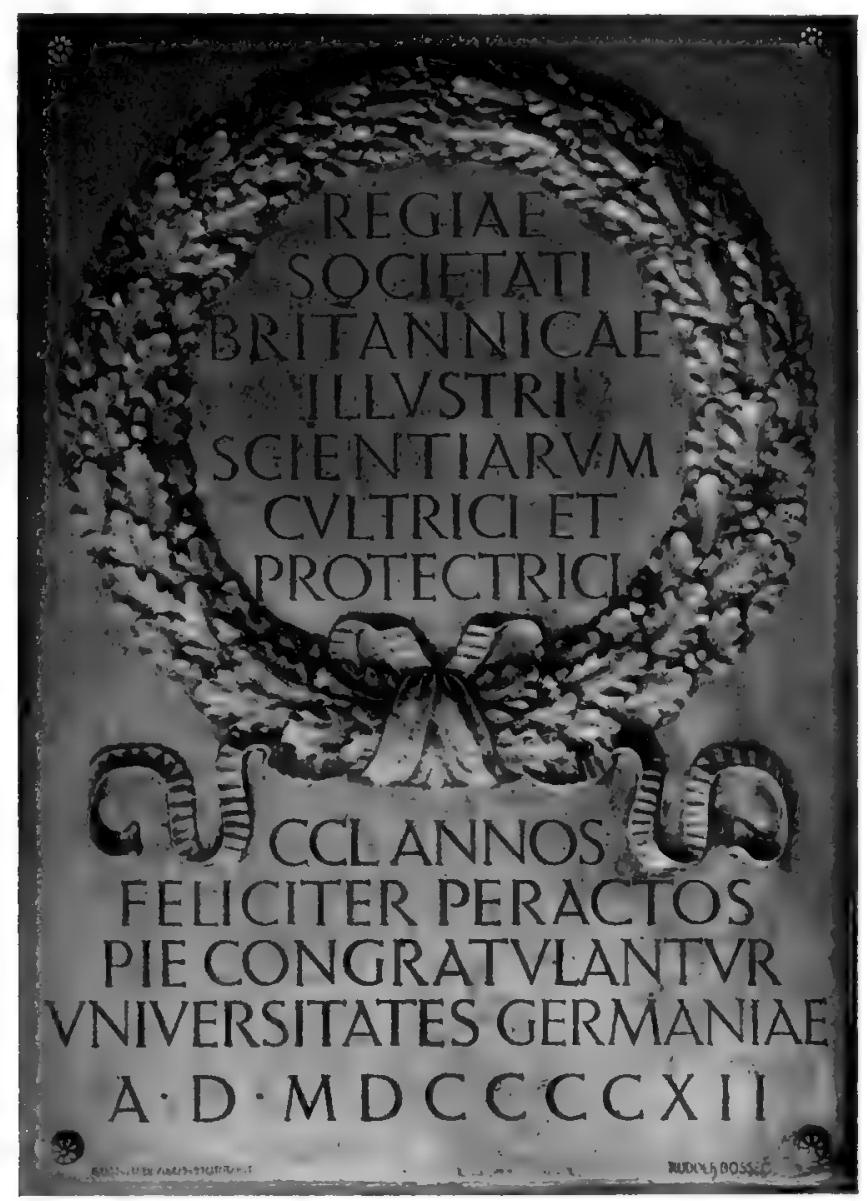




\section{Royal Society of Sciences of Göttingex}

Regiae Societati Scientiarim Londinensi quinquaginta lustrorum memoriam feliciter agenti tantam praeteritorum temporum gloriam praesentiumque felicitatem congratulantes futurorum saeculorum pares auguramur eventus. Nam quo die Societas a Roberto Boylio constituta Regiae nomen accepit, nova lux ingenii humani studiis affulsit, cum semina renatarum litterarum temporibus iacta in agro Baconis Verulamensis opera praeparato altas radices egissent et ad insperatam fructuum adcrescerent ubertatem. Satis est reminisci primitias fere Societatis magnum Newtonem protulisse. Sed post Newtonis tempora dici vix potest quot quantarumque rerum indagatio Societati Regiae debeatur. Neque enim attinet commemorare Observatorii Greenwichensis vel Laboratorii Institutionis Regiae merita, vel expeditionum Cookii, Rossii, aliorumque immortalem memoriam, vel summorum virorum nomina suscitare, quorum cum suam quisque aetatem ampliore scientiae lumine auxerit, coniuncti omnes acta Regiae Societatis inlustraverunt labore famaque. Quorum potissimum opera factum, sed et popularium prudenti liberalitate, ut inter Academias naturae scientiae deditas non aetate tantum et vetere gloria, verum virtute et factis aut cum primis aut prima numeretur ac robore vere iuvenali gaudens futuri quoque temporis palmas victrices affectet. Qua laude fulta Regia Societas ut semper quae communi scientiarum utilitati inservirent sua auctoritate promovit, hac nostra aetate Academias totius orbis coniuncti laboris vinculis colligandi grande consilium cepit et executa est. Quod non sine nostra opera factum esse libenter recordamur atque in posterum quoque longam studiorum communionem feliciter duraturam esse speramus.

Regia Societas Litterarom Gottingensis.

Datum Gottingae, die $X V$ mensis Iunii a. MCMXII.

\section{Royal Prussian Academy of Sciences, Berlin}

Der Royal Society of London entbietet zur Feier inres 250 Jährigen Bestehens die Königlich Preussische Akademie der Wissenschaften zu Berlin herzlichen Glückwunsch und schwesterhichen Gruss.-Wenn auch einige andere wissenschaftliche Gesellschaften auf ein ebenso ehrwürdiges Alter zurückblicken können, so darf sich doch die Royal Society rühmen, in dem Vierteljahrtausend ihres Bestehens auf dem von ihr gepflegten Gebiet der Naturwissenschaften mehr geleistet und auf die Entwickelung dieser Wissenszweige einen grösseren Einfluss ausgeübt zu haben als irgendeine der gelehrten Korporationen aller Kulturvölker. Die Jubilarin ist nicht, wie viele ihrer Schwestern, aus kleinen Anfängen zu ihrer heutigen Grösse und Bedeutung hervorgewachsen. Vollendet, wie Minerva dem Haupte Jupiters entstieg, tritt sie uns gleich nach ihrer Begründung als eine stolze Genossen- 
schaft von Forschern ersten Ranges entgegen. In der Liste der Mitglieder, welche die Begeisterung für die Wissenschaft und die Freude an der neuen Experimentierkunst im Jahre 1662 zu gemeinsamer Arbeit in den Räumen des Gresham College vereinigte, lesen wir mit Ehrfurcht die Namen von Robert Hooke, Robert Boyle und anderen, deren Entdeckungen heute die Grundlage weitverzweigter Wissensgebiete bilden. Aber der Glanz dieser Namen wird iiberstrahlt von der leuchtenden Ruhmessonne Isaak Newtons, des grössten Physikers aller Zeiten und grössten Denkers auf dem Gebiet der Astronomie, wie ihn Helmholtz genannt hat. Mehr als die Begründer selbst hat dieser gottbegnadete Meister, der wenige Jahre später der Gesellschaft als Mitglied beitrat und während eines Zeitraums von 24 Jahren ihr Präsident war, der Royal Society den Stempel seiner Persönlichkeit aufgeprägt. Es darf der Jubilarin das hohe Lob gespendet werden, dass sie stets von dem Geiste der grossen Männer beseelt war, die an ihrer Wiege gestanden haben und zu denen sich im Laufe der Jahrhunderte eine unabsehbare Reihe hervorragender Forscher auf allen Gebieten der Naturwissenschaften hinzugesellt hat. Frei in ihren Institutionen, ist sie durch alle Zeiten eine Pflegstätte der reinen, von Vorurteilen unbeirrten Forschung geblieben, eine für geistige Freiheit kämpfende Genossenschaft, die ihre hohe Devise: 'Nullius in verba" mit berechtigtem Stolze führt. Möge sie in diesen edeln Traditionen fortleben, möge es ihr vergönnt sein, auch in künftigen Zeiten eine so grosse Zahl hervorragender Männer und führender Geister in ihrer Mitte zu vereinigen, und möge sie, den alten Ruhmesblättern stets neue hinzufügend, auch fernerhin die Wissenschaft mit neuer und immer reicherer Erkenntnis beschenken, zur Ehre ihres grossen Vaterlandes und zum Segen der ganzen Menschheit!

Die Königlich Preussische Akademie der Wissenschaften.

ROETHE. DIELS. WALDEYER. PLANCK.

\section{Royal Bavarian Academy of Sciences, Munich}

Der Königuichen Geseldschaft zu London, gegründet zu einer Zeit, in welcher nur im Geburtslande der neueren Kultur und auch hier nur als eine ephemere Schöpfung fürstlicher Gunst (der besonders von Schülern Galileis gebildete 'Cimento' in Florenz) eine Akademie zur Pflege der exakten Wissenschaften entstand, und seitdem durch ihre Tätigkeit ununterbrochen einen eminenten Einfluss auf die Fortschritte in der Erforschung der Natur ausübend, sendet hiemit zu ihrem 250jährigen Wiegenfeste eine um 100 Jahre jüngere Schwester, die Königlich Bayerische Akademie der WissenSCHAFTEN ZU MÜNCHEN, ihre aufrichtigsten Glückwünsche.

Miinchen, im Juli 191\%.

Dr, von HEIGEL, Präsident.

Dr. v. GOEBEL, Sekretär der mathematisch-physikalischen Klasse. 


\section{Natural Science Union, Hamburg}

Der Naturwissenschaftuiche Verein in Hamburg dankt der Royal Society in London bestens für die Einladung zum zweihundertfünfzigsten Stiftungsfeste und sendet ihr in freudigster Anerkennung ihrer hohen Verdienste um unsere Wissenschaft die herzlichsten Glück wünsche. Möge sie weiter wachsen, blühen und gedeihen als leuchtendes Beispiel für alle Völker und alle Zeiten.

Prof. Dr. G. GƯRICH, I. Vorsitzender.

\section{ITALY}

\section{UNIVERSITY OF RoMe}

Universitas Studionum Romana libentissimo animo se sociam ceteris omnibus optimarum artium institutis, quotquot in orbe terrarum sunt, addit, ut una cum iis Societati Regali Londinensi, quae per CCL ex quo condita est annos (grande et gloriae plenum aevi spatium) liberales disciplinas summo opere promoverit atque propagaverit, maximam admirationem gratumque animum profiteatur. Nam ista Societas postquam a Bacone illo Verulamiensi animo est concepta, quo tempore disciplinae omnes miro quodam virorum doctorum studio renovabantur atque ut ille apud Britannos, ita in Academiis Linceorum et Experimenti nostrates, Galileius eiusque discipuli, rerum natura qua ratione esset pervestiganda docebant, exemplo praemonstrabant, ab incunabulis suis usque ad hoc tempus in optimis artibus colendis promovendisque nunquam viam ceteris munire destitit; quidquid autem eius auspiciis aut inventum aut investigatum est, id ommibus est hominibus patefactum celeberrimis editis actis quibus nomen est Philosophical Transactions, quo exemplo usi sunt ceteri ad sua quoque inventa in lucem proferenda. Magnum Newtonii nomen est cum Societate Regali Londinensi tam arte coniunctum, ut nemo possit de illius optimis inventis cogitare quin statim in Societatis memoriam redeat, cui ille usque ad extremum vitae diem praefuerit. Universitas Studiorum Romana vota pro Societate Regali Londinensi nuncupat precaturque ut prospera semper utatur fortuna atque summa ut nunc in perpetuum floreat gloria. Delegatus est qui personam Universitatis Regiae Romanae gerat V. Volterra, Eques torquatus, physicae mathematicae Professor ordinarius, inter Senatores Italici regni adlectus, Facultatis scientiarum Praeses.

Romae, Die I mensis Iulii MCMXII.

ALBERTUS TONELLI, Rector Romanae Universitatis. I 2 


\section{University of BologNa}

$\mathbf{R}_{\text {EGali }}$ Societati rebus naturalibus cognoscendis Londini ante annos prope CCL institutae nunc feriis indictis natalem suum celebranti Universitas litterarum et artium Bononiensis fausta omnia, proinde ac merita est, spe bona certaque precatur.

Namque alid ex alio clarescet, nec tibi caeca nox iter eripiet quin ultima naturai

pervideas : ita res accendent lumina rebus.

Bononiae, VIII Kal. Iul. a. MCMXII.

LEO PESCI, Rector Universitatis.

\section{University of Palermo}

Rector Senatus Professones Athenaei Panhormitani Praesidi Concilio Sodalibus Regiae Societatis Londinensis S. D.-Qua estis humanitate, annum quinquagesimum et ducentesimum concelebraturi, ex quo Carolus II regio rescripto Societatem vestram constituit, unum e nostro numero vobiscum Londini esse concupivistis. Quod maxima nos voluptate adfecit. Vetus enim amor coniunctioque inter Italos Britannosque est manetque nobis, ut Vergiliano illo versu utamur, alta mente repostum quanto studio Britanni Italiae renascentis exordia prosecuti sint. Cuius amoris vinculo quo Itali et Britanni coniunguntur, alterum additum est, quo praesertim Athenaeum nostrum Societati vestrae adhaeret, ex quo Stanislaum Cannizzarum qui, in hac urbe natus, in Athenaeo nostro decem circiter annos adolescentes docuit atque erudivit antequam Romam se contulit, in amplissimum Collegium vestrum cooptandum et Copleiano nummo ornandum censuistis : cui honori vix ullus anteponendus videtur, cum Societas vestra de tot ingeniis mirifice excellentibus glorietur et, si quis ab ultimo fere initio rem repetere velit, de Newtono illo, sodali vestro et praeside, tam magni animi viro, ut, Galilaei nostri ardorem aemulatus, animo morituro caeli claustra perruperit polumque rotundum percurrerit. Ergo ex nostro numero libentissime clarissimum sodalem nostrum Iohannem Baptistam Guccram misimus qui votorum nostrorum interpres et nuntius his diebus vobiscum bona omnia vobis Societatique vestrae precaretur. Valete.

Datum Panhormi, Id. Iun. A. MDCCCCXII.

FED. RAFFAELE, Rector.

V. USSANI, 4 b Epistulis Latinis. 


\section{Royal Academy of the Lincei, Rome}

Regia Lynceonum Academia Clarissimo Praesidi Conchuo atque Regiae Societatis Londinensis Sodalibus Salutem.-Longo iam temporis spatio luxuriosae ac munificae suae vitae ista praeclara Regia Societas homines claritate praestantes, quorum magnos gerit spiritus genus humanum, domum suam recepit. His diebus festis ad memoriam servandam atque colendam indictis veteris et praeclarae Societatis, quae, anno MDCLXII, Rege Carolo II auspice, orta est, Societates omnes, quibus maxime sunt cordi humanae scientiae progressus, bona omnia mittunt. Regia Lynceorum Academia, me auctore, summam suam animi voluptatem significat et diei Regiae Londinensis Societatis natalis particeps est.

Romae, Mense Iulio MCMXII.

PETRUS BLASERNA, Praeses.

\section{MONACO}

\section{Oceanographical, Institute}

L'Institut oceanographique fondé par le Prince de Monaco s'associe aux témoignages de respect que bien des corps scientifiques adressent aujourd'hui à leur doyenne en songeant avec reconnaissance aux efforts qu'elle fit avant tout autre pour agrandir le domaine de l'esprit. Les savants groupés autour du Prince apportent leurs félicitations pour ce $250^{\mathrm{me}}$ anniversaire avec un empressement d'autant plus cordial que les savants anglais sont les premiers qui aient compris l'importance du rôle dévolu à l'Océanographie dans le progrès des connaissances humaines. Cette circonstance est favorable pour reconnaitre la haute influence que la Société Royale de Londres a su exercer sur le développement scientifique de l'Angleterre en faisant naître parmi les esprits cultivés la puissance de l'initiative. C'est ainsi que les grandes expéditions scientifiques conçues par les savants de l'Angleterre ont été presque toujours rendues effectives par le concours des particuliers. Souvent l'État a joint sa contribution en hommes et en nature aux grandes entreprises telles que la croisière du Challenger; puisse-t-il intervenir plus largement encore pour la solution des problèmes scientifiques dont la recherche établit mieux que toute autre manifestation d'énergie le prestige moral d'une nation. Un Etat qui favorise la culture de l'esprit sans entraver le libre essor des opinions fait honneur au pays dont il est une émanation. D'ailleurs la Grande Bretagne qui a montré comment un peuple édifie sa puissance, son prestige et sa prospérité en respectant ce qu'il y a de noble et d'émouvant dans ses traditions, la Grande Bretagne possède déjà, avec la longue existence de votre Société Royale, la tradition scientifique. Aussi une élite intellectuelle vient 
aujourd'hui saluer le génie du Peuple Britannique dans une de ses plus belles fructifications. Les hommes de science ne revendiquent pas un privilège exclusif dans l'évolution de la mentalité humaine: de grands cerveaux ont cultivé les éléments de celle-ci lorsque la science n'existait pas encore, mais quand, déjà, la recherche de la vérité en toute chose lui préparait les voies. C'est pourquoi nous voulons glorifier la mémoire des hommes qui se sont illustrés dans les diverses branches de l'activité intellectuelle, qui ont répandu sur la Grande Bretagne les premiers bienfaits de la civilisation moderne, et dont la renommée se confond avec celle de la Société Royale.

ALBERT, $P^{\mathrm{OR}}$ de MoNaco.

\section{NETHERLANDS}

\section{University of Amsterdam}

Societatis Regalis Praesidi, Conchlio, Sodalibus, viris amplissimis, Rector et Senatus Universttatis Amstelodamensis, S. P. D.-Societas Regalis illustrissima per CCL annos vim illam scientiae insitam in usum generis humani promovit. Quam ob rem magno et sincero gaudio affecti cum per legatum nostrum C. WINKLER, virum clarissimum, ad Vos missum, tum per hanc epistulam sollemnem, quantum Vestrae laetitiae simus participes, libenter profitemur. Quid scientia sodalibus Vestris, summis illis viris, quid verbis et factis Societatis Vestrae non minus Patria Vestra quam mundus debeat universus, grato animo recordamur. Utinam labores et studia, quae ad hunc diem in promovendas artes impendere voluistis, ad lucem veritatis diffundendam et vim scientiae augendam aptissima, per futura quoque tempora splendeant semper clarissimeque conspiciantur.

Dabamus Amstelodami, die XI mensis Iulii A.D. MCMXII.

Dr. C. WINKLER, Rectore Magnifico.

J. D. v. d. WAALS, Jr., Senatus Actuario.

\section{University of Groningen}

Societati Regali pro Scientia Naturali promovenda Londini conditae Senatus Usiversitatis Groninganae S. P. D. Q. B. F. F. F. Q. S.- Si bene et sapienter a maioribus nostris institutum est, ut singuli homines quotannis diem suum natalem celebrent, quo vitam ante actam paulisper saltem respicere possint, non minus prudenter eadem consuetudo diei natalis celebrandi etiam ad universitates translata esse videtur. Quapropter, viri illustrissimi, magnopere gaudemus, quod vos urbem celeberrimam hegotiosissimam frequentissimam 
incolentes, hunc diem festum, quo ducentis quinquaginta annis ante Societas vestra a Carolo Secundo, rege augustissimo, constituta est, silentio praeterire noluistis. Iam vobiscum longum illud tempus memoria recolentes laetamur, quod Societas vestra tamdiu floruit viguitque, gratulamur autem, quod numerus Sodalium semper augetur neque eorum studium et diligentia umquam remissa est, denique vehementer speramus fore ut Societatis vestrae gloria et felicitas etiam in posterum firmentur. Petentibus vobis, ut unus e coetu nostro ad vos delegaretur, qui vobiscum dies festos concelebraret, Senatus Universitatis Groninganae decrevit ut ipse Rector, v. cl. Gerardus Corneluus Nisног, ad vos legatus mitteretur. Nos autem eiusdem Senatus decreto sollemni obsecuti hanc gratulationem et haec vota sincera ad vos misimus.

Groningae, Kalendis Iuliis MC.MXII.

G. C. NIJHOFF, Senatus Univ.Gron. Rector.

J. H. KERN, Senatus Univ. Gron. Ab actis.

\section{UNIVERSITY OF LEYDEN}

Societati Regiae Londinensi feliciter peractum quinquagesimum lustrum gratulantur Universitatis Lugduno-Batavae Rector et Senatus.-Laetissimas iam iam celebraturis ferias ex animi sententia Vobis gratulamur, utpote qui Vobiscum gaudeamus longum et memorabile respicientes tempus a Vestra peractum Societate, nec minus decus illud vigoremque contemplantes quo nunc splendet illa nitetque. Quod dum facimus, simul mente pia illorum virorum recolimus memoriam, qui pauci numero-atque in ea re Vestra patria fere ceteris omnibus regionibus monstravit viam-coierunt ut naturae detegerent arcana et prudentibus accuratisque inquisitionibus collectam doctrinam in omnium mortalium converterent utilitatem. Ex illo surculo, strenue adiuvantibus viris illustribus, ipsa adiuvante Republica legibus opibusque suis, sed praesertim Sociis Vestris praeclaras suas mentis dotes indefessamque industriam intendentibus, sanctissima illa succrevit arbor, quae nunc umbra sua tegit recreatque totum campum illum disciplinarum physicarum, qui per totum orbem terrarum extenditur. Vestra historia, quae nobis exhibuit illa nunquam interituro splendentia fulgore ingenia, Newtoni, Harveii, Darwinii, Kelvini, aliorum, eximias quasdam implet paginas libri quo universae humanitatis fata enarrantur celebranturque. Illa nobis exponit ars geometrica quomodo humanae mentis opibus subsidio venerit, caeli profunda quae sit emensa ratio, qua sint sagacitate extremi naturae perlustrati recessus, morborum avertendorum reprimendorumque quae sint inventae artes. Cumque semper singulorum doctorum conamina prudenti sustentastis atque incitastis admonitione, saepe, cum initum esset aliquod consilium egregium sed unius populi superaturum vires, Vos auctores fuistis communis cuiusdam militiae 
omnibus gentibus allaturae salutem et prosperitatem. Gratissimo vero animo laetissimis hisce diebus quibus vinculis Vobiscum iuncti fuerint permulti viri qui in nostra patria naturae legibus investigandis dederunt operam recordamur. Vobis acceptum referre nunquam desinemus quod Leeuwenhoekius noster suas de animalibus microscopicis disquisitiones in lucem edere communem potuit; Huygensium quem tamquam physicorum nostrorum principem suspicimus colimusque, semper cum proavis Vestris de gravissimis rebus iniisse consilia tenemus memoria. Neque nostro tempore deesse Neerlandicos doctos, atque ipsius huius Universitatis alumnos, qui extranei socii Vobis sint adscripti laetamur gloriamurque. Quas res pia grataque recolentes mente ex animi sententia pro Vestrae Societatis vota facimus salute. Sint futura praeteritis similia tempora, atque in longam annorum seriem pergat Societas Vestra cum toti vitae humanae tum disciplinis illis augustis salutiferisque lucem ferre subsidiumque.

Lugduni Batavorum, d. vi m. Iulii MCMXII.

F. PIJPER, Rector.

B. D. EERDMANS, Actuarius.

\section{UNIVERSITY OF UTRECHT}

Societatis Regalis Londinensis Praesidi Concilio Sodalibus S. P. D. Senatus Universitatis Ultraiectinae.-Propter Societatis Vestrae dignitatem et doctrinae celebritatem eximiam cum Rectorem Magnificum huiusce Academiae ad Vos, Viri Doctissimi, legavimus, ut nostro nomine praesentes Vos compellaret sensumque erga Vos nostrum obsequiumque declararet, tum committere non potuimus quin per has litteras diem natalicium Vestrae Societatis ducentesimum quinquagesimum Vobis ex animo gratularemur. Quae quantum in scientia naturali promovenda laborarit quamque uberrimis fructibus humanum genus per lustra illa quinquaginta bearit, cum nemo ignoret, nunc commemorare non decet; hoc vero et nos et omnes scientiarum amantes precari vel maxime decet ut diem sollemnem Deus O. M. Vobis'fortunet, Societatem Vestram usque servet incolumem florentemque atque omni bonorum abundantia cumulet. Vaiete, Viri Illustrissimi antistites Societatis Regalis insignissimi, Vobisque ita persuadeatis nos nihil magis optare quam ut diu porro et nos et omnes scientiae studiosi subsidio Vestro ac luce fruamur. Iterum valete.

Datum Traiecti ad Rhenum, Idibus Iuliis A. S. MCMXII.
A. A. NIJLAND, $h, t$. Rector Magnificus.
C. EIJKMAN, $h$ 。 $t$. Actuarius. 


\section{Royal Academy of Sciences, Amsterday}

The Royal Academy of Sciences of Amsterdam offers its best congratulations to the Royal Society of London on the occasion of the celebration of its two hundred and fiftieth anniversary. In these two hundred and fifty years Science has reached a high degree of development, to which the Royal Society, as one of the earliest scientific institutions, has powerfully contributed. The Royal Academy of Sciences remembers with pleasure the feelings of friendship which have always existed between the Royal Society and Dutch scholars throughout the period of its existence. For ever memorable, not only to the Academy, but also to the whole of the Dutch nation, will be the encouragement which the Royal Society shortly after its foundation gave to Leeuwenhoek by appointing him a Fellow of the Society in 1679, a distinction highly valued by him, and which has undoubtedly been promotive both to the production and to the spread of his inventions, which he communicated in a correspondence with the Royal Society extending over forty-four years. Further the Academy recalls on this occasion with great acknowledgement, how Christian Huygens, the contemporary and correspondent of Newton, Flamsteed, Boyle, Locke, with which famous men he was personally acquainted, was one of the first foreign members of the Royal Society. And how on Boerhaave, also a Fellow of the Royal Society, the special honour was conferred that Cromwell Mortimer, then Secretary of the Royal Society, dedicated the thirty-ninth volume of the Philosophical Transactions to this scholar in 1735. The Royal Academy of Sciences wishes the Royal Society many years of great prosperity, and expresses the hope that the mutual feelings of friendship, which have been entertained for two and a half centuries, may continue to exist in the future.

Amsterdam, July 191\%.

P. D. CHANTEPIE DE LA SAUSSAYE, President.

P. ZEEMAN, Secretary.

\section{Dutch Society of Sciences, HaArlem}

The President and Council of the Dutch Society of Sciences offer their most sincere congratulations to the Royal Society on the occasion of its 250th anniversary. Few Societies can look back on an uninterrupted existence of two and a half centuries, less on a continuous activity during so long a time and none on a higher class of scientific work than that published by the Royal Society. The President and Council of the Dutch Society of Sciences can therefore frame no better wish, than that the Royal Society may for many more centuries continue to promote knowledge and consequently human happiness in the same admirable way as heretofore. For the President and Council of the Dutch Society of Sciences,

Haarlem, July 12th, 1912.

LOTSY, perpetual Secretary. 


\section{Batavian Sochety of Experimental Philosophy, RotTERDaM}

Regali Societati Societas Philosophiae Expermantalis Batava, anno MDCCLIX a Steven Hoogendijk Roterodami instituta, Salutem.-Ducenti quinquaginta fere anni sunt ex quo Carolus Secundus Rex, ut artes atque scientias, praesertim philosophica studia, quae solidis experimentis conantur aut novam extundere philosophiam aut expolire veterem, promoveret, Societatem instituit consistentem de Praesidente Concilio et Sodalibus, quae vocabatur et nuncupabatur Regalis Societas. Sodalium eius magna multitudo iam dudum immortali doctrinae et ingenii acuminis gloria in omnibus orbis terrarum partibus floret per ea opera quae magnam partem in libris Philosophical Transactions, qui dicuntur, servantur. Neque minus qui in eorum locum successerunt optimis artibus maximaque eruditione studia philosophica colere et famam Regalis Societatis tueri pergunt. Optimo igitur iure Societatem vestram fundatam celebratis. Societas nostra, quae isdem studiis operam dat, vobis successum ex imo pectore gratulatur et ut in posterum quoque Societati vestrae non modo eadem gloria frui sed etiam magis magisque crescere detur optat et orat. Quanto studio vobiscum concelebraremus natalem Societatis ut significaremus, hoc documentum, signatum sigillo nostro cum voce, 'Certos feret experientia fructus,' conficiendum et vobis mittendum curavimus.

Datum Roterodami, die XIV mensis Iulii MCMXII.

Nomine Societatis philosophiae experimentalis Batavae:

S. BIRNIE, Praeses.

R. H. VAN DORSTEN, $A b$ actis.

\section{NORWAY}

\section{Royal University of Norway, Christiania}

The Royal University of Norway to the Royal Society of London. Greeting. A quarter of a millennium has elapsed since the foundation of the Royal Society. Since the days of Boyle and Newton, the Royal Society has enrolled on its list of members the names of almost all the eminent scientists of Great Britain, and among these are recorded the illustrious names of founders of all branches of modern science. Always alive to the vast importance of science to the various spheres of mental life throughout the world, the Royal Society has, in all likelihood, contributed more towards the development and advancement of mankind than any other scientific association. As a natural consequence of this leading position among 
scientific institutions, the Royal Society has suggested the foundation of 'the International Association of Academies', and has thus enhanced the prospect of establishing solidarity within the domains of scientific research throughout the universe. The innumerable momentous scientific results and the fundamental ideas this illustrious Society has given to the world merit the admiration and gratitude of all, especially of the scientific institutions of all countries. The Royal University of Norway therefore begs to express its gratitude for the weighty contributions your Society has yielded to the common work of culture, and tenders heartiest greetings and congratulations on the occasion of your 250th anniversury, coupled with best wishes for ever increasing prosperity.

Christiania, July 4th, 191\%.

BREDO MORGENSTIERNE, Rector. CHR. AUG. ORIAND, Secretary.

\section{Academy of Sciences, Christiania}

Societati Regali Academia Scientiarum Christianiensis S. - In natura rerum pervestiganda per hosce ducentos quinquaginta annos Societas Regalis fulget velut sol splendens, qui vi radiorum penetralia rerum occulta perfringit atque modos illustrat multiplices variosque, quibus in mundo animato inanimoque cum per orbem terrarum tum per spatium caeleste viget natura. Magnum agmen virorum, qui in studiis eminuerunt quorumque nomina praeclara cum Societate Regali conexa sunt, societates sororiae verecunde grateque recordantur, quarum numero coniungi iuvenis nostra societas, quae non minus ducentis annis post vestram instituta est, honorem sibi ducit et magnopere gaudet, cum pie vobis salutem plurimam scribit optatque ut Societas Regalis cursum suum tenere itaque honorem patriae augere universoque generi humano prodesse pergat.

\section{RUSSIA}

\section{Imperial Academy of Sciences, St. Petersiurg}

Amplissimae Societatis Regalis Londinensis Praesidi Concilio Sodalibus Imperialis Academia Scienriarum Petropolitana S. P. D.-Cum recitarentur in concilio nostro literae vestrae humanissime nos invitantes, ut sollemnibus, quibus ducentesimum quinquagesimum Societatis vestrae diem natalem celebraturi estis, per legatum nostrum adessemus, ultro subiit animos illius temporis recordatio, quo Academia nostra, vixdum secundum aetatis annum ingressa, per epistulam, ab ipso Isaaco Newton, immortalis viro memoriae, ad 
concilium Societatis Iondinensis relatam, tamquam soror sororem natu maiorem adloquens, Societatem multis magnisque ingeniosae eruditionis operibus iam tum nobilitatam rogabat, ut sibi faveret studiorumque suorum primitias benivole acciperet. Eadem semper reverentia Academia Petropolitana acerrimam fecundissimamque Societatis vestrae industriam prosecuta est, eadem nunc observantia ei gratulatur ducentos quinquaginta annos ita $a b$ ea peractos, ut priorum temporum gloriam novarum laudum cumulaverit splendore atque etiam ad recentissimos naturae rerum cognitionis progressus quam plurimum se contulisse iure gloriari possit. Quorum meritorum magnitudinem vehementer admirantes et praeteritis praesentibusque futura augurantes, enixe exoptamus ut Societas Regalis Londinensis per infinitam saeculorum seriem vigens ac florens sincerae veri inquisitionis lumen et columen permaneat.

Datum Petropoli, die XVI mensis Mai anni MDCCCCXII Iuliani.

Pro Academiae Praeside, PETRUS NIKITIN. Secretarius perpetuus, SERGIUS DE OLDENBURG.

\section{University of Moscow}

Q. B. F. F. F. Q. S. Vetustissima Russicarum Universitas Caesarea Mosquensis Vetustissimae Britannicarom Societati Regali Londinensi S. D. P.-Magna sunt per annos ducentos quinquaginta Societatis Vestrae amplissimae in litteras merita, cuius sodales fuerunt viri clarissimi et doctissimi, qui et mathematicas artes et de rerum natura doctrinam studiis suis scriptisque valde adiuverunt. Nam commentarii vestri cum alii, tum ii qui Philosophical Transactions inscribuntur, thesaurus est omnis doctrinae, quae per multos annos collecta per multos annos posteris usui futura est. Quo factum est ut in Societatem Vestram recipi ab omnibus viris doctis pro maximo honore haberetur. Qui honor quod nostris quoque nonnullis professoribus delatus, non minus id nobis gratum est, quam quod in numero sociorum honorariorum Universitatis nostrae aliquot viros doctissimos Britannos habemus, qui iidem Societatis Vestrae sodales sunt. Sed quoniam Societas Vestra cum ceterarum gentium doctissimos homines sibi asciscit, tum maxime Britannos, Universitas nostra, cum illi gratulatur, Britannorum vim ingenii praedicat, cui omne genus humanum tam multa inventa tantosque in omnium rerum magnarum scientia progressus gratissimo animo debet. Vivat crescat floreat Societas Regalis Londinensis per innumerabilem seriem annorum.

Mosquae, D. XII Iunii A. MCMXII. Rector Universitatis Mosquensis: MATTHAEUS LUBAWSKY. 


\section{University of Odessa}

Regali Socherati Londiniensi. Univerisitas Caesarea Novorossica maxima admiratione permota Clarissimorum de litteris artibusque optime meritorum Virorum, quorum memoriam Societas Regalis Londiniensis nunc annum ducentesimum quinquagesimum agens celebrat, gratissimo animo Doctissimos Illustrissimos Sodales salutat et optat cupitque, ut iis eadem via gloriosissima pergere et litteris prosperrima fortuna colendis totum genus humanum semper maximis beneficis afficere liceat.

Odessa, 28 Iunii 191\%.

Rector: SERGIUS LEVASOFF.

\section{UNIVERSITY OF WARSAW}

Inclitae Societatis Regalis Londinensis Praesidi, Concilio, Sodalibus Universitatis Caesareae Varsaviensis Rector ert Senatus S. P. D.-Quod ducentesimum quinquagesimum natalem illustrissimae Societatis Vestrae sollemniter celebraturi huius laetitiae nos quoque participes esse voluistis, pergratum nobis est. Summa enim reverentia atque admiratione immortalis gloriae virorum doctorum recordamur, qui per hos CCL. annos inter sodales Vestros recepti vel scientiarum doctrinarumque experimentalium nova eaque firmiora fundamenta posuerunt, vel in iis promovendis usque ad nostram aetatem maxima diligentia optimoque eventu elaborarunt. Quis est porro quin sciat, Societatem Vestram, certis sapienterque inventis legibus et praeceptis fultam, omnibus scientiae naturalis partibus excolendis strenue sagaciterque studuisse atque, quotiescunque rerum naturae investigationis utilitas postulaverit, pro virili parte operam praebuisse, ut optimo iure Britanniae decus haberi interque clarissima totius orbis instituta, bonarum artium studia spectantia, numerari possit. Quae omnia reputantes atque in ipsis fundamentis et principiis, quibus labores et studia illustrissimae Societatis Vestrae nituntur, pignus quoddām perpetui naturae cognitionis processus incrementique perspicientes, CCL annos feliciter peractos Ei congratulamur piisque animis exoptamus, ut insequentibus quoque saeculis eodem quo adhuc successu pro communi generis humani gloria atque utilitate laborare pergat. Valete, Viri doctissimi, nosque Vobis commendatos habete.

Datum Varsaviae, a. d. IV. Kalendas Iunias a. MDCCCCXII.

Senatus Academici nomine:

I. TREPICIN, $h . t$. Rector Universitatis.

S. VECHOV, h.t. Decanus ordinis historicorum et philologorum.

P. MITROPHANOV, h.t. Decanus ordinis physiconum et mathematicorum.

TH. SIGEL, $h . t$. Decanus ordinis iurisconsultorum.

A. KOLOSOV, h. t. Decanus ordinis medicorum. 


\title{
Imperial Society of Naturalists, Moscow
}

Societati Regali (Londiniensi) Societas Caesarea Naturaf Curiosorum Mosquensis S. D. P.-Omnium quae sunt in Rossia Physicorum societates antiquissima Caesarea Societas Naturae Studiosorum, a. MDCCCV condita, Societati Regali lustrum quinquagesimum celebranti pio lubentique gratulatur animo, gratissima recolens memoria quantum Societas Illustrissima hoc longo spatio ad disciplinas physicas propagandas tribuerit, quantamque ob ingentia erga universum genus humanum merita auctoritatem apud omnes ubicumque sunt viros doctos, scientiarum quae dicuntur exactarum cultores, optimo iure habeat. Quis enim est qui nesciat, quam saepe Societas Vestra virorum doctorum agmina in diversas ingentis Imperii Britannici partes sua impensa legaverit, quibus ex legationibus praecipue eminet illa quae Challengeri ducis nomen prae se fert, vel illa altera quae solis discum Veneris sidere occultatum observavit? Summa omnino liberalitate sodales sociosque suos Societas Regalis adsiduo adiuvabat, ita ut omnes denique oceanos omnesque orbis terrarum partes fructiferis laboribus suis amplexa sit, cui rei Philosophical Transactions illae, quae inde ab anno MDCLXIV eduntur, nec non Proceedings, qui iam amplius centum annos florent, luculentissimo documento plane sunt. Crescat ergo Illustrissima Societas, permaneat in iis rationibus, quas Oxonienses illi Societatis Creatores secuti sunt postque hos egregii Sodales pio animo coluere coluntque, quorum quod multi clarissimi viri nostrae Societatis Socii Honorarii sunt, summo est nobis gaudio.

\author{
Praeses: Prof. emer. N. UMOW. \\ Vice-Praeses: Prof. temer. A. SABANEJEFF. \\ Secretarii: Prof, ond. DR. E. LEYST,
} V. DEINEGA.

Dedimus Mosquae, die XVI mensis Iulii, a. MCMXII.

\section{FINLAND}

\section{University of Finland, Helsingfors}

\begin{abstract}
Societatis Regalis pro Screntia Naturali phomovenda Praesidi Consilio et Sodalibus Rector et Senatus Imperialis Universtatis Arexandreae Finlandensis Salutem.-In Regali Societate Vestra hodie ducentos quinquaginta annos celebratura e longe diversis excultorum populorum civitatibus permulti confluunt ab academiis, Universitatibus, doctrinae institutis legati, ut illi verecunde gratulantes tam decoram memoriam rite revocent et cum Sodalibus Vestrae Societatis laetentur, quod ea ipsa usque per saecula magnam
\end{abstract}


vim suam servavit et auxit. Ac felici quidem tempore instituta est Socictas Regalis, quo tempore cognitio naturae experimentis niti et valere ct latius manare coepit, quo primo est intellectum quantum illa ratione adhibita res naturae obscurae et absconditae erui possint, quo innumerae his in rebus quaestiones quasi proruperunt, quo propter methodorum et operum novitatem in immensis camporum nondum cultorum spatiis omnis conatus magnos attulit scientiae fructus et novas cognoscendi vias invenit. Multa et praeclara in Regalis Societatis Annalibus servantur nomina et ex initiis illis et ex tanto praeteriti iam temporis tenore, et quidquid magni in scientiis naturae per has aetates profectum est, id fere omne variis modis cum operibus sive ipsius Societatis sive Sodalibus eius reperietur coniunctum. Clarissimum autem inter nomina illa tamquam sidus Isaaci Newton fulget, qui quidem immortalem adeptus honorem reperta universali corporum caelestium attractione non solum ex una repetivit lege eorum corporum motus, quae velut summa suoque genere absoluta in ceteris frustra scientiis expetita est, sed etiam fundamenta posuit cogitandi rationi ad logices artem aptius accommodandae et omnino ei intellegendi mori, qui recentiore humanitatis cultu continetur. Regali Societate constituta magis magisque et consociati sunt inter se in omni scientiarum genere viri docti et quae effecerunt latius fusa sunt et dispersa semina posteritati profutura. Atque etiam si Britannos maxime scientiae deditos voluit in unum cogere, in omni tamen orbe terrarum ei haud modice debentur vires unitae. Ceteris enim gentibus haec Vestra Societas luce clarius propositum est exemplum, quod ut imitarentur monitae quamvis longo, ut par fuit, intervallo secutae sunt. Earum igitur rerum, quas multas a Vestra Societate impulsi in scientiis viri docti gesserunt, memor eademque ad Vos benigne invitata, gratias Vobis agit sinceras Imperialis Universitas Alexandrea Finlandensis et Regalem Societatem hac insigni die optimis omnibus venerabunde prosequitur. Ex decreto Senatus Universitatis Helsingforsiensis.

\section{ANDERS DONNER, Rector Magnificus. TOR CARPELAN, Secretarius.}

\section{Finnish Society of Sciences, Helsingfors}

To THE Royal Societr.-On the occasion of the 250th anniversary of the Royal Society the Societas Scrextianum Fennica begs to present its sincere congratulations and to express its admiration and profound esteem. The Royal Society was already one of the chief centres of science before the time when the great author of Principia Mathematica became its president. Vast indeed has been the growth of the knowledge which it has witnessed and, through its own work, promoted during these two and a half centuries, from a time when the Mosaic cosmogony held universal sway and the alchemist 
was still striving after the philosopher's stone down to the days of Darwinism, radioactivity, and the application of science in all departments of human life. It has seen the birth of many academies, from the antipodes almost to the polar circle, but ever maintains in their midst its position of leadership. Its publications, beginning with the Proceedings and Philosophical Transactions, and ending with the new International Catalogue of Scientific Literature, still carry out to the full its object: 'to improve Natural Knowledge.' To the many brilliant names which have illuminated its annals, and still do so, new ones will be added in the future; and each time a fresh star flashes into being in this bright constellation-one of the greatest in the firmament of sciencethat admiration will steadily increase which the scientists of the whole world feel towards your Society. We have the firm conviction that it will, during a limitless future, continue its truly royal work. On behalf of the Societas Scientiarum Fennica.

KNUT TALLQVIST, President. ANDERS DONNER, Secretary.

\section{SWEDEN}

\section{UNIVERSITY OF LUND}

Societati Regali pro Scientia Naturali promovenda.-Societati Vestrae, natalem celebraturae CCL annorum, ob egregia in scientiis merita grata memorique admiratione imbuta gratulatur Universitas Carolina Lundensis. Ut in saeculis iam peractis socii Vestri egregii, quales fuerunt Isaacus Newton et Carolus Darwin, summa ingenii sagacitate excellentes naturam rerum indagarunt, haud secus in futura quoque saecula confidenter optamus ut Vestri recipiantur sodales, qui novis ingenii inventis condiciones sublevaturi humanas, nova gloria patriam Vestram inclutam sint affecturi Societatemque Regalem celeberrimam.

Datum Lundae, d. XIV m. Iunii a. MCMXII.

AXEL KOCK, Rector.

\section{University of Stockholm}

To The Royal Societry of London.-With the deepest feelings of veneration and thankfulness the University of SтоскноL takes part in the solemn commemorating of the foundation, a quarter of a millennium ago, of the Royal Society of London. The long and glorious history of this distinguished Society is the history of a great number of the most prominent pathfinders and heroes of science. It is also with the fullest appreciation of the great and important influence exerted by the Royal Society upon 
the development of human knowledge that we beg on this occasion to submit our most respectful and hearty congratulations to the first scientific institution in the land of Newton and Darwin.

Stockholm, July, 191\%。 Sтоскноцм Hogsкola through GERARD DE GEER, Prorector.

\section{UNIVERSTTY OF UPSALA}

Q. B. F. F. Q. S. Universitas Regia Upsaliensis Societati Regai, Londniensi Salutem plurimam dicit.-Vobis perhumaniter invitantibus, ut diem jllum fortunatum vobiscum celebraremus, quo abhinc CCL annos Societas vestra illustrissima rescripto regio constituta est, non mediocri cum gaudio obsecuti e nostro numero legavimus sodalem, qui in coetu vestro ornatissimo grates, gratulationes, vota Universitatis Upsaliensis perferret. Nam quod Societas vestra illustrissima magnum sane ac praeclarum sibi proposuit, ut scientiam promoveret, id Universitates quoque pariter omnes spectant et sequuntur, quamquam illis quidem tot tamque diversa sunt munera sustinenda, ut haud semper tantum quantum optandum est in scientia novis inventis augenda atque amplificanda elaborare valeant. Nihilo tamen minus operae Universitatum atque industriae plurimi in optima quaque arte excolenda debentur progressus; cuius rei Universitas nostra iusta fiducia memor eo vobis libentius ac sincerius ex animi sententia congratulatur, quod Societas vestra illustrissima tam egregie de omni humanitatis artiumque liberalium cultura promerita est quodque tot tantosque viros, in suo quemque genere praestantissimos, sodalium in numero habuit. Accedit, quo magis etiam vobiscun gaudeamus, suavis memoria recordantium, praesidem ipsum illustrissimum Societatis vestrae a nobis olim doctorem honorarium creatum esse, unde maior etiam spes nobis certiorque fides suggeritur, amicitiam illam, quasi dato pignore, permansuram; quae ut in posterum magis magisque firmetur et corroboretur, valde nobis cordi erit. Magna spe tenemur, vos in posterum quoque eadem, qua antea, ac maiore etiam fortuna usos multa alia sollemnia saecularia cumulata gloria acturos. Valete nobisque favete.

Dabamus Upsaliae, mense Maio MCMXII.

Nomine Universitatis Upsaliensis:

HENRIK SCHÜCK.

\section{Royal Swedish Academy of Sciences, Stockholm}

To the Royal Society of London. - It is with great and sincere pleasure that the Royal Swedish Academy of Sciexces has received an invitation from your world-renowned Society to take part in the commemoration festival of the 250th anniversary of the Society's foundation, to be held in London on 
the 16th of July and the two following days; and the Swedish Academy has thought fit to let itself be represented on this great occasion by its VicePresident. Your venerable Society, which in the course of time has united with itself the greatest scientific names in the history of the world, can with legitimate pride look back upon a magnificent work in the service of science and for the benefit of mankind. The Royal Swedish Academy therefore feels impelled to convey their warmest felicitations, and at the same time to express the conviction that your renowned Society will continue henceforth, as in the past, to carry the standard of science high.

Stockholm, 20th June, 1912.

For the Royal Swedish Academy of Science:

H. G. SO̊DERBAUM, President.
HJALMAR THEEL, v. Secretary.

SWITZERLAND

\section{University of Berne}

Universtatis.Litterarum Bernensis Rector et Senatus Societatis Regiae Londiniensis Praesidi Concilio Sodalibus S. D. P.-Postquam Societas Regia illustrissima abhinc annos CCL Regis Caroli Secundi regio rescripto constituta inter tot societates academias universitates vetustissimas et illustrissimas nostram quoque Almam Matrem in partem diei natalis ducentesimi quinquagesimi celebrandi vocavit, libenti gratoque animo collegam nostrum Theophilum Studer, Medicinae et Philosophize doctorem, Zoologiae et Anatomiae comparatae professorem publicum ordinarium, allegavimus, qui vobis gratias ageret quam maximas gratulationisque nostrae interpres esset disertissimus. Nostro igitur nomine gratuletur vobis ex animi sententia, quod Societatis vestrae sodales inde a primis annis superstitione vulgari impugnata mentis ingenii oculorum testimonio invocato praeter ceteros illorum temporum viros doctos victoriam triumphumque communis qui dicitur sensus effecerunt atque caligine, quae hominum ingeniis offusa erat, discussa totius generis humani cultui atque saluti fortiter et strenue inserviverunt. Non est quod singula omnium sodalium Societatis vestrae merita enumeremus, qui inde ab Isaac Newton usque ad Carolum Darwin in sua quisque scientiae naturalis disciplina principes fuerunt, sed nostro nobis iure liceat his diebus festis civis nostri primarii Albrechti de Haller theatri anatomici Gottingensis praesidis et rectoris, urbis Bernensis luminis et principis, memoriam renovare, qui anno MDCCXLIII a Georgio II Rege Britanniae, cuius tum medicus aulicus erat, ordini vestro adscriptus vita doctrina scriptis illo honore dignissimum se praebuit. Et quum his proximis annis Hugonem Kronecker, qui nunc instituto physiologico Bernensi, quod Hallerianum vocatur, cum 
diligentia et doctrina praeest, dignum iudicaveritis qui sodalis vester extraneus sit, itaque Alma Mater Bernensis a longissimis temporibus artiore quodam vinculo cum Societate Regia Londiniensi sit coniuncta, hodie pia vota nostra cum vestris coniungimus, ut vivat crescat floreat Societas Regia in aetema tempora. Valete nobisque favete.

Dabamus Bernae, mense Iulio anno MCMXII.

Litterarum Universitatis Bernensis h. t. Rector Magnificus:

CAROLUS MARTI,

Theologiae Doctor, Theologiae Linguarum Litterarumque Semiticarum prof. publ. ord.

\section{UNiversity of Geneva}

L'Universite de Genève à The Royal society of London for Promoting Natural Knowiedge. - Le Recteur et le Sénat de l'Université de Genève envoient leurs salutations au Président et aux membres de la Royal Society of London et leur expriment leurs plus vives félicitations à l'occasion du glorieux anniversaire célébré les 16, 17 et 18 Juillet. Nombreux sont les rapports qui se sont établis depuis l'époque de la Réformation entre les hommes de science de la Grande Bretagne et de la Cité genevoise. Dans une adresse remarquable, précieuse entre beaucoup, envoyée en 1909 à l'Université de Genève, à l'occasion du jubilé commémoratif de sa fondation, votre Président rappelait les noms de nos maitres qui ont figuré sur la liste d'honneur de la Royal society. Les solennités du $250^{\circ}$ anniversaire de la fondation de votre Société nous rappellent deux noms de savants anglais qui nous sont chers: celui de Robert Boyle, dont les grandes découvertes sont précisément de l'époque où votre illustre Compagnie s'est constituée, et qui, peu de temps auparavant, passait comme jeune étudiant deux années à Genève; celui de Sir Humphry Davy qui, ảprès avoir séjourné plus d'une fois dans notre ville, y décédait en 1829 et auquel notre petite République, toujours jalouse des prérogatives de la haute culture, fit des funérailles officielles. Ce souvenir s'est perpétué chez nous sous la forme d'un prix universitaire qui porte le nom de Davy : récemment encore, la vie de ce savant illustre était donnée en exemple à nos étudiants dans une de nos fêtes académiques. Il nous a paru utile d'évoquer ainsi le passé pour mieux exprimer le caractère des liens qui unissent notre Université à votre savante Confrérie. Que la Royal Society continue à briller au premier rang des sociétés scientifiques! C'est le vou très sincère que forment le Recteur et le Sénat de l'Université de Genève.

Genève, Juillet 1912.

Le Recteur,

Dr. A. MAYOR. 


\section{University of Lausanne}

L'Université de Lat'sanke a la Soctété royale britannique.-Monsieur le Président et Messieurs,-Les circonstances ne nous ont pas permis de répondre à votre appel et de vous envoyer un délégué. Mais nous tenons à vous dire qu'en ces jours de fête nous prenons part à votre joie et que, en vous présentant nos félicitations pour votre glorieux passé, nous faisons des voux pour votre avenir. Créée par le libre effort de quelques hommes avides de pénétrer les secrets de la Science, la Société Royale a reçu, voici deux cent cinquante ans, sa première charte du roi d'Angleterre Charles II. Tôt après, elle attirait, par ses lettres et ses publications, l'attention de tous les savants et philosophes du continent. Elle n'a, dans la suite, plus cessé de croitre: réunissant des matériaux scientifiques, enrichissant sans relâche son admirable bibliothèque, donnant le désir et le pouvoir de vivre à d'autres sociétés, ses sœurs cadettes du Royaume Uni, groupant, à chaque génération, des hommes toujours nouveaux, chercheurs modestes ou initiateurs illustres, qui prirent part à ses travaux ou, tel le grand Newton, présidèrent ses séances. Aujourd'hui la Société Royale est plus puissante, plus active que jamais; elle rend des services à l'humanité entière; il n'est personne, dans le monde de la culture, qui ne connaisse et respecte son nom. Nous nous joignons à ceux qui l'admirent et, avec tant d'autres, nous fui exprimons notre reconnaissance.

Lausanne, le 8 juillet 1912.

\section{Au nom de lUniversité: \\ Le Recteur,}

\section{E. ROSSIER.}

\section{Helvetic Society of Natural Sciences, Geneva}

\section{La Sociéte Helvétique des Sciences Naturelies a The Royal Society of} London for Promoting Natural. Knowledge.-La Société Helvétique des Sciences Naturelles a tenu à honneur de s'associer au juste tribut d'hommages qui seront rendus par les savants du monde entier à la Royal society, à l'occasion du $250^{\circ}$ anniversaire de sa fondation. Elle lui apporte ses voux et souhaits les plus sincères pour l'avenir en même temps que l'expression de sa vive admiration pour le passé. La Royal Society a droit à la profonde reconnaissance de tous en raison des services incomparables rendus à la science et à l'humanité par les hommes illustres qu'elle a comptés au nombre de ses membres. Leur oeuvre admirable embrasse toutes les branches du savoir humain et a rayonné au loin comme un phare étincelant au milieu de l'Océan des Sciences. Les naturalistes suisses saisissent cette occasion pour rappeler le rôle considérable joué par la science anglaise dans l'étude de la grande 
nature alpestre, rôle symbolisé récemment par l'érection du monument elevé dans le site grandiose de Belalp à la mémoire de l'ullustre Tyndall et placé sous l'égide de la Société Helvétique des Sciences naturelles et du Club alpin suisse. Honneur soit aux savants dont les travaux portent actuellement au loin la renommée de la Science anglaise! Honneur soit à la Royal Society qui n'a cessé de représenter avec éclat la haute culture scientifique dans ce qu'elle a de plus profond et de plus brillant.

Genève, Juillet 1912.

Pour le Comité Central de la Société Helvétique des Sciences Naturelles:

$\begin{array}{ccc}\text { Le Président, } & \text { Le Vice-Président, } & \text { Le Secrétaire, } \\ \text { ED. SARASIN. } & \text { R. CHODAT. } & \text { PH. A. GUYE. }\end{array}$

Federal Technical High School, Zurich

A la Sociéte Royale de Londres, à l'occasion de son deux cent cinquantik̀me anniversaike, l'École Polytechnique Fédérale apporte ses félicitaTIONS ET SES HоMмAGEs. - Cet anniversaire attire les regards du monde savant tout entier vers votre Société, si vénérable par son glorieux passé, si jeune par son inlassable activité. Vos fondateurs ont été bien inspirés, et doués en quelque sorte d'une vue prophétique, quand ils assignèrent comme but à votre Société l'exploration expérimentale de la Nature. Les deux cent cinquante ans écoulés depuis lors furent d'une fécondité incomparablement plus grande que les siècles qui les ont précédés. Des relations nouvelles ont été découvertes, la chaleur et la mécanique, l'optique et l'électricité se sont réunies dans des sciences plus larges et le philosophe, de plus en plus, entre en possession d'une vue d'ensemble des phénomènes naturels. Mais plus apparentes encore sont les transformations opérées dans les conditions de la vie matérielle. Par une série de brillantes découvertes l'homme a décuplé ses moyens d'action, sa richesse; la durée de la vie elle-même a été prolongée. Dans cette ouvre, Messieurs, votre part a été grande. L'histoire de la Société Royale est l'histoire d'une notable fraction de la pensée humaine. Vos annales sont pleines de noms glorieux, que nous ne pouvons tous énumérer. Quelques-uns, très grands, sont dans toutes les mémoires et appartiennent à tous: Newton, Faraday, Darwin, Maxwell, Joule, Kelvin. D'autres, présents parmi vous et très grands aussi, continuent la lignée de ces illustres devanciers. La Suisse que rapproche de votre pays la parenté des institutions et un égal amour de la liberté a, elle aussi, compris de bonne heure ce que peut la Science pour la culture des esprits et la grandeur des nations. Pénétrée des pensées qui animent votre Société, elle doit à l'esprit expérimental le développement de son industrie et son rôle initiateur dans les œuvres d'éducation. Les fêtes 
auxquelles vous nous avez conviés proclament bien haut la vertu efficace d'une idée qui fut la vôtre et qui nous est chère. Elles prouvent au monde entier qu'une institution, pour prospérer, pour devenir non seulement grande par la Science, mais aussi puissante par son action et bienfaisante par son rayonnement, doit rester en communion intime avec la masse de l'humanité qu'elle éclaire et qu'elle guide dans sa marche vers de lointaines destinées. La Suisse s'associe avec une émotion profonde à des fêtes qui sont celles de la Science tout entière et aux voux que l'humanité pensante forme pour la Société Royale.

Zurich, Juillet 1912.

\author{
Au nom de l'École Polytechnique Fédérale: \\ Le Président du Conseil, \\ Dr. R. GNEHM. \\ Le Recteur, \\ THEODOR VETTER.
}

\title{
JAPAN
}

\section{Imperial University, Tokyo}

Adpress of Congratulation from the Imperial University of Tokyo to THE Royal Soclety of Londos.-(Translation.) The Imperial University of Tokyo is much honoured in being invited by the Royal Society of London to participate in the celebration of the two hundred and fiftieth anniversary of its foundation, and is delighted to join with other Universities and Learned Societies in tendering most hearty congratulations on this memorable occasion. So marvellous has been the progress of Science during the last two and a half centuries, and so illustrious the history of the Royal Society, its foremost promoter, that we cannot, in this short address, refer in adequate terms to any of the individual work of its Fellows, however important that work may be. We can but gratefully recall the fact that the two fundamental laws of Nature-the law of universal attraction and the law of evolution-were both brought to light by the Fellows of the Royal Society, one of whom held the office of President for the long period of twenty-four years and is, probably, the greatest man of science the world has ever produced. We would rather signalize the profound influence which the Royal Society has had upon man's thought. By steadfastly pursuing the great and noble object with which it was founded, the Royal Society has not only enlarged the bounds of man's knowledge and increased his power and happiness to an extent almost beyond words, but has also, especially during the last half-century, broken down inherited prejudices and traditional opinions, established freer and more direct methods of reasoning, and altogether raised the standard and widened the sphere of man's thought. And, immense as are the material benefits which Science has conferred upon mankind, this greater intellectual freedom 
and this wider range of thought, which have chiefly followed from the work of the Royal Society, are certainly not of less price. Moreover, when we remember that the bringing in of this liberal mental attitude has been of immense service in remodelling the civilization of Japan within the last fifty years, we feel that no words can adequately express our deep sense of gratitude. If, on this occasion of world-wide significance, we are allowed to refer to another matter, which still more directly concerns the Imperial University of Tokyo, we would gratefully record the valuable assistance rendered to us in past days by several, who have since become Fellows of the Royal Society, in fostering the spirit of scientific investigation in this country. We must not omit to express our grateful thanks also for the active part taken by the Royal Society in initiating and organizing the International Catalogue of Scientific Literature and the International Association of Academies. Such international organizations are not only of great importance for the primary objects with which they have been established, but will also be a powerful means of promoting the brotherhood of mankind. In conclusion, the Imperial University of Tokyo tenders its most hearty good wishes for the prosperity of the Royal Society and hopes that in the future, as in the past, it may lead the world in "The Promotion of Natural Knowledge'. On behalf of the Imperial University of Tokyo.

BARON ARATA HAMAO, President.

The fifteenth of June, one thousand nine hundred and twelze.

\section{Imperial University, Kyoto}

To the Royal Society of London for Improving Natural Knowleider, Greetings from the Imperial University of Kхото.-The progress of the world is due to the development of science and art. Especially has the advancement of the physical sciences been a predominant factor in producing the increased welfare of humanity. The philosophy, the literature, and the Arts of every age are the flowers of its endeavour; but it is always the advancement of the physical sciences that increases our knowledge of nature and points the way to its exploitation, thus substantially promoting the wellbeing of mankind. Great Britain has produced many scholars remarkable in different spheres of human learning; but those who are distinguished in the physical sciences are especially numerous. This is due in part to the innate character of the English people who particularly love positive and practical knowledge; yet more especially is it due to those varied means for promoting and encouraging scientific research in which Great Britain abounds. The Royal Society of London for Improving Natural Knowledge was established with the approval of Charles II, and incorporated in sixteen hundred 
and sixty-two. It is the oldest scientific association in Great Britain, and one of the oldest in the world. Among its fellows are included those of the greatest scientific eminence in Great Britain; and by their indefatigable activity in the realm of natural science and by their keen counsel, the Society has wonderfully fulfilled its purpose. The institution, by the Society, of the annual grants for the promotion of scientific research, and of awards of various medals to those making important discoveries, has been of great service to the progress of knowledge in physical sciences. The publications of the Society are among the most useful agencies for encouraging and disseminating scientific information throughout the world; and by them Japan has been greatly benefited. The Imperial University of Kyoto appreciates highly the Society's cordial invitation to participate in the celebration of its two hundred and fiftieth anniversary, and herewith commissions her representative to attend the ceremony, paying honour to the Society's glorious past and praying for its still more glorious future.

July 16, 191\%.

\section{UNITED STATES OF AMERICA}

\section{Clark University, Worcester}

Praesidi et Socis Societatis Regiae apud Londinenses Universitas Clarkiana Salutem!-Viri doctissimi, maguo cum gaudio accepimus litteras humanissimas, quibus nos ad celebrandum festum diem quo ante hos CCL annos Societas vestra diplomate regis constituta est, invitastis ac libentes merito nobis videmur vestrae laetitiae participes esse. Itaque legatum nostrarumque gratulationum interpretem creamus et ad vos mittimus virum insignem, magistrum exploratoremque rerum naturae, Arthurum Gondon Werster, Ph.D., Sc.D., LL.D., physicorum professorem in Universitate Clarkiana. Non ignoramus longissimam seriem inclutorum virorum qui Societatem Regiam ornaverunt et ornant; inter alios Newton, Davy, Faraday, Young, Hooker, Huxley, Stokes, Kelvin, Lister, Rayleigh, Geikie. Neque enim de sola patria Britannica, sed de genere humano Societas vestra propter naturam explorandam merita est. Iure consanguineo gratulamur vobis, quod, si liceat parvum magno conferre, haec Universitas nostra instar Societatis vestrae ad promovendam scientiam rerum experientia condita est.

Datum in urbe Vigornia apud Massachusettenses, die XXIV mensis Maii $M C M X I I$.

G. STANLEY HALL, Praeses. 


\section{Columbia University, New York}

Curatores Universitatis Columbiae in Urbe Novo Eboraco Praesidi Concilio Sodalibus Societaitis Regalis S. P. D.-Perquam nobis acceptum exoptatumque accidit quod nos eorum sollemnium testes participesque esse voluistis quibus diem natalem Societatis vestrae per annos iam ducentos quinquaginta in scientia naturali promovenda florentis propediem celebraturi essetis. Neque enim fieri poterat quin series illa mirabilis rerum inventarum per quas toti generi humano non solum via et ratio naturam complectendi sed etiam vitae condicio cotidianae tantum in melius mutata esset, nos quoque penitus commoveret. Nam si primam memoriam ordinis vestri repetere libet et recordari quam longe aliter de specie et ratione naturae illo atque hoc tempore vulgo senserint, difficile est eis satis digne gratias agere qui ingeniis studiisque effecerunt ut hodie et qualia sint foedera naturae tanto subtilius intellegamus et qualis necessitudo inter hominem ipsum et universam naturam intercedat tanto liberius iudicemus. Longum est nec vero hoc loco necesse-eminent enim omnibusque qui sapiunt in ore sunt-eos recensere paene innumerabiles qui vestrae Societatis sodales se in caecas veri latebras insinuaverunt atque inde victores quid fieri posset, quid nequiret rettulerunt. Duo autem, Carolus Iyell et Carolus Darwin, summo ingenio praestantes, nullius, ut vobis moris est, addicti iurare in verba magistri, rerum cognoscere causas tam feliciter potuerunt ut si quis reperta eorum praetermittere velit, nullo iam modo neque de hoc orbe terrae neque de vi et natura animantium neque de ipsa omnium hominum consortione quicquam recte cogitare queat. Hi et tot alii ex ordine vestro illustrissimo vitam humanam per inventas artes excoluerunt omnesque sui memores iure fecerunt merendo. Namque eos, ut ait Lucretius divinus ille poeta,

$$
\begin{aligned}
& \text { usus et impigrae simul experientia mentis } \\
& \text { paulatim docuit pedetemptim progredientis: } \\
& \text { sic unum quicquid paulatim protrahit aetas } \\
& \text { in medium ratioque in luminis erigit oras. }
\end{aligned}
$$

Itaque libenter vobis morigerantes, Nicolaum MUrray Butler, Universitatis nostrae praesidem, virum et multiplici ingenio praeditum et, ut verbis Evelyn vestri utamur, omnia explorare meliora retinere solitum, ad vos legavimus per quem velut praesentes et vobis partam gloriam gratularemur et ut peractis paria essent futura saecula exoptaremus. Valete.

Dabanus Novi Eboraci, Idibus Iuniis anno Salutis MDCCCCXII.

GEORGE L. TIVES, Curatorum Magister.

JOHN B. PINE, A Secretis. 


\section{Cornell University, Ithaca, N. Y.}

Universitas Cornelliana Societatis Regalis Londiniensis Prafsidi Concilio Sodalibusque Salutem Plurimam Dicit.-Vobis, viri doctissimi, ex animo gratulamur quod Societas vestra annos ducentos quinquaginta peregit laboribus abundantes qui famam vestram gloriamque ad ultimas oras pertulerint. Summa quidem voluptate cum ceteris universitatibus orbis totius terrarum matris societatum omnium quae ad scientiam naturalem potissimum spectant promovendam diem natalem reverentes concelebramus. Consilia eorum qui die illo memorabili abhinc tot annos fundamenta vestra iecerunt vos summa cum laude exsecuti estis atque indagationis rationes veras legesque inter omnes gentes splendidissime promovistis. Nos Americani vobiscum non lingua solum communi sed etiam eisdem sententiis animisque coniunctissimi quodam modo sentimus viros illustres illos innumerabiles qui annales vestros nominibus illustraverint quosque vos incitatos coronaveritis nobis quoque ipsis esse honori gloriaeque. Quod vos et illi tempore praeterito exemplum tam insigne ceteris ad imitandum proposuistis nos quidem gratiam habemus merito infinitam. Quod ad posteros pertinet speramus, quin etiam confidimus Societatem vestram annis cedentibus saeculisque beneficia generi toti humano benignius etiam atque copiosius esse diffusuram. Cuius Societatis in honorem Johannem Henricum Comstock entomologiae in Universitate nostra professorem mittebamus qui illis diebus felicibus faustisque mensis Iulii proximi nostro ipsorum nomine interesset gaudii vestri particeps votorum nostrorum interpres atque voluntatis amicissimae.

\section{J. G. SCHURMAN, Praeses.}

\section{VIII K. Apr. A.D. MDCCCCXII, Ithaca ex Civitate Noveboracensi.}

\section{Harvard University}

Uxiversitas Harvardiana Regiae Societati S. P. D. - Societati vestrae vetustissimae, $O$ viri clarissimi et illustrissimi, propter res in scientia promovenda gestas, propter sodales, propter nummos viris excellentibus donatos, propter illas Transactiones Philosophicas laude summa atque gloria ornatae, nostra Universitas his laetis diebus honore potius recepto quam conlato gratulationes facit maximas. De expeditionibus vero terra marique susceptis, de investigationibus, excogitationibus, inventionibusque ex quibus Sodales Regiae Societatis gloriam immortalem consecuti sunt atque de omnibus rebus, ne plura dicamus, quae hac Societate fovente naturalem scientiam auxerunt, vobis gratulamur. Propter studium autem vestrum atque industriam in rerum naturalium cognitione positam meritissimo ad tam altum dignitatis gradum pervenistis ut beneficia quae omnes cupiunt, pauci adipiscuntur in 
praeclarissimos atque illustrissimos vobis conferre liceat. Nobis igitur eos recordantibus huius Universitatis alumnos quos sodales peregrinos cooptavistis -inter alios illum qui fluminum glacialium est fluxionem mensus et hunc quem nullum sidus umquam fefellit-animum spiritumque adsumimus. Nec de memoria excidere potest ille comes, genere Americanus, civitate Anglus, domicilio diu Germanus, qui apud vos nummum memorialem suum instituit, apud nos artem physicam profitendam pecuniis suis curavit. Quibus vinculis vobiscum coniuncti gaudio laetitiaque, ita ut decet, hoc quidem tempore festo complemur atque precamur ut qua laude per saecula peracta Regia Societas ornata est eadem aut etiam maiore-si tantum sperare licet-per nova saecula in perpetuum fruatur. Valete.

Scribendo adfuit

A. L. LOWELL, Praeses.

Datum Cantabrigiae in Aula L'viversitatis, Kal. Iun. A.D. MDCCCCXII, Coll. Harv. CCLXXVI.

\section{Johns Hopkins Univerity, Baltimore.}

Universitas Hopkinsiensis Societati Regalt pro Sciextia Naturali PromovENDA S. P. D.--Nomen Societatis Regalis et gloriam illorum qui inter Sodales vestros scientiam promoverunt quis doctorum hominum animo non percepit et memoria custodivit? Qua de causa vos comprobamus et vehementer laudamus quod, festo per triduum d. XVI-XVIII mensis Iulii agendo, illos sodales celeberrimos singulari honore decoraturi estis, et voluptate afficimur non mediocri quod nos participes esse voluistis. Ergo incluta Societas vestra quae rescripto Caroli Secundi constituta iam natalem suum ducentesimum et quinquagesimum vidit nos absentes precamur ut semper novetur et augeatur. Atque ut dies festos quos acturi estis eo quo par est honore prosequamur, ex nostro ordine Academico Gulielanm Bullock Chark delegimus professorem illustrem virum Geologiae peritissimum qui praesens vobis gratulandi munus obiret et vobiscum Sodalium vestrorum memoriam debita laetitia et religione celebraret.

Dabamus Baltimorae, Kal. Iun. MCMXII.

IRA REMSEN, Praeses.

\section{University of Michigan}

Societatis Regalis Praesidi, Concilio ex Sodalibus Praeses ex Senatus Universitatis Mrchiganexsium S. P. D.--Pergratae nobis sunt litterae vestrae, viri eruditissimi, in omni scientiarum genere praeclari, quibus nos certiores facitis vos consilium iniisse natalem vestrae Societatis illustrissimae, quinquagesimo lustro feliciter exacto, festis sollemnibus celebrandi, et nos 
liberaliter invitatis ut legemus qui gaudiis vestris caerimoniisque intersit. Adlegavimus Gulielmum Herbert HobBs, professorem in nostra Universitate, qui unus pro cunctis vestrae Societati gratuletur et vestris studiis in scientia promovenda laetos in perpetuum successus exoptet.

HARRY B. HUTCHINS, Praeses.

ARTHUR G. HALI, Sec. Senutus.

Dabamus Annarbore, die III mensis Maii anno MCMXII.

\section{University of Pennsyluania, Philadelphia}

Universitas Pennsyluaniensis Societati Regiae S. P. D.-Litteras vestras quibus nos quoque ad natalem ducentensimum quinquagensimum Societatis Regiae concelebrandum benevole invitastis haud cum parvo gaudio accepimus. Vincula enim perlibenter agnoscimus quibus omnes academiae inter se continentur, nec possumus oblivisci eum quem inter conditores nostrae Universitatis iusto iure nominemus, Beniamin Franklin, Societatis Regiae sodalem fuisse. Itaque, viri doctissimi, voluntati vestrae obsecuti, legato de nostro numero electo imperavimus ut vobis festos dies merito agentibus gratuletur et verbis nostris vobis fausta omnia precetur. Valete.

Datum Philadelphiae, mense Maio, anno Domini milensimo nongentensimo duodecimo.

EDGAR F. SMITH, Praefectus. EDWARD ROBINS, Sigilli custos.

\section{University of Princeton, New. Jersey}

Societatt Regaul Londiniensi per tot annos feliciter exactos lumen scientize praetendenti, numen veritatis pie colenti, immo quasi soli sapientiae in caelo refulgenti, gloriam dei in operibus manuum eius annuntianti, eo ut in fines orbis terrae exierint mortalibus verba vestra, audita audienda oboedienda, nos quoque qui, ut verbis Tullianis utamur, trahimur et ducimur ad cognitionis et scientiae cupiditatem, in qua excellere pulchrum putamus, labi autem errare nescire decipi et malum et turpe ducimus, sodalitati vestrae illustrissimae lustrum quinquagesimum iam iam impleturae, per praesidem ordinis nostri academici Ionnnem Grier Hibben, qui has litteras vobis adferet praesens, fausta felicia fortunata ore more amore exoptamus Praeses Curatores Professores Universitatis Princetoniensis.

Dabamus Princetoniae in Aula Nassovica, Kal. Iun. MCMXII.

C. W. McALPIN, $A b$ actis. 


\section{UnIVERSITY OF Wisconsin}

To the Royal Society of London.-The University of Wiscoxin sends to the Royal Society of London its congratulations on the two hundred and fiftieth Anniversary of its foundation, a memorable event in the history of the oldest and most noted scientific society of the English-speaking people. Its long roll of members contains the names of many men who have initiated great movements in science, and includes others less distinguished by whose wisdom and labour science has become enriched. By the lives and work of these men the Royal Society has contributed in large measure to the great intellectual heritage of England, and through that nation to the enlightenment and freedom of the human race. The University of Wisconsin, while gratefully recognizing with all the world of learning this unique service, has the confident belief that the Royal Society during the centuries to come will continue its illustrious history.

CHARLES R. VAN HISE, President.

\section{American Academy of Arts and Sciences, Boston}

Academia Artium et Scientiarum Americana Praesidi Coxcilio Sodalibusque Societatis Regalis pro Scientia Naturali Promovenda.-Omnium orbis terrarum societatum eruditarum quae lingua Anglica utuntur matri, filia, jpsa aetatis non spernendae, Academia Artium et Scientiarum Americana, hoc die natali eius ducentesimo quinquagesimo plurimam dicit salutem atque alterum sperat totidem annorum saeculum non minorem gloriam ei quam primum attulerit, cum maiorem non possit, esse allaturum. Legatum ad vos, viri doctissimi et clarissimi, mittit haec Academia scribam suum ab epistolis, Edvinum Herbertu m Hall, Universitatis Harvardianae Philosophiae Naturalis Professorem, qui ipse gratulationes Academiae ferat atque vobiscum Societatem vestram fundatam concelebret. Valete.

Datum Bostoniae, die XXVI mensis Iunii MCMXII, in nomine Academiae Americanae.

JOHN TROWBRIDGE, Praeses.

\section{Connecticut Academy of Sciences and Arts}

Praeses ex Socil Academiae Scientianum ext Artium Connecticutensis Praesidi Concilio Sodalibus Societatis Regalis S. P. D. - Iucundum profecto et honorificum nobis accidit quod participes esse possumus laetitiae vestrae et interesse sacris saecularibus quibus natalem vestrum celebrandum constituistis. Animi igitur sensus qui nostro nomine coram testetur legatum 
ad vos misimus Ernestum Guliflmum Brown vestrae Societatis nostraeque Academiae sodalem et in Universitate Yalensi professorem. Valete nobisque favete.

Dabamus Novo Portu in Re Publica Connecticutensi, Id. Apr. A.D. MDCCCCXII.

SIMEON E. BALDWIN, Praeses.

Amenican Philosophical Society, Philadelphia

Societas Philosophica Americana S. P. D. Sochetati Regiae.-Vobis, viri illustrissimi, nos ex animo gratulari liceat, quod Societas vestra, non vetus tantum et antiqua, sed summo etiam in honore per totum orbem terrarum merito habita, natalem ducentensimum quinquagensimum optimis hoc anno celebratura est auspiciis. Et est cur id libentiore etiam faciamus animo. Namque ommes ubique societates, quae ad scientiam promovendam sunt constitutae, communi artium et scientiarum studio sunt consociatae; Societas autem Regia cum principalem inter omnes tenet locum, tum artioribus cum nostra vinculis est coniuncta. Conditor enim noster, Beniamin Franklin, ipse Societatis Regiae sodalis, cum in Terra Nova sodalitatem instituere vellet, quae scientiam utilem, ut ipsis illius verbis utamur, promoveret, usque ab initio Societatem Regiam oculis proponebat ut exemplum dignissimum quod imitaretur. Ubi vero anno millensimo septingentensimo quadragensimo tertio ex sodalitate ab illo condita, cui Iunto nomen dedit, provenit Societas Philosophica Americana, Societatis vestrae propositum atque rationem voluit et imitari et, quoad tamen potuit, aemulari. Quae affinitatis vincula semper artiora fiunt fiantque. Quibus de causis quasi fratres natu minores fratribus nostris eisdem pro studiis trans Oceanum laborantibus gratulationes votaque mittimus, et spem fovemus certissimam fore ut Societas Regia sempiterna floreat gloria. Valete.

Datum Philadelphiae, ante diem quintum Kalendas Iulias, anno Domini millensimo nongentensimo duodecimo.

WILLIAM W. KEEN, Praeses. I. MINIS HAYS, Ab epistulis.

\section{Franklin Institute, Philadelphia}

To the President, Officers, and Fellows of The Royal Society of London for the Promotion of Natural Knowledge. - The Frankuin Institute or the State of Pennsyluania for the Promotion of the Mechanic Arts extends to you cordial greetings and sincere congratulations on the happy occasion of the two hundred and fiftieth Anniversary of the Incorporation of your Society. Few charters looking to the progress and welfare of peoples have resulted in greater benefits to civilization than that granted to the Royal Society by King Charles II, and no similar society can boast such a long and unbroken 
chain of illustrious men whose labours have done so much to unravel the secrets of nature and subdue her forces to the uses of man. The Franklin Institute is glad to have this opportunity to acknowledge its deep indebtedness for the inspiration and incentive continuously derived since its founding from the Proceedings and Transactions of the Royal Society and from the many distinguished men who have represented the Society in America.

Philadelphia, U. S. A., July 15, 1912.

COLEMAN SELLERS, Jr., Vice-President.

R. B. OWENS, Secretary.

\section{Carnegie Institution, Washington}

The Trustees and The Investigators of the Carnegie Institurion of WASHINGToN extend greeting and congratulations to the Royal Society of London on the occasion of the celebration of its two hundred and fiftieth Anniversary. With sentiments of admiration and gratitude for the encouragement of investigation and for the contributions to knowledge which have rendered the Royal Society of London illustrious in the annals of science, we of the younger organization for the promotion of research tender this tribute of appreciation to the officers and fellows of the older organization, and wish for them and their successors a long-continued career in the advancement of learning, understanding, and progress throughout the world.

ROBERT S. WOODWARD, President.

\section{National Academy of Sciences, Washington}

The National Academy of Sciences sends its cordial greeting to the Royal Society of London for Improving Natural Knowledge on the occasion of the celebration of the two hundred and fiftieth Anniversary of its foundation. The National Academy of Sciences, having been incorporated as adviser on matters scientific by an act of the Congress of the United States of America, desires, with the congratulations of its members, to express their admiration and indebtedness to the Royal Society of London. Progress has marked its life, and its contributions to science are acknowledged by the world. The Royal Society has a heritage of historic glory which is an inspiration to the learned body which expresses itself in a common language. With felicitations go the earnest hopes of the Members of the Academy for the long life and increasing achievements of the oldest scientific society in Great Britain. The National Academy of Sciences has chosen Dr. Arnold Hague, its Home Secretary, to convey this message to the Royal Society and to unite with representatives of other institutions of learning in celebrating the event. In behalf of the Council and Members of the Academy.

Washington, June 3, $191 \%$.

IRA REMSEN, President. 


\section{Smithsonian Institution, Washington}

The Smithoniax Institution at Washington sends cordial greeting to the Royal Society upon the occasion of the two hundred and fiftieth Anniversary of its foundation. In compliance with the request of the President, the Council, and the Members of the Society, the Secretary of the Smithsonian Institution takes pleasure in designating Arnold Hague, Ph.B., Sc.D., LL.D., M.N.A.S., Geologist of the United States Geological Survey, as the representative of the Smithsonian Institution at the celebration. In offering its congratulations, the Smithsonian Institution calls to mind, with great satisfaction, the circumstance that its founder was for more than forty years a member of the Royal Society. The unparalleled achievements in science, extending over two and a half centuries, which have made the name of the Royal Society known and honoured throughout the world, are an unfailing source of inspiration to the Smithsonian Insfitution in its labours for the increase and diffusion of knowledge among men.

Attest: CHARLES D. WALCOTT, Secretary.

June the fifteenth, One thousand nine hundred and twelve.

\section{United States Coast and Geodetic Survey, Washington}

To the Presidext, Councir, and Fellows of the Royal Society.-The members of the United States Coast and Geodetic Survey, admiring followers of the illustrious men whose names adorn the records of the Royal Society, send greetings and congratulations on the two hundred and fiftieth Anniversary of the founding of the Society, whose activities have been the inspiration of succeeding generations of scientific workers.

Washington, July 191\%.

O. H. TITTMAN, Superintendent.

\section{Washington Academy of Sciences}

The Officers and the Members of the Washington Academy of Scrences extend greetings and congratulations to the Royal Society of London on the occasion of the celebration of its two hundred and fiftieth Anniversary. With the admiration of a disciple, the younger Society for the increase of Knowledge hails the elder Society, now dignified by age and illustrious by achievement, and wishes for it continued prosperity and renown.

FREDERICK V. COVILLE, President. 


\title{
BRITISH DOMINIONS BEYOND THE SEAS
}

\author{
AUSTRALIA \\ University of Sydney, New South Wales
}

Univeritas Sydneiensis Sociftatis Regairs Praesidi Conchlo Sodaitrusque. Salutem.-Gratum admodum nobis, viri doctissimi, fecistis quod nos ad celebrandum vobiscum natalem Societatis vestrae ducentesimum quinquagesimum tam benigne invitastis. Nostra quidem laude parum indiget Societas Regalis, cuius tot praesides et sodales scientiae naturalis, complures iam per aetates, praeclarissima lumina fuerunt; ita ut ea certe fundanda Rex Carolus Secundus, qui nunquam, uti fertur, locutus est insulse, fecerit etiam sapientissime. Voluntati vestrae libenter obsecuti, adlegamus Anderson Stuart, M.D., LL.D., Physiologiae Professorem ac Facultatis Medicinae Decanum, qui feriis vestris intersit, quique ut semper floreat Societas vestra, teneatque semper praecipuum illum inter tales toto orbe terrarum societates locum quem tot per annos fere omnium consensu obtinuit, nostro nomine optet et precetur.

Datum Sydneiae, Nonis Maiis, MCMXII.

H. N. MACLAURIN, Cancellarius.

ROBER' A. DALIEN, $h$. $t$. Registrarius.

\section{Royal Society of Tasmania, Hobart}

The President, Royal Socifjy of London. Sir,-The President, Council, and Members of the Royal Socrety of Tasmania desire, most cordially and sincerely, to offer to the Royal Society of London their heartiest congratulations on the two hundred and fiftieth Anniversary of its foundation. Honoured by the name of the parent Society, and working to promote its objects in Tasmania, we join with other kindred bodies in gratefully recalling the past of the Royal Society of London, rich in names of men who have profoundly influenced the progress of Science, and who for such service have gained world-wide renown. On this Anniversary not the least cause of pride in the great work of the Society must be the thought that its methods and ideals are animating the lives of men in parts of the world entirely unknown to its distinguished founders. We, at this time, also recall the fact that 
it was at the instance of the Royal Society of London that Captain James Cook was sent out by the English Admiralty on that voyage which led to such remarkable results in the history of these Southern Lands, results none the less famous in Science from the labours of Sir Joseph Banks, afterwards your President for over forty years. The Royal Society of London has ever been pre-eminent in promoting the highest ideals of knowledge and truth. It has helped in a unique degree to mould the intellectual life not only of Britain but also of Europe and the whole civilized world. While it is impossible to estimate the enormous influence that has radiated from it during the two and a half centuries of its existence, yet this aspect may be specially noted : there can be no national bond stronger than that of common scientific interest, and in carrying out its more definite objects the Royal Society of London has also been eminently assisting to draw closer the political and social bonds of the Empire. The Royal Society of Tasmania names as its delegate and representative to convey this greeting, Gregory Sprotr, M.D., Member of the Council. Signed on behalf of the Council and Members of the Royal Society of Tasmania.

HARRY BARRON, President.

Hobart, May, 1912.

\section{GAM. H. BU'LLER, Chairman of the Council.}

\section{Royal Society of Victoria, Melbourne}

The President, Council, and Members of the Royal Society of Victoria, a humble but aspiring unit of the body of seekers after knowledge, send hearty greetings to the Royal Society of London, its great mother and prototype, on the completion of the 250th year of its valuable life. The faithful work of many devoted students of nature in the London Society has brought fresh light into countless dark places, and the stimulus given by them, rolling like a wave to the remotest corners of the British Empire, inspires distant workers in the fields of science with energy and hope to new endeavours. The Royal Society of Victoria gratefully acknowledges its debt to these noble men, and ventures to trust that the efforts of its own members to emulate the work of the parent Society may have added some vigour to the growth of the Tree of Knowledge, that by continuing so to do it may be for ever weaving fibres of kinship that shall assimilate its results ever more closely to those of its illustrious progenitor.

By order of the Council:

J. R. HOGG, Fellow of the Royal Society of Victoria, Delegate to the Meetings celebrating the 250th anniversary of the foundation of the Royal Society of London.

July, 1912. 


\section{CANADA}

\section{McGill Univerity, Montreal}

'To the Royal Societr on the occasion of the celebration of the two hundred and fiftieth Anniversary of the beginning of a career in the course of which it has won world-wide fame for the great benefits it has conferred on mankind by the advancement of scientific knowledge and the practical application of that knowledge to the needs of human life $\mathbf{M}^{\mathrm{C}}$ GiLL UNIVERsiTY sends heartiest greetings and best wishes for continued prosperity and usefulness.

\section{STRATHCONA, Chancellor.}

Montreal, Brd June, 1912.

\section{University of Toronto}

Cancellarius eit Senatus Universitatis Torontonensis Praesidi Concilio et Sodalibus Regalis Societatis Londini S.P.D. - Gratulamur vobis, viri illustrissimi, vos annum ducentesimum quinquagesimum a Regali Societate inaugurata feriis saecularibus celebrare. Gratias agimus quod nos, ut feriis vestris per vicarios adsimus, invitastis et, ut gratulationem nostram ad vos ferat, Robertum Alexandrum Fatconer, M.A., LL.D., D.LitT., C.M.G., praesidem nostrum, constituimus et delegavimus. Quod quidem a nobis vos summo iure impetratis. Ii enim qui in hac Universitate cognitioni rerum naturae operam dant-quorum e numero quattuor suñt Sodales Regalis Societatis-exempla, quae vestra Societas praeposuit, sequuntur et imitantur. Nec enim gloria vestra apud Britannos solum viget et apud exteras nationes quae angusto mari a Britannia dividuntur. Multum quoque hoc Septentrionali orbe valetis. Haud immerito. Viris enim paene divinis qui vestra gerunt et semper gesserunt, eum, quo nunc utimur, ordinem rerum et cultum acceptum referre possumus. Illi enim prima clara voce praedicant illa Baconiana: Artes et scientias per experimentationem solum et observationem promoveri : scientiam et potentiam humanam in idem coincidere.

W. R. MEREDITH, Cancellarius.

JAMES BREBNER, Registrarius.

D. ex Aede Academ. Toronton., Id. Iun., MCMXII. 


\section{Nova Scotian Institute of Science, Halifax, N.S.}

Societatis Regalis Praesidi Concilio Sodalibus Societas Scientiarum QUAE IN Nova Scotra Est S. P. D.- Societas pro Scientia Naturali promovenda, quae in Nova Scotia est, partem aliquam habere cupit in gratulationibus, quae nunc ex omnibus regionibus in quibus sedem invenerit Scientia, vobis offeruntur, quod mox natalem ducentensimum quinquagensimum vestrae Societatis celebraturi estis. Splendide quidem Societas Regalis stimulando et propagando assidue continenterque per tot saecula scientiarum studio se praestitit cum primam tum inclutissimam inter societates quae in imperio nostro Scientiam colunt; et iuste, inter multa alia, gloriari potest in societatibus quae eisdem studiis se dederunt, quae permultae ubicunque terrarum homines lingua Anglica utuntur, diffusae sunt; nam huic uni hae omnes originem suam debent. Semper viam monstret Societas Regalis atque in scientia promovenda et propaganda et civitatis necessitatibus adhibenda semper sit princeps.

Datum Halifaxiae, Kalendis Iuliis MCMXII.

W. L. BISHOP, Praeses.

HARRY PIERS, Secretarius.

\section{INDIA}

\section{UNIVERsity OF Bombay}

To the President, Council, and Fellows of the Royal Societr of London, on the occasion of the 250th Anniversary of the Constitution of the Society by Royal Warrant.-THe Universtry of BombaY, in accepting the invitation of the President, Council, and Fellows of the Royal Society of London to send a delegate to the celebration of the two hundred and fiftieth Anniversary of its constitution by King Charles II, desires to convey through its representative, DR. F. G. SELBX, M.A. (Oxon.), LL.D. (Bom.), its cordial felicitation, and to express its sympathetic interest in the historical commemoration of one of the most important events in the history of scientific inquiry in any part of the world. In the University of Bombay, as in every other seat of learning and research, the influence of the Royal Society has been a stimulus to investigation and interpretation in many different fields, and it is with gratitude that the University desires to share in the celebration. The University of Bombay is specially anxious to be identified with the celebration because the Royal Society has during its history taken such a very large interest in the development of inquiry in the 
tropics and specially in India. Several of its leaders, and notably Sir Joseph Banks, President of the Royal Society in the latter part of the eighteenth century, and Sir Joseph Dalton Hooker, one of its most eminent members in the nineteenth century, spent much of their life and strength in investigation into tropical conditions, and were almost the first to draw attention to the important light which such inquiry would shed on general scientific questions. The interest in tropical and Indian questions has not flagged since that time, and the Society has again and again placed its experience at the disposal of the Government of India and private bodies in this country. At the present time it acts as the adviser of the Indian Government on matters connected with scientific inquiry in India, and also as an advisory body on the management of the Observatories in India. It has Committees which are studying tropical diseases which are among our worst scourges. And the Royal Society has always shown itself willing to assist with advice and counsel, any public body which appealed to it. The University of Bombay, therefore, joins in congratulating the Royal Society of London on the present occasion, on the noble part it has played in the advancement of knowledge in the past, and wishes for it a future even more glorious, in which it will appear that the present commemoration represents but the beginning of a new era of adsancement and usefulness.

Bombay, June 20th, 1912.

\section{Univerity of Calcutta}

\section{A Congratulatory address to the Royal Society}

1. Those who daily improve the modern world by new discoveries, who spend their lives in search after truths about the material world, who plunging deep into the ocean of science collect gems, may those sober-minded scientists live for ever for the benefit of this world.

2. Many learned men were born, will be born, and are being born on this earth which was created long ago; but indeed there are few who are really successful and who by diving into the ocean of science have found out hidden gems.

3. The Creator, hoary with age, created the universe with the earth and other elements; but surely he concealed the forces of material objects. A new creator, more powerful than the first, being born discovered the longhidden forces of material objects.

4. In the store-house of the universe created by the aged sage Brahma many precious things were kept hidden; but Newton breaking open the doors of superstition revealed a new method of discovery.

5. May the bright glory of the Royal Society, founded by him, continue to shine through Royal patronage as long as the Sun and the Moon endure. It 
is time for us to celebrate the jubilee, now that it has completed its two hundred and fiftieth year of existence.

6. Electricity, fire, water, and other elements that were ever known as inanimate things caught in the machines (of the Society) toil like ghosts discharging vapour (tears), and constantly propel steam-ships, etc. during the day and night: seeing this wonderful mechanical skill the Creator himself is now surprised.

7. Within London lies the famous tank, called the Royal Society, in whose waters of science on white lotuses plays the Goddess of Learning in her splendour and where the Sun of knowledge never sets but always shines out of joy. To add to the beauty of that tank we send this fresh blooming lotus (Praphullachandra) of our own country.

8. May the garland of this poem composed by Asutosh and presented by him with deep regard be accepted. If the savants living in the garden of science wear it as an ornament, then his labour will be requited.

Calcutta University, May, 1912.

ASUTOSH MOOKERJEE, Vice-Chancellor.

\section{UNIVERSity of Madras}

London, 16 July, 1912. To the President of the Royal Society of London. $\mathrm{Sir}$,-Under instructions from the Vice-Chancellor, I have the honour to convey to the Royal Society of London the congratulations of the University of Madras on the occasion of the two hundred and fiftieth Anniversary of the Society. Like all other academic or learned bodies, the University of Madras most cordially recognizes the great work which the Royal Society has done in extending the bounds of natural knowledge and in maintaining the high traditions which ought to be associated with the pursuit of that knowledge. I have the honour to be, Sir, Your most obedient servant,

A. CRICHTON MITCHELL, Delegate, University of Madras.

\section{Asintic Society of Bengal, Calcutta}

\section{[Translation from the original Sanskrit.]}

The Astatic Society of India offers her respects, regards, and reverence to the august Royal Society of august England, the importer of scientific knowledge.

Be it known:-

How can one describe thy glory, 0 Society? Full two centuries and a half have elapsed since thy foundation at the command of the Sovereign. Asia 
offers her tribute to Europe in the garb of this eulogy of thee. May the wise rejoice at the sight of this union of ours, so beneficial to the world. Vibhvana, Vajja and Rbhu, celebrated in the Rig Veda, these three together rejuvenated their old father and attained to heaven. Still higher and all unrivalled is the region that you have reached by rejuvenating the old world through Science and Art.

Vāyu, Varuṇa, Agni, the Aśvins, Rudras and Vasus, worshipped by the Aryans of old, have been praised in beautiful hymns in the Vedas; through thy constantly employing all of them in devoted service for the good of humanity, thy glory, moving among the regions of the air and the waters, extends over the earth. Having come to congratulate thee, $O$ [Society] of glorious fame and unequalled majesty, I am satisfied with thy various virtues. Mayest thou live long, patronize the learned, and be highly honoured for the good of the world.

\section{Indian Institute of Science}

To the President and Council of the Royal Society of London.-On the occasion of the two hundred and fiftieth Anniversary of the foundation of the Royal Society, the Council and Senate of the Indian Institute of Science send greetings and good wishes.

MORRIS W. TRAVERS, Director.

\section{SOUTH AFRICA}

\section{Royal Society of South Africa}

Societatis Regalis Arricae Meridionalis Praeses Concilium Soci et Sodales Societati Regali S. P. D.-Laetissimis animis litteras vestras accepimus quibus certiores nos fecistis vos in animo habere natalem dien Societatis vestrae antiquissimae et illustrissimae Iulio mense huius anni celebrare. Gratulamur vobis quod nunc quoque sicut maiorum temporibus Societas vestra operam semper dat ut lumen scientiae quam latissime diffundatur. Nos quidem, huius longinquae Imperii Britannici partis incolas, qui, eius luminis non expertes, vestrum exemplum et nomen imitati, Societatem Regalem ipsi nuper condidimus, in primis decet, filiorum ritu, natalem Societatis vestrae diem ducentesimum quinquagesimum vobiscum concelebrare. Quare commendamus vobis legatum nostrum Davidum Girs, equitem illustrissimum et optime de scientia astronomica meritum, qui praesens nostro nomine salutem vobis dicat.

L. PÉringuey, Prases. 


\section{BRITISH ISLES}

\section{ENGLAND AND WALES}

\section{University of Oxford}

Cancellarius Magistri et Scholares Universitatis Oxoniensis Societatis Regalis Praesidi Concilio et Sodalibus S. P. D.-Regalem Societatem ducentesimo iam et quinquagesimo anno diem natalicium celebrantem nos Oxonienses salvere ex animo iubemus. Namque haec ex quo tot abhinc annis est instituta prolatandorum uno tenore scientiae finium dux et auspex exstitit: haec illius sapientiae, cuius res gestas non solum annalium et librorum memoria sed etiam mutata in melius mortalium condicio testatur, arcem et caput ut olim fundavit ita nunc tuetur,

\section{dotans vitam humanam novis inventis et copiis.}

Neque absurdum videtur gratulationem in tali die a nobis potissimum offerri, quippe qui cum inter primos lucem e tenebris elatam a cive et doctore nostro viderimus, nunc ea quae foveatis studia indies intentius et diligentius exerceamus. Quid quod non voluntate solum et animis coniungimur, sed et multi nostrum vestris ordinibus sunt adscripti? adeo, ut quisque in naturali scientia se exercuit, ita plenissimam laborum mercedem consequi visus est si vestrae Societati adscisceretur: id quod multis Oxoniensibus contigit. Itaque quando aliquem a nobis delegatum festis adhibere benignissime vultis, illi ipsi hoc officium mandavimus qui cum nunc conciliis nostris magna cum laude praesideat, testis erit benevolentiae nostrae locupletissimus. Venit igitur ad vos Carolus Bulier Heberden, Artium Magister, Doctor in Iure Civili honoris causa, Collegii Aenei Nasi Principalis, Vice-Cancellarius: qui quid animis sentiamus voce praesens docebit.

Datum Oxoniae in Domo nostra Convocationis, die Decimo Octavo mens. Iunii, A. S. MCMXII.

\section{University of Cambridge}

Universitas Cantabrigiensis Regali Societati Londiniensi S. P. D.Gratulamur vobis omnibus, viri rerum naturae et scientiarum amore nobis coniunctissimi, quod annos ab origine vestra ducentos quinquaginta prospere peractos propediem estis celebraturi. Etenim Idibus illis Iuliis, die vestro natali, scientiarum templum illud aedificari coeptum est, cuins 
imago quaedam, domus Salomonis sub nomine, Baconis nostri in Nova Atlantide olim adumbrata est. Vobis igitur etiam in posterum curae erit (ut eiusdem utamur verbis) ' ex eis quae iam sub oculis sunt, nova experimenta, lucis sublimioris, atque in naturam altius penetrantia, excitare et dirigere'. Societatis vestrae auspicio (quod et vobis laudi et nobis honori fuit) primum in lucem prodierunt alumni nostri Newtoni, postea Praesidis vestri, Philosophiae Naturalis Principia Mathematica, quorum exemplar ipsius manu scriptum inter thesauros vestros in perpetuum conservandum curavistis. Societatis vestrae consiliis, in inceptis magnis scientiarum in provincia promovendis, diu libenter usi sunt ei qui patriae toti administrandae praefuerunt. Societatis denique vestrae auctoritate pecuniae publicae scientiarum finibus proferendis quotannis distributae sunt, et praestantissimo cuique ex scientiarum cultoribus praemia insignia donata. Atqui non praemiorum exspectatione sed veritatis amore ingenuo per tot annos adducti, rerum naturae miracula recondita et penitus abstrusa orbi terrarum identidem patefecistis, philosophi cuiusdam Romani praeceptum illud praeclarum exemplo vestro comprobantes: 'quod, inquis, erit pretium operae? quo nihil maius est, nosse naturam; neque enim quicquam habet in se huius materiae tractatio pulchrius; cum multa habeat futura usui, quam quod hominem magnificentia sui detinet, nec mercede sed miraculo colitur.' Laetamur Societati vestrae tot viros insignes praefuisse, inter quos alumnos nostros complures exstitisse gloriamur. Ergo, congressus vestri saecularis in honorem, Cancellarium nostrum illustrem, Baronem Rayleigh, quondam Praesidem vestrum insignem, legatum ad vos libenter mittimus, qui non modo Universitatis nostrae personam summa cum dignitate sustinebit, sed etiam nostrum omnium in vos benevolentiam optime interpretabitur. Valete.

Datum Cantabrigiae, pridie Idus Martias, A. S. MCMXII ${ }^{\circ}$.

\section{University of LoNdoN}

Societati Regali Universitas Londinensis S. P. D.-Litteras vestras, viri doctissimi atque insignissimi, summo gaudio accepimus, cum natalicia Societatis Regalis CCL annos abhinc fundatae celebraturi nos etiam participes tam faustae occasionis esse velitis. Societati vestrae gratulamur, quae per tot iam saecula scientiae iumen non tantum inter Britannos sed per totum terrarum orbem auget atque diffundit. Vobis enim datur

\section{munita tenere}

edita dortrina sapientum templa serena, despicere unde queas alios, passimque videre errare, atque viam palantes quaerere vitae.

Nos vero, quibus, Universitati illius urbis adscriptis in qua vos sedem excelsam et tanquam arcem habetis, scientiae inter cives nostros docendae atque 
propagandae officium est impositum, vestram praecipue Societatem suspicimus ; nec gloriari pudet nonnullos Universitatis nostrae doctores et alumnos, in numerum sodalium vestrorum adscitos, aliquam et ipsos partem vestris auspicis in scientia promovenda praestitisse. Delegavimus autem ProCancellarium nostrum, Wilmot Palker Herringham, Medicinae Doctorem, qui vobiscum in feriis celebrandis consociatus tot tantorumque memoriae meritorum vota pro futura Societatis Regalis prosperitate coniungat.

Dabamus Londinii, XVmo mensis Iunii, A. S. MCMXII.

ARCHIBALDUS, COMES DE ROSEBERY, Cancellarius.
WILMOT PARKER HERRINGHAM, Pro-Cancellarius.
EDUARDUS HENRICUS BUSK,
Praeses Graduatomu Convocatorum. HENRICUS ALEXANDER MIERS, Praefectus.

\section{'The University of Birmingham}

To the Royal Society from the University of Birmingham.-T'rustee of the loftiest traditions of scientific inquiry, and guardian of natural knowledge through troublous times, -we welcome the opportunity of expressing our admiration for your past, and our confident anticipation of a noble future. The seal of the University of Birmingham was affixed hereto in the presence of the undersigned members of the Council.

CHARLES G. BEALE, Vice-Chancellor. OLIVER LODGE, Principal.

GEO. H. MORLEY, Secretary.

\section{University of Bristol.}

Societati Regali Universitas Bristolliensis S. P. D.-Gratulamur vobis, viri doctissimi, tot lustra feliciter peracta, tot secreta naturae abscondita iam in lucem atque oculorum quotidianum aspectum prolata, tot res salutares in usum commodumque hominum arte miranda inventas. Neque certe Academiae nostrae minimae est laudi quod complures inter professores nostros in praeclarissimam vestram Societatem alii alio tempore adsciti sunt. Nunc autem ipsum Cancellarium nostrum, virum maxime egregium et in rationibus philosophiae vel subtilissimae explicandis imprimis acutissimum, publica legatione mittimus, ut unus pro omnibus hanc nostram communem vocem ad vos deferat. Illius ergo verbis et auspiciis precamur hunc tam faustum natalem vestrum laeto ac frequentissimo coetu celebretis, atque optima illa studia, quibus ad hunc usque diem tam bene floruistis, ita in posterum semper excolatis.

Dabamus ex Universitate Bristolliensi, a. d. IV Kal. Iun. MCMXII. 


\section{University of Durham (Armstrong College)}

Societati Regali Universitatis Dunelmensis Cancellarius et Srantus S. P. D.-Cum nuper nobis nuntiatum sit vos Societatis vestrae per quinquaginta iam lustra prosperrime servatae diem faustum celebraturos esse, de re tam felici vobis ex animi sententia gratulamur. Dicitur festivus ille rex Carolus Secundus omnia si quis alius stulte fecisse: sed falso, quoniam id saltem imprimis sapientis fuit, quod Societati vestrae minora ut videtur initia sumenti adfuit ultro Fundator et Patronus. Quo patrocinio exortum quis est quin sciat quanto splendore quam late tum Britanniae tum ceteris gentibus affulserit saluberrimum Scientiae lumen? Quippe vos regale nomen regaliter factis exornastis exornatis: adeo ut quem ad modum Cineae Romanus sic nobis vester Senatus totus ex regibus constare videatur. Nam contigit vobis re vera, Baconio quod erat in votis, ut naturae regno potiti fines vestros in dies latius proferatis. At praesidum sociorumque vestrorum tot tantaque Scientiarum in rem publicam merita vix quisquam oratione complectatur: longum est scilicet vel nomina summatim percurrere. Quae tamen ne omnino hoc praesertim tempore praetermittamus, ubi, ubi, inquimus, terrarum ignotus est Newtonius vester-

\section{clarum et venerabile nomen-}

Archimedes alter, immo ipso Archimede praestantior? Legentem quem non delectat Pepysii perurbana garrulitas? aut Boyleii singulare ingenium? aut Evelynus Dryadum idemque Musarum cultor? Cui non cordi est secum recolere vel Wrenum basilicarum altitudines molientem vel Harveium 'de motu cordis et sanguinis' disserentem vel operis metallariis consulentem Daveium? Quid? recentioris Scientiae qui signa ducebat Darwino num quis hodie iustam laudem denegabit? Nempe iam nemo ne Episcopus quidem reformidat ne horribili quodam casu inter simios numeretur. Recentissimos autem si quis respiciat, quanto opere desideratur e physicis Kelvinus, e medicis Listerius, quorum alter navigantibus, medentibus alter multo plus praestitit securitatis! Hos viros insignissimos et alios horum similes recordantibus fieri non potest quin Maronis illud nobis succurrat,

\section{felix qui potuit rerum cognoscere causas,}

ita tamen succurrat ut felices illos quoque velimus qui cognitione sua alienis commodis inserviendum putarint. Hodie vero feriantibus vobis utinam priscus ille praeses Brounckerius adesset! Salutaret profecto suae laudis vicarium: salutaret socios tam fama quam numero pollentes: perlustraret oculis astronomicos, medicos, physicos, mathematicos, mechanicos, chymicos, alios complures,

$$
\text { nullius addictos iurare in verba magistri, }
$$

sed omnes suam quemque operam navantes, ut Philosophiam Naturalem longius promoverent. Quae cum ita sint, animis libentissimis adlegavimus 
Georgum Hare Philipson, Vice-Cancellarium nostrum, medicum inlustrem inter equites adscitum, qui nostram erga vos amicitiam praesens testetur. Sunt sane multa nobis vobiscum necessitudinis vincula, quorum nunc liceat si non plura at unum vel potius unicum illud referre, quod viget apud nos, et diu vigeat, Gulielmus Greenwell, socius vester, noster alumnus, archaeologorum Nestor indefessus, qui pariter iam omnes, nisi fallimur, et vestros socios et nostros alumnos aetate superavit. Proinde, doctorum doctissimi, scitote nos vestris in gaudiis gaudere et impense simul precari ut nominis vestri vetus amplitudo novis atque anplioribus etiam per saecula praemiis augeatur.

G. W. KITCHIN, D.D., Cancellarius et Decanus.

Datum Dunelmi, Kal. Iul., A.S. MDCCCCXII.

\section{University of Leeds}

To the President, Counch, and Fellows of the Royai Society.-The UNiversity of LEeDs begs respectfully to congratulate you on the Anniversary which you are about to celebrate. For two hundred and fifty years your Society has filled a unique place in our national life. No institution has ever been animated by a greater love of truth or by a deeper reverence for unfettered freedom of thought. The experimental methods followed by the Royal Society have proved themselves to be true methods of advance; and to-day mankind is its debtor for the enlightenment and the welfare which attend vast additions to natural knowledge. The scientific achievements of your Society are universally acknowledged both at home and abroad. A point less generally observed is its indirect influence in all parts of the British realms. Happily inclusion in the Royal Society does not withdraw and isolate men who have found a career among the growing populations of our time. No thoughtful dweller in our own city can help feeling that Leeds would have lost greatly had Joseph Priestley never lived and worked here. In large industrial centres men like Priestley are the best of educators. They are true 'merchants of light', if we may borrow a phrase from that New Allantis which foreshadows so closely, in some important respects, the purposes of your own foundation. And since Priestley's day there have never been wanting among the citizens of Leeds other members of your body who have not merely advanced natural science by special research but have spared no effort to encourage learning in all its many branches. Not the least active among the founders of our University have been Fellows of the Royal Society who have not allowed the claims of particular investigations to blind them to the wide range and essential unity of human knowledge.

ARTHUR G. LUPTON, Vice-Chancellor.

July, 1919.

MICHAEI, E. SADLER, Pro-Chancellor. 


\section{University of Manchester}

Praesidi Consilio Sodalibus Societatis Regalis pro Naturatil Scifatia Promovenda annum CCL feliciter celebrantibus S. P. D. Universitas MancuNIENsIS.-Si iure ille aestimandus est

$$
\text { felix, qui potuit rerum cognoscere causas, }
$$

ut confiteri non sine dubio aliquo videtur Vergilius, nulla certe hominum Societas quae usquam gentium ad hune diem exstiterit maiorem huius gloriac ac felicitatis sibi partem vindicavit quam Regalis vestra ablyinc iam CCL annos instituta. Sive enim ad fundatorum eius aetatem spectamus ubi de Expansione Aerea primas leges celeberrimus ille Boylius invenit sive ad viri omnium clarissimi Neutonii ipsius reperta, per quae

\section{caelum ac terras camposque liquentes lucentemque globum lunae Titaniaque astra}

iam tandem Motus Legibus certo fundamento positis subiecit; sive ad eos qui Neutonium insecuti sunt, Ioulium qui primus Caloris atque Energeiae coniunctam rationem exhibuit, vel Daltonium qui primus Atomorum pondera certum in ordinem reduxit, ille artis Mechanicae hic Chemicae hodiernae paene fundator; hos omnes Societas Regalis inspiravit instinxit adiuvit. Quid? cum ad ingens illud tum fidei Christianae tum artis apud nostrates architectonicae monumentum Sancti Pauli quam vocant Cathedralem suspicimus, nonne recordari libet illam a nobili vestro mathematico Christophero Wren subtilissima in physicis scientia inchoatam exstructamque? Cum vero ad recentiorum victorias convertimur, quid dicamus de Daruinii illius maximi Wallaciique doctrina unde

\section{genus omne animantum \\ et.quae marmoreo fert monstra sub aequore pontus}

in suam quodque originem luculenter tractum est? Sin vero ad artes iam plurimas quibus vita hominum tutior vel dulcior facta est, ut de Medicorum vestrorum repertis omnino taceamus, quis hos per menses Humphreii Davy oblivisci potest, qui in subterraneis metallis carbonem quaerentibus

lumen de suo lumine accendit,

aut Perkinii, qui ex materia eadem nigerrima pulcherrimos veris colores in solis lucem revocavit, oculos hominum complens ac reficiens purissima naturae voluptate? Per haec atque talia, doctissime Praeses, Sodales alumnique vestri veritatis amorem nostrorum saeculorum ingeniis alte insitum stimulantes ipsi atque implentes, hunc ipsum terrarum orbem, illum innumeris orbibus splendentem mundum cum in regnum non caecae fortunae sed rationis certae adseruerint, non solum hominibus aptius domicilium sed etiam, si cum poetis reverenter loqui licet, vestem Auctore omnium ipso longe quam unquam antea cognitum est digniorem esse demonstraverunt. Vobis 
igitur festa haec natalicia celebrantibus ex animo nos gratulamur, quibus inter iuniores Britanniae Universitates antiquissimus conceditur locus; simul a vobis comiter rogati Principem nostrum dilectum, equitem inlustrem, Aluredum Hopkinson, delegavimus laetitiam nostram vobis praesentem praesentibus testaturum.

ALFRED HOPKINSON, Praeses.
EDWARD FIDDES, Registrarius.

R. S. CONWAY, Humanitatis Professor.

\section{University of Shenfield}

Universitas Sheffieldiensis Societati Regali pro Scientia Naturali Promovenda S. P. D.-Annum vobis ducentesimum et quinquagesimum implentibus cursus felicissimi et eis prope aequalis artibus quas uno nomine scientiae hodie complectimur, vehementer et vere gratulamur, et eadem qua ceteri omnes nos laude prosequimur. Optime enim de sapientibus estis meriti, res plurimae et utilissimae vobis auctoribus et ducibus sunt inventae, annalibus vestris memoria illius quo ad Naturae notitiam pervenimus itineris magna ex parte continetur. Oramus igitur atque obsecramus ut eventu in dies prosperiore en vobis per multos annos agere liceat per quae sapientissimus quisque maximos faciat progressus et omnes qui in toto orbe terrarum his studiis favent artiore vinculo necessitudinis inter se coniungantur.

Sheffieldi dabamus, mense Iunio, MCMXII.

W. M. HICKS, Praeses Senatus.

\section{UNIVERSTTY OF WALES}

Universitas Cambrensis Societati Regali pro Scientia Naturalix Promovenda S. P. D.-Ferias celebraturis ob annos ducentos quinquaginta feliciter exactos vobis ex animo gratulamur. Pergratum erit vobis per tot annorum spatium respicere et in memoriam reducere nomina eorum qui Scientiae Naturalis promovendae studio incensi tot arcana Naturae enucleaverint atque operam ad mentes hominum exacuendas et vitam artibus excolendam navaverint. 'Alii laboraverunt et nos in labores eorum introivimus.' Delegavimus Vice-Cancellarium nostrum, Henricum Rudolph Reicher, Equitem, M.A., LL.D., qui sollemnibus vestris intersit et omnia vobis bona fausta felicia precetur.

Dabamus pridie Non. Iul. MCMXII.

KENYON, Pro-Cancellarius.

J. MORTIMER ANGUS, Registrarius. 


\section{Royal College of Physicians}

Socherati Regai Collegium Regale Medicondm Londinense S. P. D.-Ad sollennia vestra, viri doctissimi, per literas vestras gratissimas nuper vocati, misimus nos Praesidem nostrum, Thomam Banlow, Baronettum, Ordinis Regii Victoriae Equitem, nostra inter comitia simul ac vestra socium honoratissimum, qui studia nostra vobis exprimat, et de natalibus gratuletur. Maximi certe debentur Societati Regali honores, quae per ducentos et quinquaginta annos lampada tradiderit Scientiae, quae tot sibi consociaverit magistros, a Neutono illo usque ad Carolum Daruinum, necnon multos alios in re physica, geologica, chemica, physiologica doctissimos, ne dicam Medicos quosdam illustrissimos, qui inter nostram vestramque Societatem quasi arcta vincula fuerunt, atque amicitiae signa mutuae et perpetuae. At quanta ante oculos vestros patent regna! nihil enim in natura est pro cognitione vestra nimis vastum, nihil nimis minutum aut arcanum; quaeritis qua lege labantur sidera, quibus ignibus ardeant soles, quaenam sit terrarum et rupium aedificatio, quaenam molecularum et atomorum intima natura, quomodo et quibus ex primordiis propagentur florum animalium hominumque genera. Talia igitur contemplantes, et tanto Scientiae amore raptos, non turbat vos popularis aura, non odium theologicum, non furor politicus; sufficit enim ipsam Naturam prospicere, ac divino eius impleri afflatu; ita ut de vobis illud videatur cecinisse Vergilius,

felix qui potuit rerum cognoscere causas.

Valete!

THOMAS BARLOW, Praeses.

J. A. ORMEROD, Registrarius.

Datum Londini, Kalendis Iuliis, MCMXII.

\section{Royal Coleege of Surgeons}

We, the President, Vice-Presidents, and Council of the Royal College of Surgeons of England, have the honour to convey to the President, Council, and Fellows of the Royal Society our cordial congratulations on the occasion of the celebration of the $250 \mathrm{th}$ Anniversary of its foundation. It is gratifying to us to remember that, among the many illustrious men who have brought honour to the Society, not the least famous have been members of the medical profession, and that in three instances the Presidential Chair has been filled by a Fellow of our College. It is therefore with special interest and pleasure that we join in doing honour to the Society, and offer to its President and Fellows our best wishes for the success of their commemoration. In witness whereof we have caused the Common Seal of the College to be hereunto affixed this 13th day of June, 1912.

RICKMAN J. GODLEE, President. 


\section{Society of Antiquaries, London}

Socierati Regali inter omnes Britanniae Societates antiquissimae et praeclarissimae annum a Societate condita Ducentesimum Quinquagesimum Celebranti Societas Antiquarionum Londinensis S. P. D.-Societati Regali, inter ipsa scientiarum quae vocantur naturalium incunabula nascenti, mandato Regis Caroli Secundi sancitum est ut aut novam excuderet philosophiam aut veterem expoliret: quod propositum quanto cum successu sit consecuta, iam dudum non patriae modo sed orbi terrarum universo innotuit. Atqui, licet superfluum sit ut seriem virorum qui et Societatem et nomen Britannicum illustraverunt recenseamus, eorum saltem qui in utramque sodalitatem, et vestram et nostram, adsciti fuerint non omittenda est memoria: quorum e numero Martinus Foulkes uno eodemque tempore utrique Societati praefuit, Augustus Franks, Iohannes Evans, apud vos socii apud nos Praesides illustrissimi exstiterunt. Neque illud tacendum duximus nostram scilicet Societatem, quamvis $\mathbf{L V}$ annis natu minorem, vestrae et proximum obtinere locum, et firmissimo semperque ut speramus duraturo amicitiae foedere esse devinctam : quocirca vobis plenum studiorum fructum, felicitatem perpetuam, honoris, si id fieri potest, incrementum, iterum atque iterum libentissimis animis exoptamus. Delegavimus hodie Praesidem nostrum, Caroun Herculem Read, militem eundemque Legum Doctorem qui congratulationes nostras vobis unus pro omnibus afferat.

Dabamus Londini ex aedibus nostris, Kal. Iul. anno Domini MDCCCCXII.

C. H. READ, Praeses.

\section{British Academy, London}

The President, Council, and Fellows of the Royal Society of London.We, the President, late Presidents, Council, and Fellows of the Brrrish Academy, desire to offer to the President, Council, and Fellows of the Royal Society our cordial congratulations on the completion of the two hundred and fiftieth year of its illustrious career. On this memorable occasion we approach you with feelings of special attachment and confidence, inasmuch as our Academy was, at a still recent date, founded with the co-operation and goodwill of your august Society, and we take pride in the thought that we may almost regard our own Body as the offshoot of an historic Institution which has flourished through so long a period of the national life. The Royal Society had its beginnings in troublous times, when the proud legend inscribed on the Society's seal found in very deed a wide application; but at no time has it been other than true to the high and arduous ends to which its labours have from the first been devoted, or ceased from the pursuit and 
service of Truth. One of the earliest of the Associations founded in any European country 'for promoting Natural Knowledge', it has extended its investigations, so as to comprehend all the Physical as well as Mathematical Sciences, and the roll of its Presidents, Secretaries, and of successive generations of its Fellows, as well as of its Medallists, covers the entire range of modern scientific progress. 'The 'Invisible College' of the years preceding the Grant of the Society's first Charter, which it commemorates to-day, has long since established its leading position among the chief agencies in the advancement of 'Natural Knowledge' throughout the world. Nor can we forget that the list of its Officers and Fellows includes many names notable in the annals of British Letters, and in the history of those Studies which have of late found particular representation among the members of our own Body. Of the long and varied labours of the Royal Society a record of monumental completeness is presented in its Transactions, extending over very nearly the whole of the two hundred and fifty years of its strenuous existence. To the work thus unintermittently carried on by the Society has been added its faithful and fruitful administration of the important trusts committed to it by the Government of the Country, and through other Benefactions, as well as its wise distribution of the Annual Grants made to it, and its judicious award of Distinctions marking great achievements in original Scientific Investigation. All these high and onerous functions have been performed by the Royal Society in a spirit of self-devotion and with a fullness of success which entitle it to the grateful acknowledgements of a long series of generations, including the present of which we form part. With the sincere expression, on the present great occasion, of this widespread and well-merited recognition, the British Academy, in a spirit of faithful and grateful homage, desires most cordially to associate itself.

(Signed)

A. W. WARD, President of the British Academy.

\begin{tabular}{l|l} 
REAY - & Late Presidents of the \\
E. MAUNDE THOMPSON & British Academy. \\
I. GOLLANCZ, Secretary of the British Academy.
\end{tabular}

Date of Sealing, June 14, 1912.

\section{British Museum, London}

To the President, Council, and Fellows of the Royal Society.-The Trustees of the British Museum desire to offer to you their cordial congratulations on the occasion of the two hundred and fiftieth Anniversary of the foundation of your Society. Few institutions for the advancement of natural knowledge can claim an existence of equal length; none can boast a longer list of services to humanity than that which stands to the credit of 
the Royal Society and its Fellows. A Corporation such as yours, which includes within its ranks all the most eminent representatives of every branch of natural knowledge within the British Dominions, which commands the confidence of the nation and receives the support of the Government, can direct and co-ordinate effort, can encourage enterprise, can reward achievement, and thereby can promote the advance and welfare of scientific investigation with a power altogether outside the reach of individuals or of special societies. The Royal Society is one of the glories of England and the Empire; and all Englishmen are glad to join in celebrating this landmark in its long career of usefulness. The Trustees of the British Museum feel that they have a special claim to approach you on this occasion and to share in your rejoicings. The British Museum owes its origin to a munificent bequest from a Fellow and President of the Royal Society, Sir Hans Sloane; and the Act of Incorporation, by which it was founded in 1753, ordains that among the official Trustees of the Museum shall always be the President of the Royal Society for the time being. Thus, throughout its whole existence, the British Museum has had the advantage of the counsel, and has enjoyed the support, of every President of your Society ; and not least would the Trustees gratefully acknowledge the assistance they have received from the distinguished. man of science who now holds that high and enviable post. The interests of the British Museum are closely intertwined with the interests of science. The Museum, in its Library and its Natural History Departments, provides the materials for a vast amount of scientific research. Much of that research has been conducted by the officers of the Museum, past and present, many of whom have received the coveted honour of the Fellowship of your Society. It is, therefore, with the interest that is born of close association and common aspirations that the British Museum, in the person of its Trustees, rejoices in the glorious past of the Royal Society, and wishes it a long and not less glorious future.

Sealed woith the Common Seal of the British Museum, 6 July, 1919.

\section{Chemical Society, London}

The Chemical Society to the President, Council, and Fellows of the Royal Society, Greeting.-Amongst the many learned bodies represented here to-day there is certainly none which can wish to offer you more sincere and heartfelt congratulations than the Chemical Society. The Officers, Council, and Fellows of our Society desire to associate themselves with you in celebrating the two hundred and fiftieth Anniversary of the birth of a scientific corporation which in the distinction of its history is assuredly 
second to no similar body in the World. The great army of diligent and determined workers who are united by the solemn covenant to extend Man's knowledge of Nature look with reverence and gratitude on the Society which, during two and a half centuries, has kept alive in these Islands the sacred fire of Research, and has included within its Fellowship men whose names and achievements are amongst the most imperishable glories of the human race. We desire to take this opportunity of expressing, however imperfectly, our indebtedness to the Society of Boyle, of Cavendish, of Priestley, of Dalton, and of Davy, and we are proud to remember that these early masters of our Science, by the stimulus which their investigations gave to the growth of Chemical Knowledge, led to the origin of our Society by a natural process of gemmation from your body. It is, therefore, in the capacity of children, and as an act of filial piety, that we desire to offer to you, our parents, dutiful felicitations to-day. We would take this opportunity again of gladly and freely acknowledging before all men that whatever success our own Society may have achieved, whatever may be the dignity to which we have attained, and whatever service to Science and to Mankind we may have been privileged to perform, we largely owe to the inspiration which our founders drew from the magnificent traditions of the Royal Society. This quickening influence has been and, we trust, may long be maintained by a close association with you, by the community of Fellowship which exists between your Society and ours, and by the kindred ideals and aspirations which animate us both. Signed on behalf of the Chemical Society:

PERCY F. FRANKLAND, President.

ALEXANDER SCOTT, Treasurer.

ARTHUR W, CROSSLEY

SAMUEL SMILES Secretaries.

HORACE T. BROWN, Foreign Secretary.

Sealed in Council this Trentieth Day of June, One Thousand Nine Hundred and Treelve.

\section{Entomological Society, London}

Societati Regtae Societas Entomologica Londinensis S. P. D.-Benevole a vobis invitati, ut unum aliquem nostrum delegemus, qui natalicia vestra vobiscum celebret, munus hoc vel potius honorem Praesidi nostro, qui nunc est, contulimus, mandavimusque ei ut, epistolae huius testimonio, vobis declaret, nostrum omnium in votis esse ut Societas vestra virorum illustrium - sapientiae doctrinaeque Britannicae iam per tot annos decus et tutamenfelicitate, gloria, denique rebus omnibus optabilibus, magis magisque semper 
floreat, utque indagatio ac scientia rerum physicarum (quo ex fonte unum quasi rivulum fluentem Sodalitas nostra, quantum potest, consectari amat) patrocinio et favore vestro adiuvari nunquam desinat. Valete.

F. D. MORICE, Praeses.

\section{$\left.\begin{array}{l}\text { A. HUGH JONES } \\ \text { JNO. HARTLEY DURRANT }\end{array}\right\}$ Vice-Praes.}

$\left.\begin{array}{l}\text { JAMES J. WALKER } \\ \text { GEORGE WHEELER }\end{array}\right\}$ Hon. Sec.

Datum Londini, mense Iulio, MCMXII.

\section{Geological Society, London}

Regiae Londinensium Societati Geologica Londinensium Societas S.P.D.Hodie, viri amplissimi, Regiae Londinensium Societati Societas Geologica corde gratulatur ducentos quinquaginta annos summa cum laude confectos. Occasionem auspicatam laeti arripimus confitendi quid nos potissimum debeamus Almae Matri omnium fere collegiorum quae nunc apud Britannos exstant arcana naturae explorandi causa. Ad origines vestrae Societatis paulisper respicere liceat. Videtisne ut ex illo philosophorum globo, qui id temporis congressi sunt inquisitionem rerum physicarum promovendi causa, nata sit indagatio ista subterraneorum aenigmatum (eorum praecipue quae ad interius orbis terrarum tegumentum spectant) quae luce clarius edocuit arcana naturae, non modo in re geologica, verum etiam in unaquaque scientiae provincia, congregationibus indagantium et partitione operis potius quam singulorum investigatorum ope in lucem esse proferenda? Iam centum abhinc annos nos fratres geologici domicilio, ut ita dicam, proprio utimur; gratis tamen animis ad Almam Matrem nutricemque respicimus. Cui nostrum non surgunt cristae quum secum reputet matris nostrae cordi esse quae ipsi penitus investigare propositum habemus? Quis non superbit quod tu, vir amplissime, quem nos fratrem commilitonemque in nostra militia salutamus, in sellam praesidialem huius velut praetorii scientiarum, contubernalium suffragiis, accitus es? Societas Regia optime de Republica merita est, quippe quae ubique ardorem indagandi tum genuerit tum stimulaverit. $O$ si quae laus eam saeculis superioribus prosecuta est, ea per ventura saecula splendore haud imminuto illustret!

AUBREY STRAHAN, Praeses.

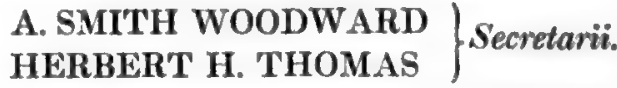

BEDFORD McNEILL, Thesaurarius. 


\section{Geological Survey of Great Britain and Museum or Practical Geology, London}

Address of the Geological Survey of Great Britain and the Museum of Practical Geology to the Royal Society of London.-The Geological Survey of Great Britain and the Museum of Practical Geology desire to take their part in the congratulations which are being offered by the whole civilized world to the Royal Society of London on the attainment of its two hundred and fiftieth Anniversary. To the influence of the Society in carrying out its vocation of improving Natural Knowledge, the growth of the science of Geology was chiefly due for nearly a century and a half, and though now for upwards of a hundred years geologists have found other homes, they can never forget that the Royal Society is the parent of all scientific institutions in the British Dominions. The Geological Survey and Museum are proud to remember that all their Directors and many other members of their staff have been Fellows of the Royal Society, and more especially that a former Director General now occupies the Presidential Chair. Being well aware of the great work performed by the Society not only in original research in every branch of science but in advising the State on scientific matters, in administering funds for the furtherance of research, and in investigations leading to the improvement of man's position upon the earth, it is the fervent wish of these Institutions that the Royal Society of London may long continue its eminently distinguished and useful career.

\section{J. J. H. TEALL, Director}

July, 1912.

\section{Instrtute of Chemistry; London}

The President, Council, and Fellows of the Instutute of Chemistry of Great Britain and Ireland have great pleasure in offering to the President, Council, and Fellows of the Royal Society of London their sincere and hearty congratulations on the occasion of the two hundred and fiftieth Anniversary of the incorporation of the Society. The Institute of Chemistry desires to be associated with Academies, Learned Societies, and all Scientific Institutions in rejoicing that the Royal Society which justly takes precedence as the parent of all our Scientific Societies, has with such marked success upheld the worldwide prestige of Science generally, and that throughout the two and a half centuries of its existence the great objects of its founders have been faithfully maintained to the honour of this country, and to the everlasting benefit of the cause of civilization and humanity at large. In the domain of Chemistry, no less than in other branches of Science, the Royal Society has fostered the 
progress of Learning and Research. The Institute recalls with pride that from its foundation in 1877 its Register has borne the names of no less than 106 Fellows of the Royal Society, while at the present time 48 Fellows of the Institute enjoy that distinction. It is the earnest hope of the Institute that the Royal Society may continue its career with undiminished vigour and success and that the great traditions of its past history may be carried on by future generations of its Fellows.

This 15th day of July, 1912.

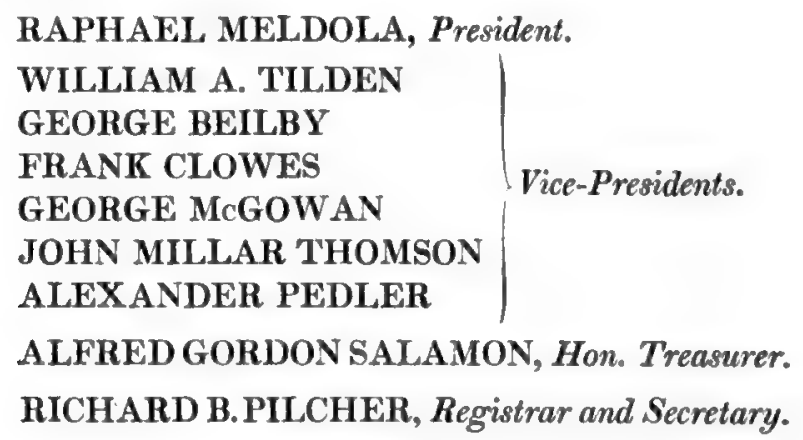

\section{Institution of Electrical Engineers, London}

To the President and Council of the Royal Society of London Greeting.-The President and Council of the Institution of Electrical. Eingineers offer their congratulations to the Royal Society on the completion of the two hundred and fiftieth year of its existence. They are happy to recall how much the Royal Society has done since the days of Robert Boyle and Francis Hauksbee to promote the discovery of electrical phenomena and of the laws of electricity and magnetism. They will ever remember the additions to electrical knowledge due to Sir Isaac Newton, Stephen Gray, Benjamin Franklin, Joseph Priestley, Abraham Bennet, Sir Humphry Davy, Michael Faraday, John Frederick Daniell, Sir William Grove, Sir Francis Ronalds, James Prescott Joule, Sir Charles Wheatstone, John Tyndall, Latimer Clarke, David Edward Hughes, Lord Kelvin, James Clerk Maxwell, John Hopkinson, George Francis FitzGerald, William Edward Ayrton, and other Fellows of the Royal Society. They express the hope that the Royal Society may enjoy unbroken prosperity, and may continue to promote the progress of electrical science.

On behalf of the Institution, the XVI day of July, MDCCCCXII.

S. Z. DE FERRANTI, President.

W. DUDDELI, President Elect.

P. F. ROWELL, Secretary. 


\section{Iron and Steel Institute, London}

Instituti Ferai ex Chalybis Praeses et Conchulum ext Socil Praesidi et Concillo ex Sodalibus Societatis Regalis Salutem. - Fausta oblata occasione, quod natalem diem doctissimae vestrae Societatis annos iam CCL constitutae celebrandum statuistis, antiquissimae et illustrissimae omnium in hac patria nostra societatum, quae Scientiae Naturali promovendae studuerunt, nos laeti et pietate affecti, cum ceteris huiusce generis societatibus, parenti nostrae insigni et dilectae gratulationem non simulatam agimus, et vota conferimus ut stabilita in annos floreat et praevalescat.

Datum Londinii, Id. Iul. MCMXII et manu nostra et signo confirmatum.

ARTHUR COOPER, Praeses.

G. C. LLOYD, Secretarius.

\section{Linnean. Society, London}

The Linnean Society of London desires to present its congratulations to the Royal Society of London on the celebration of the two hundred and fiftieth Anniversary of its foundation, on the completion of a period which has witnessed so vast a development of the Sciences, and on the noble part which the Society itself has borne in this boundless 'Improvement of Natural Knowledge'. 'The Linnean Society rejoices to recall, not only the many who have been and are on the Rolls of both Societies, thereby constituting links between the two, but also that Sir Joseph Banks, who took a large part in the foundation of the Linnean Society, presided for forty-one years over the Royal Society, and that the great Swedish naturalist whose name is borne by the Linnean Society, was also a Foreign Member of the Royal Society.

Given under the Common Seal of the Society this Twentieth day of June, 191\%.

EDWARD B. POULTON, President.

B. DAYDON JACKSON

OTTO STAPF

Secretaries.

GILBERT C. BOURNE

\section{Lister Institute of Preventive Medicine, London}

Praesidi Sodalibusque Illusthissimae Societatis Regalis Regentes, Professores, Studiosi in Collegio quod Lister Institute of Preventive Medicine appellatur S. P. D.-Libenter, viri doctissimi, litteras vestras accepimus necnon summa erga vos voluntate quod, tot annis rite peractis in 
arcanis Naturae exquirendis, Sodalitatem vestram praeclaram, fortunatis auspiciis conditam, tanta prudentia perfectam, celebrare velitis, Societati Regali pro temporis opportunitate gratulamur. Nos qui sub auspiciis Lister (hominis praeclarissimi et quondam Sodalitatis vestrae praesidis) abditas causas, in quibus requiritur ex quibus principiis nostra corpora sint, quid secundam quid adversam valetudinem faciat, patefacere laboramus, haud immemores sumus illorum tam praeclarorum virorum, Boyle, Mayow, Hales, Jenner, Young quorum nomina cum multis aliis necnon illustribus in fastis Societatis vestrae inscripta sunt. Tanto desiderio, tanta in vos benevolentia vehementer commoti, virum bonum, doctissimum Henricum Roscor equitem, per multos annos Concilio nostro praepositum, qui ipse praesens ad nostram amicitiam praestandam feriis vestris intersit, legatum destinavimus. Floreat in aeternum Societas Regalis penitus dilecta honoribus novis novisque inceptis exornata!

HENRY E. ROSCOE, Praeses.

J. LUARD PATTISSON, Aerario Praefectus. CHARLES J. MARTIN, Director.

\section{Mathematical Society, London}

The London Mathematical Society, of whose duty it is part to elaborate the instrument without which all pursuit of Natural Knowledge must finally be futile, desires to offer humble congratulations on the attainment of her two hundred and fiftieth Anniversary to the Royal Society. That this Society may ever continue to be imbued with the reverent and enthusiastic desire to unravel the secrets of Nature which has characterized all her most distinguished Fellows, and may ever hold herself in readiness, untrammelled by any too intimate relations with other institutions, to take her rightful place in succeeding times of Renaissance, is the prayer of all the special societies who own her pre-eminence. On behalf of the London Mathematical Society:

$$
\text { July 16, } 1919 .
$$

H. F. BAKER, President.

\section{Mercers' Company, London}

To the President, Council, and Fellows of the Royal Society.-The Mercers' Company of London desire to offer to you the President, Council, and Fellows of the Royal Society their sincere congratulations on the occurrence of the 250th Anniversary of the incorporation of your Society, whose history from its commencement has been an uninterrupted and glorious succession of conquests over Nature, conquests differing from other conquests in that they 
have been achieved, not by resistance to Nature, but by an ever increasing knowledge of and obedience to her laws. It is a further subject for congratulation that the true method by which these results have been achieved, the method of experiment and test, which was from the first laid down by your Society, was truly laid, and has since been universally acknowledged. We acknowledge also the large share which, on a survey of your successes, must be attributed to the principle represented by the words which you have adopted as your motto and have so greatly fortified in action, the principle of the independence of the human intellect. We acknowledge it with the more gratitude, since in supporting that principle you have conferred benefits on mankind not limited to the particular subjects which you have made more especially your own. We know, from the account which has been preserved, the ideas which actuated the founders of your Society, and it is very fitting that we of the present day, who can judge by the event the value of those ideas, should join with you in celebrating, and render our respectful homage to, the memory of those gifted men who formulated the principles and laid down the lines of your work, though they could only prophetically foresee the grandeur of the results to follow. May the Royal Society long continue its glorious career to the increase of true knowledge, the honour of our nation, and the welfare and happiness of the whole human race.

HORACE CULLEN, Master.

July, 1912.

\section{Mineralogical Societry, London}

Societas Mineralogica Societati Regali S. P. D.-Gratulamur Societati vestrae quod annos ducentos et quinquaginta ab origine vestra feliciter peractos mox estis celebraturi. Simul maximas gratias agimus quod scientias illas quae ad terrae structuram minerralem pertinent auxilio vestro et hortatione semper fovistis.

W. J. LEWIS, Praeses.

W. P. BEALE, Thesaurensis.

GEORGE T. PRIOR, Secretarins.

Datum Londini, die XVIII mensis Iunii, MCMXII.

\section{Pharmaceutical Society, London}

Societatis Pharmaceuticae Magnae Britanniae Praeses, Concilium, Sodales Societati Regali Salutem.-Gratulamur animo quam amicissimo Societati vestrae illustrissimae doctissimaeque natalem ducentesimum quinquagesimum celebranti, speramusque fore ut ita in posteros annos floreat ut cumu- 
latis quae iam antea laudanda effecit, rerum naturae scientiam proferat atque augeat, totiusque humani generis utilitatibus serviat. Illud quoque nobis pergratum est recordari, quod Gulielmus ille Allen, qui primus fuit Societatis Pharmaceuticae anno MDCCCXLI praeses, et ipse Societatis Regalis sodalis fuit, quodque Societas Regalis semper et sua opera et ahiis incitandis magno fuit adiumento Societati nostrae, per hos septuaginta annos id agenti ut artium chemicae et pharmaceuticae scientia apud Britannos amplificaretur.

Datum Londiniz, die III mensis Iulii, MC.MXII, pro Societate Pharmaceutica Magnae Britanniae.

\section{CHAS. B. ALLEN, Praeses.}

\section{Physical Society, London}

To the President, Council, and Fellows of the Royal Society.-Many illustrious names have been inscribed on the roll of the Royal Society during the 250 years which have elapsed since its foundation; but none have added a greater lustre to the fame of the Society and to the glory of their country than those of the men who devoted themselves to the study of Physics. Newton firmly planted the Tree of Science, Young, Joule, Faraday, Maxwell, Stokes, and Lord Kelvin have spread its branches in many directions. May we, therefore, - a young Society specially devoted to the study of Physics-pay our warm tribute of regard and affection to the parent body whose members have laid the foundation on which we are trying to build! May the record of the Royal Society be as glorious in the future as it has been in the past, and may she continue to possess the confidence and admiration of all who seek the advancement of Natural Knowledge! On behalf of the Physical Society of London:

ARTHUR SCHUSTER, President.

W. DUDDELI, Treasurer. SILVANUS P. THOMPSON, Foreign Secretary. $\left.\begin{array}{l}\text { W. R. COOPER } \\ \text { S. W. J. SMITH }\end{array}\right\}$ Secretaries.

June, 191\%.

\section{Royal Anthropological Institute, London}

To the President, Council, and Fellows of the Royal Society of London. -We, the President, Council, and Fellows of the Royal Axthropological Institute of Great Britain and Ireland, desire to offer to you our hearty congratulations on the occasion of the completion of the two hundred and fiftieth year of your glorious history. Your Society has during that long period been the centre of scientific thought, the home of the most illustrious workers and discoverers in science, the representative throughout the world 
of British scientific research and the constant and trusted adviser and almoner of the Crown and the Government of the country in respect of all matters relating to the progress of Science. Our Institute has less than seventy years' record to look back upon, for the Ethnological Society of London, which forms part of it, was founded in 1843, and the Anthropological Society of London, which forms the other part of it, in 1863. The two Societies were combined in 1871, and it is to one who conferred lustre on your Society, our then President, Thomas Henry Huxley, that that happy combination was due. We have owed much to other great men who, belonging to your body, have devoted themselves especially to the work of Anthropological Science, and have presided over our Institute. Among these are George Busk, Francis Galton, John Evans, John Beddoe, Augustus Franks, Augustus Pitt-Rivers, Daniel Cunningham, and others who are departed, as well as Lord Avebury, Alexander Macalister, Edward Burnet Tylor, and other distinguished members of your body who happily remain with us. It is to one of the ornaments of your Society-Charles Darwin-that the science of Anthropology owes its most powerful inspiration. The Origin of Species and the Descent of Man gave a new impulse and direction to the students of our science and formed for them a fresh starting-point for laborious and fruitful investigation. We have for many years felt the assured conviction that your body, as the acknowledged leaders of scientific thought, had the most complete sympathy with our work; that you viewed the growing development of it with cordial satisfaction; and that you had thus contributed much towards its successful prosecution. It is accordingly with a special feeling of gratification that we have deputed our President, Dr. A. P. Maudslay, to be our representative at the Celebration of your auspicious Anniversary and to present to you in our name this our Address of Congratulation.

ALFRED P. MAUDSLAY.

Dated the 11th day of June, 1912.

\section{Royal Astronomical Society, London}

$\mathrm{WE}_{\mathrm{E}}$, the President, Vice-Presidents, and Council of the Royal Astronomical. Societr, desire to offer our most hearty congratulations to the Royal Society on the celebration of the 250th Anniversary of its foundation. We would testify to the unceasing efforts of the Royal Society to promote the advancement of Natural Knowledge, which have eminently contributed to the present remarkable development of the sciences and their application to technical and industrial arts. Particularly do we desire to acknowledge the beneficial influence of the Royal Society on the study of Astronomy evidenced by the large number of important memoirs on Astronomical Science found in its publications. We note with pride the long roll of distinguished Astronomers 
who have been Fellows of the Society; and we are mindful that it was the extensive progress of Astronomy made in Great Britain under the encouragement of the Royal Society, which led to the formation of the Royal Astronomical Society. We are confident that the Royal Society will in the future, as in the past, continue to exercise the same fostering and effective influence upon the progress and development of all branches of Natural Knowledge.

F. W. DYSON, President.

ARTHUR R. HINKS, Secretary.

June 14, 1912.

\section{Royal Geographical Society, London}

'To the Presidext and Council of the Royal Society, from the President and Council of the Royal Geographical Society. Gentlemen, - On behalf of the Council of the Royal Geographical Society, and as representing the Fellows, I desire to convey to you our warmest congratulations on the occasion of the celebration of the 250th Anniversary of the foundation of your Society. It would be superfluous for me to point out the claims which the Royal Society possesses upon the admiration and gratitude of all who have the interests of scientific progress at heart. Through long years it was the only Institution in this country devoted to the encouragement and publication of the results of scientific research on purely disinterested lines, and without any hope of reward, except the satisfaction which follows the successful search for truth. The most illustrious names in all departments of Science have been connected with the Royal Society from its foundation. From the very first every serious research into any of the many aspects of the universe was welcomed by the Society, and the results were impartially considered. In time, and largely due to the action of the Royal Society, this work of scientific research became so multifarious that other Societies grew up alongside the parent Society, and co-operated in the common object of seeking after the truth, and attempting to interpret the phenomena of the universe. In past generations the subject with which the Society is directly concerned had its fair share of attention at the hands of the Royal Society, many of whose Fellows were specialists in Geography ; and the influence and example of the Royal Society have not been without their effect in inducing British geographers to apply scientific methods in an ever increasing degree to their own department of research. In pursuing its work the Royal Society has rendered eminent services to the Empire and to the world, and we confidently hope that in the future it will continue to occupy the commanding position in Science which it has attained in the past. On behalf of the Council and Fellows of the Royal Geographical Society, I am, Gentlemen, Your obedient servant,

CURZON OF KEDLESTON, President R.G.S. 


\section{Royal Instifution of Great Britain, Lonidon}

The Members of the Royal Institution of Great Britain congratulate the Royal Society of London on the occasion of the celebration of its two hundred and fiftieth Anniversary, and wish the Society all prosperity and success in the future.

DONALD W. C. HOOD, Delegate of the Royal Institution of Great Britain.

21 Albemarle Street, London, $W$. July 16th, 1912.

\section{Royal Meteonological Society, London}

To the Royal Society, London.-We, the President and Council of the Royai. Meteorological Society, desire to offer to the Royal Society our sincere congratulations on the occasion of the two hundred and fiftieth Anniversary of its foundation. We are deeply sensible of the pre-eminent position which the Royal Society has always held in the promotion of natural knowledge, and of the beneficial influence it has exerted upon the advancement of learning and also upon the scientific development of the technical and industrial arts, by its unceasing efforts. We recognize with especial satisfaction the support which the Royal Society has afforded to the science of Meteorology, as exemplified particularly in the labours of the Meteorological Committee. Many names eminent in meteorological science occur in the Roll of Fellowship of the Royal Society, and the published records of the Society contain numerous contributions of outstanding importance to our knowledge of the mechanics and physics of the atmosphere. In congratulating the Royal Society upon a long and brilliant record of past achievement we are assured that it will continue in the future to take an equally important part in the progress of all branches of science.

Given under the Seal of the Society, June 19th, 191\%.

H. N. DICKSON, President.

FRANCIS CAMPBELL-BAYARD W. F. CABORNE Secretaries.

\section{Royal Microscopical Society, London}

The Council and Ferlows of the Royat Microscopical Socrety have commissioned Henry George Pummer, a Fellow of the Royal Society, and their own President, to act as their Delegate at the 250th Anniversary of the foundation of the Royal Society. They have desired him to convey the 
heartiest greetings and congratulations of one of the younger of its daughters to the Royal Society on this the occasion of its 250th Anniversary, and thus to testify to the honour and respect in which they hold the great Mother of the Learned Societies. Signed on behalf of the Royal Microscopical Society, by

H. G. PLIMMER, President.

WYNNE E. BAXTER, Treasurer.

JNO. EYRE
F. SHILLINGTON SCALES Secretaries.

\section{Royal Society of Arts, London}

The Royal Society for the Encouragement of Arts, Manupactures, AND Conmerce welcomes the opportunity which has been afforded to it of offering its warm congratulations and best wishes to the Royal Society on the 250th Anniversary of its foundation. Among the many services which the Royal Society has rendered to this country and to Science in general, one-not the least-has been that in proportion as the increase of knowledge has rendered necessary special and separate study of each branch of investigation, the Society has been instrumental in the formation of fresh Associations for this purpose, while itself maintaining a general interest in the whole field of progress and discovery. The Society of Arts, in whose foundation a century and a half ago several Fellows of the Royal Society took a prominent part, has from its commencement looked to the Royal Society as the parent of such Associations in this country, no less than the model for similar combinations abroad, and congratulates itself on the close connexion between the two Societies, which has been maintained throughout its existence by the presence in its ranks of many distinguished Fellows of the Royal Society. The Council have had pleasure in deputing their Chairman to represent them among the distinguished crowd of Delegates who have come from all countries of the world to take part in the celebration of this auspicious Anniversary, and they desire to express their earnest hope that the future may have in store for the first and greatest of English Scientific Societies achievements no less illustrious and beneficial to mankind than those which are recorded in its past history. Sealed with the Seal of the Royal Society for the Encouragement of Arts, Manufactures, and Commerce in the presence of

SANDERSON, Chairman of the Council.

H. T. WOOD, Secretary to the Society.

5th November, 1912. 


\section{Royal Society of Medicine, London}

The Royal Society of Medicinf,-The President, Council, and Fellows of the Royal Society of Medicine very heartily congratulate the President, Council, and Fellows of the Royal Society on the completion of two hundred and fifty years spent in the execution of the very important duties with which it is entrusted. A Society which has for its object the improvement of the Art and Science of Medicine in all its branches, towards which improvement the advancement in knowledge in various other Sciences so largely contributes, cannot but take the warmest interest in the continued prosperity and usefulness of the Royal Society, especially as there were among the original members of that Society several Fellows of the Royal College of Physicians of London, and as moreover several of its Presidents have been Fellows either of that College or of the Royal College of Surgeons of England. In former times when the power of Analysis had outrun the means of obtaining knowledge, natural Philosophy and Metaphysics and the analysis of Sense and the analysis of Thought were hopelessly confused by the attempt to solve them, not through an appeal to facts, but by the help of general theories respecting the nature of the Universe. In the philosophy of Antiquity the meaning of the word 'Science' could scarcely be explained to students, except from the mathematical sciences, which alone offered the type of Universality and Certainty. Geometry was regarded as the propaedeutic to philosophy. Somewhat of this view perhaps lingered at the time when those who afterwards gave birth to the Royal Society had 'a designe of founding a Colledge for the promoting of Physico-MathematicallExperimentall Learning'. But the Royal Society-having arisen out of the 'Invisible College' of which Boyle the disciple of Francis Bacon (both of imperishable fame) speaks in sundry letters, having been granted a Charter on July 15th, 1662, by Charles II, mathematical pupil of Hobbes, and having adopted as its title the name first applied to it by the celebrated diarist Evelyn-directed its inquiries, particularly, to what was then called the "New Philosophy' or 'Experimental Philosophy' 'for the improving of natural knowledge by experiments'. True to its origin and history, the Royal Society still elects Princes of the Blood, and persons selected by the Council from among men distinguished in walks of life other than Science; whilst by the restrictions made during the presidency of Sir Joseph Banks, and subsequently, the number of Candidates recommended for election has been limited to fifteen annually. Concurrently with this restriction of the Fellowship, Science has grown enormously; and as a consequence, other Scientific Societies have been established, some under the auspices of several Fellows of the Royal Society and by Royal Charter, some independently of either of these advantages, but all active in the promotion of special branches 
of Science. The Royal Society is 144 years younger than the Royal College of Physicians of London, but it is the oldest exclusively scientific body in Great Britain, and one of the oldest in Europe. That it may continue in the successful performance of its various functions as the promoter of scientific investigations and researches, as the adviser of the Government in connexion with national scientific works, and as the administrator of Government grants and trust funds for experiments and for the publication not only of its own invaluable Transactions and Proceedings but also of scientific papers issued through other channels, is the earnest wish of the Royal Society of Medicine, which shares with other learned bodies the honour and special pleasure of taking part in the festivities of this Commemoration.

July 15th, $191 \%$

HENRY MORRIS, President.

\section{Royal Statistical Society, London}

To the President, Council, and Felzows of the Royal Society.-We, the $P_{\text {Resident and }}$ Council, representing the general body of Fellows of the Roral Statrstical Societr, desire to present to the President, Council, and Fellows of the Royal Society on the occasion of the two hundred and fiftieth Anniversary of its foundation, our sincere congratulations and greetings. We are proud to claim association with your illustrious Society, not only because in the pursuit of exact knowledge we look to you for guidance and inspiration, but also because since the earliest days the Royal Statistical Society has received the active support of many who are eminent in Science. We recall with satisfaction that among the great names which adorn your roll are included those of many of our Presidents, while other Fellows of our Society intimately associated with our aims and activities, have added to their distinction as Statisticians the lustre of the Fellowship of the Royal Society. Among our Presidents the names of Lord John Russell, Lord Houghton, William Newmarch, Dr. William Farr, Dr. Guy, Lord Goschen, Sir Robert Giffen, Lord Avebury are prominent; while our list of Treasurers includes Henry Hallam and George Richardson Porter. It is of interest also to record that Charles Richard Weld, the historian of the Royal Society, was at one time Assistant Secretary to the Royal Statistical Society. On the maintenance of your high traditions and the continuance of your labours depend in a large degree the future welfare and greatness of our nation. Now more than ever must your researches, by their breadth, by their penetration, by their originality, give an impulse to the force and variety of our national life. Great, however, as is your national mission, there is a greater still; for Science recognizes no geographical frontiers nor is national advancement alone its incentive. Your high ideals touch the welfare of all mankind, and your labours are illumined by the whole 
firmament of Knowledge. It is because, in our more modest sphere of work, we too are guided by the same standards and inspired by the same ideals that we offer our sincere congratulations on this memorable occasion.

Given under the Common Seal of The Royal Statistical Society, 11th July, $191 \%$.

F. Y. EDGEWORTH, President. RICHARD B. MARTIN, Treasurer.

R. H. REW

G. UDNY YULE

A. W. FLUX

Honorary Secretaries.

\section{Zoological Society, London}

The Council and Fellows of the Zoological. Society of London send greetings to the Royal Society. They have commissioned Sir Herbrand Arthur Russell, Dure of Bedford, Knight of the Most Honourable Order of the Garter, Fellow of the Royal Society, and their own President, to act as their delegate at the celebration of the 250th Anniversary of the foundation of the Koyal Society and to testify to the honour and respect in which they hold this great instrument for the advancement of natural knowledge. Signed for the Council of the Zoological Society of London:

\section{BEDFORD, President.}

July 15, 191\%.

P. CHALMERS MITCHELL, Secretary.

\section{British Association for the Advancement of Science}

To the President and Council of the Royal Society.-We, the President and Council of the British Association for the Advancement of Science, offer our cordial congratulations to the Royal Society on the occasion of the celebration of the two hundred and fiftieth Anniversary of the foundation of the Society. The British Association, since its birth in 1851, has been constantly in close relations with the Society. The great majority, not only of those who took the leading parts in the foundation of the Association, but of those who have filled its presidential chair, besides many others to whose earnest co-operation the success of its Annual Meetings has been due, have been Fellows of the Society. We would express the hope that the Society may continue to prosper, and may always maintain that pre-eminent position which is the fitting reward of its labours. Signed on behalf of the Council :

July, 1912.

WILliam RAMSAY, President. 


\section{Cambridge Philosophical Society}

Whereas on the eighth day of January of the year 1912 the President, Council, and Fellows of the Royal Society invited the President and Council of the Cambridge Philosophicai. Socifty to send a representative to be in London on the fifteenth day of July following at the celebration to be then held of the two hundred and fiftieth Anniversary of the foundation of the Royal Society, now the President and Council of the Cambridge Philosophical Society hereby appoint their President, Sir Grorge Howard Darwin, Knight Commander of the Most Honourable Order of the Bath, Plumian Professor of Astronomy and Experimental Philosophy in the University of Cambridge, and Fellow of Trinity College in the same University, to be their representative on this occasion and to bear to the President, Council, and Fellows of the Royal Society their felicitations on the long-continued and illustrious services to science of the Society. The Fellows of the Philosophical Society desire to avail themselves of the present opportunity of expressing their pride in the fact that, from the days of Newton, members of the University of Cambridge and in later times of their Society have always borne an important part in the beneficent work of the Royal Society.

Sealed this sixth day of July, 1912.

G. H. DARWIN, President.

E. W. BARNES, Secretary.

\section{Manchester Literary and Philosophical Society}

Praesidi Consilio Sodalibus Societatis Regalis pro Scientia Naturali Promovenda annum CeL suum peliciter celebrantis S. P. D. Societas Littrararia et Philosophica Mancuniensis.-Etsi vix omnibus persuadebit poeta qui censebat

$$
\text { in magnis et voluisse sat est, }
$$

tamen cum praeclaros Societatis vestrae annales per tot iam saecula florentis spectemus, nostrae certe non ingrata laus erit si quis nos voluisse iudicaverit, quantum quidem intra provinciam nostram fieri posset, insistere vestigiis vestris. Nec sine gloria quadam propria nobis, qui usque ad hunc diem Daltonii illius domum habitamus, recordari licet et Daltonium ipsum et Ioulium-quibus quae nomina in rebus physicis magis illustria ?-communes socios vestri et nostri corporis fuisse, nec non inter nos, ut inter familiares suos, aliquanto prius reperta sua quemque esse confessos. Nonne enim, ut cecinit Salomo, 'ceu ferrum ferro, sic ab amico exacuitur amici facies'? Nos certe si quid unquam boni in medium conferre vel poterimus vel potuimus, inde id 
nobis contigerit quod vestro exemplo instincti doctos viros et naturae investigatores singulos ac solos laborare non patimur, sed in sociorum convivin, in rationis commercia attrahere conamur. Sit de nobis quoque dictum, ut a Vergilio olim cum Roma Mantuam comparante,

sic canibus catuli similes, sic matribus haedi,

dummodo quis hoc pro certo habeat nos haedos, quanquam iam et ipsi per centum et triginta annorum cursum saltavimus, victorias ac triumphos vestros, velut parentis, summo semper gaudio revereri, feriasque vestras hoc tempore laetissime celebrare. Et in tanto hoc populo, cuius necessitates in dies acrius Scientiae exauctae opem ante omnia implorant, diu vobis excitare ac ducere liceat magnum istum exercitum quaerentium veritatem. Horum ergo votorum nuntium, Praesidem nostrum dilectum, artis botanicae acerrimum Professorem, Fredericum Ernestum Weiss, a vobis benigne vocati delegavimus qui vobis ipse laetantibus laetitiam nostram repraesentet.

$$
\begin{aligned}
& \text { F. E. WEISS, Praeses. } \\
& \text { R. L. TAYLOR } \\
& \text { GEORGE HICKLING. Secretarii. }
\end{aligned}
$$

Datum Mancunii, ex aedibus Daltonianis, Kal. Iul. MDCCCCXII.

\section{Ashmolean Natural History Society of Oxfordshire}

The Ashmolean Natural Histohy Society of Oxfordshire sends heartiest congratulations to the Royal Society on the celebration of the 250th Anniversary of its foundation. It begs to express its profound admiration for the great part the Royal Society has played in the extensive development of Natural Knowledge, and in the enormous advancement of the beneficial and industrial Arts, during those 250 years, and thanks the Royal Society for the stimulus and encouragement it has always afforded to other Societies, throughout the Empire, by its splendid example in the field of research. For these reasons the Ashmolean Natural History Society of Oxfordshire, thus named in memory of Elias Ashmole, one of the earliest Fellows of the Royal Society, desires herewith to offer its humble homage and greeting.

AR'THUR A. RAMBAUT, President and Delegate.

\section{Society of Chemical Industry}

To the President, Council, and Members of the Royal Society.-The President and Council of the Society of Chemical Industry offer to the Royal Society their most hearty congratulations on the attainment of the two hundred and fiftieth Anniversary of its foundation and have nominated to 
represent them on this happy occasion Rudolph Messex, their President. At no time in the history of experimental science has there been any hard and fast line dividing science from its applications, and the President and Council of the Society of Chemical Industry recognize with pride that among the Fellows of the Royal Society have been found some of the most brilliant examples the world has seen of the genius which, while it seeks and grasps the highest generalizations, is at the same time intensely alive to the applications of science in arts and manufactures. As the oldest chartered scientific society in this country and the mother of many daughter societies, the Royal Society rouses the sympathy and admiration of all followers of applied science throughout the world. The Society of Chemical Industry cannot forget that it owed much of its early success to the timely support of Fellows of the Royal Society: the Right Honourable Sir Henry Roscoe, its first President; Sir Frederick Abel, Sir Lowthian Bell, Sir William Perkin, Sir William Siemens, Dr. Angus Smith, Mr. Walter Weldon, Prof. A. W. Williamson, and Dr. James Young, its first Vice-Presidents; and Capt. W. de W. Abney, Sir William Crookes, Dr. Peter Griess, and Dr. Hermann Sprengel, Members of its first Council. When the Society of Chemical Industry opened its doors to men of every country and every race, the Royal Society at once welcomed this manifestation of the brotherhood of Science, and marked its appreciation of the great importance of such international exchanges of courtesy and scientific opinion by the new departure of a reception to the Society and its members who had come across the sea. In industrial production the gain of one nation may be the loss of another, but the victories of science stand alone in that there is no encmy to vanquish but ignorance, and its conquests are for the gain and enrichment of the whole human race. The increased power over nature won by the work of Davy and Faraday, of Rumford, and of Rutherford gives no exclusive gain to any one country. The Royal Society and the Society of Chemical Industry have a common object in improving and increasing natural knowledge, and the future condition of mankind, both intellectually and materially, depends upon the growth and activity of scientific Societies. The organized and systematic application of science to industry is still far from complete. The Society of Chemical Industry looks to the Royal Society to continue to bestow upon its work the interest and encouragement which have been so fully granted in the past. In wishing for the Royal Society continued and increasing prosperity, the President and Council trust that the cordial relations existing between the Societies may be maintained and result in a more extended co-operation.

RUDOLPH MESSEL, President. THOMAS TYRER, T'reasurer. CHARLES G. CRESSWELL, Secretary. 


\section{SCOTLAND}

\section{University of Aberdeen}

Societatis Regalis Praesidi Concilio Solalibus Universitas Aberdonensis Salutem.-Societatem Regalem praeclarissimam per annos fere ducentos quinquaginta durasse omnibus saltem quotquot minimam scientiam habent probe notum est. Neque iustum esset si talis occasio silentio praetermitteretur, praesertim ab Universitatibus Britannicis. Per ea enim quae ad inlustrandam rerum naturam sodales vestri contulerunt doctrina nostra quotannis increbruit. Nos vero, qui adulescentes informare conamur, oblivisci nequimus vos semper quicquid boni operis in eorum studiis inveneritis summopere fovisse, et eodem tempore quinque professores nostros inter vestros socios esse adscriptos gloriari oportet. Itaque summa voluptate Vice-Cancellarium nostrum, virum admodum reverendum, Georgium Adam Sмiтh, D.D., LL.D., Litt. D., qui gaudium nostrum praesentia sua testetur, legare constituimus.

STRATHCONA, Cancellarius.

Datum Aberdoniae, vicesimo quinto die mensis Iunii, MCMXII.

\section{University: of Edinburgh}

Societati Regali S. P. D. Universitas Academica Edingurgensis.-Societatem Regalem cum ceteris ubique Universitatibus nos quoque, Universitas Edinburgensis, iam pridem veneramur et magni facimus, ut omnis Scientiae praeclarissimam inventricem et altricem. Multarum illa quidem instar Universitatum est, multa in fastis suis nomina habet eorum virorum qui maximo ingenio praediti, veritatis investigandae acerrimi cultores, plurimum generi humano profuerint, Newton, Humphry Davy, Faraday, Darwin, Lister, Kelvin, ut pauca tantum et praecellentia e multis enumeremus. Annum ducentesimum quinquagesimum ita implevit Societas vestra ut nullo saeculo quicquam magni in Scientia novatum et in melius provectum sit cuius illa expers fuerit. Videmus haud minus hodie florentem quam his tot annis praeteritis, diuque ut floreat optamus : diu rerum naturam indagantibus viam praemonstret novosque ad nova incepta animos inspiret; sint futuris quoque temporibus permulti qui digni sint ut in ordinem istum tam praeclarum adscribantur.

\section{WILHELMUS TURNER, Praeses.}

\section{J. GRANT, Secretarius Senatus Academici.}

Dabamus Edinburgi, mense Iulio, anno Salutis Nostrae MCMXII. 


\section{UNiversity OF Glasgow}

Ad Societatis Regalis Praesidem, Concilium, Sonales.-Universitas Grasguensis salutem sibi a vobis humanissime impertitam perlibenter reddit. Et grato animo officii gratiam accipere iuvat, quod nos in consortium tantae sollemnitatis vocare dignati estis, et eum praecipue ad vos legare cuius vel ex auctoritate eluceat quanti honoris hunc diem habeamus. Magnus enim sane ille dies qui quinquagesimum lustrum claudit ex quo nobile illud sapientum sodalicium, iusti non sine libertate imperii instaurati specimen, regiis auspiciis inchoatum est. Et proprium quoddam nobis gaudium inde percipere licet quod illorum vestrorum luminum et satis multa et satis clara se educavisse haec nostra academia profiteri potest. Placuit igitur vir. cl. Donaldum MACAlister, Praesidem nostrum et Vicecancellarium, plurimarumque eundem ipsum artium antistitem, vobis hisce litteris commendatum mittere, qui et nostris verbis et suo iure vobis de amplissima qua adhuc floruistis laude et de profectus venturi spe auspicatissima, praesens gratuletur.

Dabamus Glasguae, mens. Iul. anno MCMXII.

GEORGIUS MILLIGAN, Senatus Academici Scriba.

\section{University of St. Andrews}

\section{Societatis Regalis Praesidi Concilio eet' Sodalibus Universitas Andreana} S. P. D.-Non sine gaudio neque alieno a vobis animo acceperamus, viri doctissimi et amicissimi, ferias vos hoc anno acturos esse natalicias Societatis vestrae ducentesimas quinquagesimas, quibus ut intersit legavimus Scientiarum Facultatis nostrae Decanum, Iacorum Colqunoun Irvine, Scientiae Chemicae Professorem. Scilicet vix ullam Universitatem esse arbitramur quae benevolentius magisque ex animo Societatem vestram salutare debeat, cum apud nos litteris et philosophiae operam dederit Robertus Murray qui primus vobis praefuit et quem Societatis vestrae Animam vir summus Christian. Huygens appellavit. Nec defuerunt qui postera aetate e vestro numero apud nos quoque de scientiis bene meruerint, e quibus iuvat nomina apponere Davidis Brewster, Collegii S. Salvatoris et S. Leonardi apud Andreanos Praefecti, et Domini Playfair de St. Andrews, qui quam diligenter in scientiis promovendis elaborarint omnibus notum est. Nihil dicimus de iis quos his temporibus e nostro numero in vestram Societatem adscivistis, cum eos vobis satis cognitos et probatos certo sciamus. Vetera sane inter vos nosque vincula sunt et studiorum velut consanguinitas; optamus igitur et precamur ut vestra Societas, sicut adhuc floruit, haud minus in posterum floreat semper et vigescat.

\section{IACOBUS DONALDSON, Vicecancellarius.}

Dabamus Andreapoli, mense Iulio, MCMXII. 


\section{Royal Society of Edinburgh}

To the Royal Socrety of London.--The President and Fellows of the Royai, Societr of Eminimgir desire to offer their congratulations to the Royal Society of London upon the attainment of the two hundred and fiftieth Anniversary of its foundation. Founded for the purpose of ' further promoting by the authority of experiments the science of natural things and of useful arts', the Royal Society of London has with increasing zeal and power continued to fulfil its high calling, and commands in the world of scientific endeavour a position peculiarly its own. The Royal Society of Edinburgh recalls with pride and satisfaction that since its own foundation in 1783 there has always existed between the two Societies a close association, based not only on community of aim and interests, but in great measure also upon community of membership. Scientific men of eminence have served on the Councils, and contributed to the publications, of both Societies; and each Society can claim the late Lord Kelvin as one of the most renowned of its Presidents. At this time the personal connexion is happily exemplified by the fact that the distinguished President of the Royal Society of London has been a Fellow of the Royal Society of Edinburgh for fully half a century. May the important work which the Royal Society of London has achieved in the past be continued and extended, during many centuries to come, to the furtherance of natural knowledge and the progress of humanity.

WM. TURNER, President.

July, 1912.

$$
\text { C. G. KNOTT, Secretary. }
$$

\section{Royal Philosophical Society of Glasgow}

The Royal Philosophical Society of Glasgow to the Royal Society of London for the Advancement of Natural Knowledge -We, the Members of the Royal Philosophical Society of Glasgow, desire to express our gratification at the courteous invitation to take part in celebrating the two hundred and fiftieth Anniversary of the foundation of the Royal Society of London, and our heartiest congratulations on the uninterrupted and.pre-eminently fruitful activity of the Society over a period of such duration. Scientific Societies and Learned Bodies of all nations are bound and indebted in many ways to the Royal Society; for leadership in scientific thought, for encouragement of research, and for an unsparing hand in the dissemination of knowledge. Since its inception the history of the progress of the Royal Society has been largely the history of the advancement of science: the long 
Roll of its Fellows bears the names of almost all the illustrious men of two and a half centuries. Many of these we can recall whose names have adorned our own Roll, and we cherish with peculiar satisfaction the recollection that the late Lord Kelvin, during wellnigh sixty years, gave liberally of the offspring of his great genius to forward the interests of both societies. We also recall with pride that on the celebration of the Centenary of our Society in 1902 we were honoured by a cordial greeting from the Royal Society-the Mother and the Model of all the learned societies in the English-speaking world. It is our earnest hope that the Royal Society may long continue, with ever fresh ardour and increasing power, to carry on its great work for the advancement of knowledge.

Signed on behalf of the Members of the Royal Philosophical Society of Ghasgore, this second day of July, Nineteen hundred and twelve.

JOHN GLAISTER, President.

\section{IRELAND}

\section{University of Dublin ('T'rinity College)}

Societati Regiae Universitas Dublinensis S. P. D.-Societas vestra, viri doctissimi, quae rerum naturalium investigatoribus, tamquam sol, in regno nostro lucem et calorem praebet, vim beneficam tamdiu et tam efficaciter exercet ut vix animo concipere possimus olim, neque multis abhinc annis si vitam nationis quis consideret, eam non esse exortam. Sed cum invitatio vestra benignissima venerat ut gaudii vestri participes essemus quo quartam partem millennii naviter et feliciter peractam celebraturi estis, recordati sumus quanta et qualia in brevi spatio animus excelsus, improbi laboris prodigus, veritatis amore instinctus efficere possit. Gratis animis agnoscimus nullam esse rerum naturae partem quae non manum adiutricem Societatis vestrae senserit, sive quis ad extremos mundi fines iverit ut ad Arctoum polum via pateret, sive maris altitudines rimatus sit ut quae ibi latitarent plantae atque animalia cognoscerentur, sive ad coelum oculorum verterit obtutum ut transitiones planetarum ibi dispicerentur. Quid? opere vestro vetus cohors febrium plane fugata est et morborum vis malefica sensim in dies debilitatur: denique in omni genere laboris beneficentia vestra munere suo salutari semper fungitur. Meminisse iuvat inter auctores Societatis vestrae fuisse Robertum Boyle nostratem, multosque Hiberniae filios in Albo Sociorum vestrorum inscriptos esse, inter quos praecipuo honore nominandus est unus e Praesidibus vestris illustrissimis Gulielmus Thomson, Baro Kelvin, cuius infantia coelum hausit Hibernicum. Laeti igitur libentesque vobis gratulationes et grates agimus, et delegamus virum doctum e coetu nostro eundemque coetui vestro iamdudum adscriptum, paene tam vobis dilectum quam nobis, IoHannem 
Joly, Scientiae Doctorem, Geologiae Professorem in his aulis, qui feriis vestris adsit vobisque et nostro et suo nomine omnia bona fausta felicia ex animo precetur. Valete.

IVEAGH, Cancellarius.

ANTHONY TRAILL, M.D., Praepositus Collegii SS. Trinitatis. Dublinii, in Collegio SS. Trinitatis, mense Iulio, A.S. MCMXII.

\section{Royal Irish Academy, Dublin}

Societati Regiae Academia Regia Hibernica S. P. D.-Cum iam, viri doctissimi, post annos ducentos quinquaginta feliciter peractos Societas vestra illustris optimo iure ferias plusquam saeculares habitura sit, laeti libentes invitationem vestram benignam accepimus qua nos quoque in partem gaudii vestri vocavistis, utpote qui vobis non solum studiorum et naturae similitudine simus consociati sed etiam vinculis quibusdam propriis constricti. Nam ad exemplum vestrum saeculo XVIII ${ }^{\circ}$ fundata est Academia nostra, unde utrisque nobis Prid. Kal. Decembr. quotannis dies est prae ceteris sollemnis: porro Ioseph Banks, Eques auratus, Societatis vestrae Praeses in diplomate constitutionum nostrarum inter primos sodales nostros nominatus est, et Praesides vestri propter coronam tantam illis a vobis collatam inter sodales nostros honoris causa merito sunt semper adscripti. Quanta beneficia generi humano semper et ubique contuleritis in scientia rerum promovenda, in ignoratione removenda, gratis animis cum toto orbe terrarum agnoscimus; neque immemores sumus nosmet ipsos munificentia vestra esse nuper adiutos cum opus magni laboris suscepimus, scilicet in Hibernia Occidentali rerum naturalium perlustrationem accuratam. - Nulla est sane maior hominibus voluptas quam gaudere cum gaudentibus, praecipue cum, sicut vos et nos, multis amicitiae necessitudinibus sunt inter se coniuncti. Itaque invitatio vestra nobis maximae est laetitiae, et vobis commendamus virum doctum in coetu tam vestro quam nostro inscriptum, Iohannem Alexandrum McCleliand, Scientiae Doctorem, ab Actis Academiae, Professorem Rerum Naturalium in Collegio Universitatis Dublinensis, qui feriarum vestrarum celebrationi adsit et Academiae gratulabundae et vobis grates gratiasque habentis personam tam laete quam sincere gerat. Valete.

J. P. MAHAFFY, Praeses Academiae.

LOUIS C. PURSER, Ab Actis Concilii Academici.

Dublinii, in domo Academica, a. d. IV. Idus Iulias, A. S. MCMXII. 


\section{Royal Dublin Society}

The Royal. Dublin Society to the Royal Society of London Greeting.'The President and Council of the Royar. Dubun Society heartily join in congratulating the Royal Society of London on the attainment of the two hundred and fiftieth Anniversary of its foundation. Great has been the progress of science since the Society under Royal auspices undertook the task of improving natural knowledge, and the Fellows may well look with pride upon the conspicuous part they have taken in winning from Nature her wellguarded secrets. We earnestly hope that the Royal Society may continue its beneficent labours with increasing success, ever widening the bounds of knowledge and extending man's control over Nature.

- Given under our Common Seal at Leinster House, Dublin, this first day of August, 1912.

HOWARD GRUBB, Vice-President.

\section{Quefn's University of Belfast}

To the President and Fellows of the Royal Society of London.-We, the Chancellor and Members of the Queen's University of Belfast, desire to convey our congratulations on the occasion of this your Fifth Jubilee, and, with our elders in learning, to acknowledge the blessings which your example and generous endeavour have bestowed upon the commonwealth of Science. The Virtuosi of Gresham College planned with confidence in their purpose and in their successors. Within five years the poet's compliment that your Society was 'worthy a history' found proof in the memorable record of your first efforts 'to increase the Powers of all Mankind'. At this remove it is our privilege to do honour to a great tradition, and to see in that tradition less the pride of accomplishment than the continuing promise of 'ransom to the mind of man'.

Signed in name of the University, on the fffeenth day of July, me thousand nine hundred and twelve. 


\section{TELEGRAMS AND LETTERS}

\section{FROM FOREIGN MEMBERS AND OTHER MEN OF SCIENCE ABROAD}

Professor Emil Fischer, University of Berlin, Foreign Member of the Royal Society.-Zum Jubelfeste beehre ich mich der Royal Society herzlichen Glückwunsch darzubringen.-Emi Fischer.

Professor Hendrik Antoon Lorentz, For. Memb. R.S., and Professor VanDESANDE BaKhUYsen, both of the University of Leyden.-Hearty wishes for lasting prosperity and glorious future.-VANDESANDE BAKHUY,EN, LoRENTZ.

Professor Crement A. Trmiriazeff, University of Moscow, For. Memb. R.S. -Accept warmest congratulations to the fifth jubilee of the Society's glorious career.-TimiRiazeFF.

Professor C. Wilhelm Röntgen, University of Munich.-Leider gestattet meine Gesundheit nicht nach London zu reisen; ich bitte der Royal Society meinen Dank und die herzlichsten Glïckwünsche zu überbringen.-W -W HELM RöNTGEN.

Professor Philippe A. Guye, University of Geneva.-Empêché à mon vif regret de prendre part au brillant anniversaire Royal Society, je prie son Président et ses membres d'agréer mes félicitations les plus sincères et mes vœux les plus cordiaux._Professeur Philippe Guye.

\section{FROM UNIVERSITIES, ACADEMIES, \&c.}

UnIVERsity of Graz.-Universitas literarum Graecensis gratulatur ex animo. - Haure, Rector.

Bohemian Karl-Ferdinand University of Pragivi. - Sir, - - I am very sorry to be prevented by official duties from personally taking part in the Celebration of the 250th Anniversary of the Royal Society.

I beg to heartily congratulate you and the Royal Society in the name of the Bohemian University of Prague, adding my own sincere wishes for the continued prosperity of the Royal Society, of which you are the President. I remain, Sir, very truly yours, F. VEsDovsKY.

UNIVERSITY of Sophia.-University of Sophia congratulates the Society at its jubilee and wishes it a still more glorious future in intensive and scientific work.-Rector JURINitch.

The Prusgian Minister of Enucation, Berdin.-Der Royal Society, die während eines Vierteljahrtausends durch ihre berühmten Mitglieder und 
ihre bedeutenden Arbeiten die Wissenschaft hervorragend gefördert hat, spreche ich zu ihrer Jubelfeier die heralichsten Wünsche der Preussischen Unterrichtsverwaltung aus, - Preussischer Kultusminister, Von Trott zU Solz.

Universtry of Padua.-Celeberrimae isti Societati Regali natalem suum ducentesimum et quinquagesimum omnium cum plausu peragenti Rector et Sodales Universitatis Patavinae uno consensu gratulantur, ut omnia bene fausteque eveniant auspicantes adprecantes.-Rector, Rossi.

University of Pisa. - Presidente, Royal Society, London: Dispiacente che il Prof. Nasini non possa recarsi costà prego V. S. accogliere nome questo Ateneo i voti più fervidi per la prosperità di cotesta benemerita Associazione.Rettore, Supino.

Marchese A. DE Gregorto, Vice-President of the Sicilian Society of Natural Sciences. - In the happy anniversary of the constitution of the Royal Society, I have the honour to send to you (who are the honoured President) the homages of our Società Siciliana of Natural Sciences, of which I am the Vice-President. I pray you to accept my best regards and believe me, Yours very truly, Antonio de Gregono.

Bergen Museum.-Bergens Museum, grateful for the Society's important contributions to the world's scientific progress during 250 years, sends its hearty congratulations to the jubilee with best wishes for the future.-KLaus $\mathrm{H}_{\text {ANSEN, }}$ JeNs Holmbor.

University of Dorpat.-Université Jouriew (Dorpat) présente ses félicitations et vœux de prospérité.-DE LA RUE J J Rotzk.

Impferial University of Kasan。-Die memorabili quem Societas Regalis Londinensis in scientia promovenda natalem 1912 celebrat Universitas Caesarea Casanensis vota ei sincera mittit: floreat, in dies crescat, scientiam ad maiorem patriae laudem fortiter promoveat clarissima Societas Regalis.-Pro Rectore Universitatis, Tonkofr.

Russian Central Chamber of Weights and Measures.-The Central Chamber of Weights and Measures, founded by the late Foreign Member of Royal Society, Mendeleeff, considers it as its duty to congratulate on the occasion of the fifth jubilee, and expresses the hope that also in future the Royal Society will flourish as highest authority promoting science and human prosperity. - Director, Egorofr.

University of Chicago.-University Chicago extends Royal Society cordial congratulations upon anniversary. Its distinguished membership includes men whose achievements are pride of English-speaking race. University expresses appreciation of their high accomplishment by sending Professor Frost as delegate.-JuDson.

UNIVERsity of QUEensLAND.-Chancellor, Queensland University, sends greetings Royal Society. 


\section{INDEX}

A.

Aberdeen University, Delegate from, 20.

Adelaide University, Delegate from, 17.

Africa, South, Delegates from, 18 ; Address from Royal Suciety of South Africa, 87.

Agram University, Address from, 32.

Aligarh, Delegate from, 18.

Allahabad University, Delegate from, 18.

American Academy, Boston, Delegate from, 17 ; Address from, 77.

American Mathematical Society, New York, Delegate from, 17 ;

National Academy ( $\boldsymbol{W}$ ashington), Address from, 79.

Philosophical Society, Philadelphia, Delegate from, 17 ; Address from, 78.

Amsterdam, Delegates from, 15; Address from University, 54; Address from Royal Academy of Sciences, 57.

Antiquaries, Delegate from Society of, 19 ; Address from, 96.

Ashmolean Society of Oxfordshire, Delegate from, 20 ; Address from, 115.

Asiatic Society of Bengal, Delegate from, 18 ; Address from, 86.

Athens, Delegate from, 14.

Australia, Delegates from, 17; Addresses from, 81,82 .

Austria-Hungary, Delegates from, 13.

B.

Bakhuysen, Professor, Telegram from, 123.

Belfast, Queen's University of, Delegate from, 21 ; Address from, 122.

Belgium, Delegates from, 13; Addresses from, 36 .

Bergen Museum, Telegram from, 124.

Berlin, Delegates from, 14; Address from the Royal Prussian Academy of Sciences, 49; Telegram from the Prussian Minister of Education, 123.

Berne, Delegate from, 16; Address from University, 66 ; Address from Helvétique Society of Natural Sciences, 68.

Birmingham University, Delegate from, 18 ; Address from, 90.

Bologna, Delegate from, 14 ; Address from University, 52 .

Bombay University, Delegate from, 18 ; Address from, 84.

Bordeaux, Delegates from, 13; Address from University, 45; Address from National Academy, 45 .

Boston, Delegate from, 17 ; Address from American Academy of Arts and sciences, 77.
Breslau, Delegate from, 14.

Bristol University, Delegate from, 18 ; Address from, 90.

British Academy, Delegate from, 19; Address from, 96.

British Association, Delegate from, 20; Address from, 113.

British Isles, Delegates from Institutious in, 18-21.

British Museum, Delegate from, 19 ; Address from, 97.

Brussels, Delegate from, 13 ; Address from Royal Academy of Sciences of, 37.

Budapest, Delegate from, 13; Address from Royal Hungarian University of, 36 .

Burlington House, 3, 4, 22.

\section{C.}

Cairo, Delegate from, 16.

Calcutta, Delegates from, 18 ; Address from University, 85; Address from Asiatic Society of Bengal, 86.

California, Delegates from, 16, 17.

Cambridge, Delegates from, 18, 20.

Cambridge Philosophical Society, Delegate from, 20; Address from, 114.

Cambridge University, Honorary Degrees conferred by, on some distinguished Delegates, 27-30; Address from, to Royal Society, 88.

Canada, Delegates from, 17; Addresses from, 83.

Cape of Good Hope University, Delegate from, 18.

Chemical Industry, Delegate from Society of, 20 ; Address from, 115 .

Chemical Society, Delegate from, 19 ; Address from, 98.

Chemistry, Delegate from Institute of, 19; Address from, 101.

Chicago University, Delegate from, 16 ; Telegram from, 124.

Christiania, Delegates from, 15; Address from Royal University, 58 ; Address from Academy of Sciences, 59 .

Clark University, Worcester, U.S.A., Delegate from, 16 ; Address from, 72 .

Clermont-Ferrand, Delegate from, 13 ; Address from University, 46 .

Columbia University, Delegate from, 16 ; Address from, 73 .

Connecticut Academy of Arts and Sciences, Delegate from, 17; Address from, 77.

Conversazione given by Royal Society, 22.

Copenhagen, Delegates from, 13; Address from University, 38 ; Address from Royal Danish Society of Science, 39. 
Cornell University, Delegate from, 16 ; Address from, 74 .

Cracow, Delegate from, 13 ; Address from Acalemy of Sciences, 33.

D.

Denmark, Delegates from, 13.

Dorpat, Delegate from, 15 ; Telegram from University, 124.

Dublin, Delegates from, 21 ; Address from University, 120; Address from Royal Irish Academy, 121.

Durham University, Delegate from, 18 ; Address from, 91.

\section{E.}

Edinburgh, Delegates from, 20; Address from the University, 117 ; Address from Royal Society of, 119.

Egypt, Delegates from, 16.

Engineers, Delegate from Institution of Civil, 19.

, Delegate from Institution of Electrical, 19 ; Address from, 102 .

, Delegate from Institution of Mechanical, 19.

Entomological Society, Delegate from, 19 ; Address from, 48.

Erlangen, Delegate from, 14.

$$
\text { F. }
$$

Finland, Delegates from, 15; Addresses from, 62-4.

Fischer, Emil, Telegram from, 123.

Florence, Delegate from, 14.

France, Delegates from, 13; Addresses from, 40-5.

Franklin Institute, Philadelphia, Delegate from, 17 ; Address from, 78.

Freiburg im Breisgau, Delegate from, 14.

$$
\text { G. }
$$

Garden Party at $W$ indsor and reception of the Council of the Royal Society and Delegates by their Majesties the King and Queen, 23.

Geneva, Delegate from, 16; Address from University, 67.

Geological Society, Delegate from, 19 ; Address from, 100.

Geological Survey of Great Britain, Delegate from, 19 ; Address from, 100.

Germany, Delegates from, 14; Combined Address from Universities of, on bronze Tablet, 48.

Giessen, Delegate from, 14.

Glasgow, Delegates from, 20 ; Address from University, 118; Address from Royal Philosophical Society, 119.

Göttingen, Delegates from, 14; Address from Royal Society of Sciences, 49 .

Graz University, Telegram from, 123.

Greece, Delegate from, 14.
Greifswald, Delegate from, 14.

Groningen, Delegate from, 15; Address from University of, 54 .

Guildhall, Dinuer in, 3, 21.

Guye, Professor, Telegram from, 123.

H.

Haarlem, Delegate from, 15; Address from Dutch Society of Sciences, 57.

Halifax, Nova Scotia, Delegate from Institute of Science, 18 ; Address from, 84.

Halle, Delegate from, 14.

Hamburg, Address from Natural Science Union of, 51 .

Harvard University, Delegate from, 16 ; Address from, 74.

Heidelberg, Delegate from, 14.

Helsingfors, Delegates from, 15 ; Address from University of Finland, 62; Address from Finnish Society of Sciences, 63.

Hobart, Address from Royal Society of Tasmania, 81.

I.

India, Delegates from, 18; Addresses from, 84-7.

Indian Institute of Science, Delegate from, 18 ; Address from, 87.

Ireland, Delegates from, 21; Addresses from, 120-2.

Iron and Steel Institute, Delegate from, 19 ; Address from, 103.

Italy, Delegates from, 14, 15; Addresses from, $51-3$.

J.

Japan, Delegates from, 16; Addresses from, $70-2$.

Johns Hopking University, Delegate from, 16 ; Address from, 75.

K.

Kasan University, Telegram from, 124.

Khartoum, Delegate from, 16.

Kingston, Ontario, Delegate from, 17.

Königsberg, Delegate from, 14.

Kyoto, Delegate from, 16 ; Addrese from Imperial University, 71.

\section{L.}

Lausanne, Address from University of, 68 .

Leeds University, Delegate from, 18 ; Address from, 92 .

Leipzig, Delegates from, 14.

Leland-Stanford University, Delegate from, 16.

Lemberg University, Address from, 34.

Leyden, Delegate from, 15; Address from University, 55.

Lille, Delegate from, 13.

Linnean Society, Delegate from, 19 ; Address from, 103.

Lisbon, Delegate from, 15.

Lister Institute of Preventive Medicine, Delegate from, 19 ; Address from, 103. 
Liverpool University, Delegate from, 19.

London, Delegates from Institutions in, 18-20.

London University, Address from, 89.

Lorentz, Professor, Telegram from, 123.

Louvain, Delegate from, 13 ; Address from University, 36 .

Lund, Delegates from, 16; Address from University, 64 .

M.

McGill University, Montreal, Delegate from, 17; Address from, 83.

Madras University, Delegate from, 18 ; Address from, 86.

Madrid, Delegate from, 15 .

Manchester, Delegates from, 19, 20 ; Address from University, 93 ; Address from Literary and Philosophical Society, 114.

Manitoba University, Delegate from, 18.

Marburg, Delegate from, 14.

Mathematical Society, Delegate from, 19 ; Address from, 104.

Melbourne, Delegates from, 17; Address from Hoyal Society of Victoria, 82.

Mercers Company, Delegate from, 19 ; Address from, 104.

Mexico, Delegate from, 17.

Michigan University, Delegate from, 16; Address from, 75 .

Milan, Delegate from, 14 .

Mineralogical Society, Delegate from, 19 ; Address from, 105 .

Minnesota University, Delegate from, 16.

Monaco, Delegate from, 15 ; Address from Oceanographical lnstitute, 53 .

Moscow, Delegate from, 16; Address from University, 60 ; Address from Imperial Society of Naturalists, 62 .

Munich, Delegates from, 14; Address from Royal Bavarian Academy of Sciences, 50. Münster, Delegate from, 14.

\section{N.}

Nancy, Delegate from, 13; Address from University, 46.

Naples, Delegates from, 15.

Natal University College, Delegate from, 18.

National Academy, Washington, Delegates from, 17.

National Physical Laboratory, Delegate from, 20.

Netherlands, Delegates from, 15; Addresses from, 54-8.

New BrunswickUniversity, Delegate from, 18.

New South Wales, Delegate from, 17 ; Address from, 81.

New York, Delegates from, 16, 17; Address from, 73.

Norway, Delegates from, 15; Addresses from, 58.

Nova Scotia, Delegates from, 18 ; Address from, 84 .
O.

Odessa University, Address from, 61.

Ordnance Survey, Delegate from, 20

Ottawa, Delegates from, 18.

Oxford University, Delegates from, 18; Honorary Degrees conferred by, on distinguished Delegates, 24-6; Address from, to Royal society, 88.

\section{P.}

Padua University, Telegram from, 124.

Palermo, Address from University of, 52.

Paris, Delegates from, 13; Address from University of, 40; Address from Academy of Sciences of, 42; Address from Observatory of, 44; Address from French Society of Physics, 45; Address from Botanical Society of France, 45 .

Pennsylvania, Delegate from, 16 ; Addresses from, 76-8.

Pharmaceutical Society, Delegate from, 19 ; Address from, 105.

Philadelphia, Delegates from, 16; Address from University, 76 .

Physical Society, Delegate from, 19; Address from, 106 .

Pisa University, Telegram from, 124.

Portugal, Delegate from, 15 ; Address from University of, 34 .

Prague, Delegate from, 13; Telegram from Bohemian Karl Ferdinand University, 123.

Princeton University, Delegate from, 16 ; Address from, 76.

\section{Q.}

Queensland University, Telegram from, 124.

R.

Rome, Delegates from, 14; Address from University, 51 ; Address from Academy of the Lincei, 53 .

Röntgen, Professor, Telegram from, 123.

Rostock, Delegate from, 14.

Rotterdam, Delegate from, 15; Address from Batavian Society of Experimental Philosophy, 58.

Royal Academy of Arts, Delegate from, 19. Royal Agricultural Society, Delegate from, 19.

Royal Anthropological Institute, Delegate from, 19; Address from, 106.

Royal Army Medical College, Delegate from, 19 .

Royal Astronomical Society, Delegate from, 19: Address from, 107.

Royal College of Physicians, Delegate from, 19 ; Address from, 95.

Royal College of Surgeons, Delegate from, 19 ; Address from, 95.

Royal Cornwall Polytechnic Society, Delegate from, 20. 
Royal Dublin Society, Delegate from, 21 ; Address from, 122 .

Royal Geographical Society, Delegate from, 20 ; Address from, 108.

Royal Horticultural Society, Delegate from, 20.

Royal Institute of British Architects, Delegate from, 20.

Royal Institution of Great Britain, Delegate from, 20 ; Address from, 109.

Royal Irish Academy, Delegate from, 21 ; Address from, 121.

Royal Meteorological Society, Delegate from, 20 ; Address from, 109.

Royal Microscopical Society, Delegate from, 20 ; Address from, 109.

Royal Observatory, Greenwich, Delegate from, 20.

Royal Society, Address by President of, 8 . ", "Charter of, 1, 2.

, , Diary of Anniversary Celebration of, 3 .

, Invitation issued by, 2.

, $\quad$, List of Delegates to, 13.

," $\quad$ Record of, 1, 2.

Royal Society Club, Dinner to Delegates given by, 23 .

Royal Society of Arts, Delegate from, 20 ; Address from, 110.

Royal Society of Medicine, Delegate from, 20 ; Address from, 111.

Royal Statistical Society, Delegate from, 20 ; Address from, 112.

Royal United Service Institution, Delegate from, 20.

Russia, Delegates from, 15; Addresses from, 59-62.

Russian Central Chamber of Weights and Measures, Telegram from, 124.

\section{S.}

St. Andrews University, Delegate from, 20 ; Address from, 117.

St. Petersburg, Delegates from, 15 ; Address from Imperial Academy of Sciences, 59.

San Francisco, Delegate from, 17.

Scotland, Delegates from, 20; Addresses from, 117-20.

Sheffield University, Delegate from, 19 ; Address from, 94.

Sicilian Society of Natural Sciences, Letter from President of, 124.

Smithsonian Institution, Washington, Delegate from, 17 ; Address from, 80 .

Sophia Lniversity, Telegram from, 123.

Spain, Delegate from, 15.

Stockholm, Delegates from, 16; Address from University, 64 ; Address from Royal Swedish Academy of Sciences, 65.

Strasburg, Delegate from, 14.
Sweden, Delegates from, 16; Addresses from, 64-6.

Switzejland, Delegates from, 16 ; Addresses from, 66-70.

Sydney University, Delegate from, 17 ; Address from, 81 .

Syon House, Garden Party at, given by the Duke and Duchess of Northumberland, 22.

T.

'Tasmania, Delegate from, 17; Address from, 81.

Timiriazef, Professor, Telegram from, 123.

'Tokyo, Delegate from, 16; Address from Imperial University, 70 .

Toronto University, Delegate from, 17 ; Address from, 83.

Toulouse, Delegate from, 13.

Turin, Delegate from, 15.

\section{U.}

United States of America, Delegates from, 16, 17; Addresses from, 72-80.

United States, Coast and Geodetic Survey, Address from, 80.

Upsala, Delegate from, 16; Address from University, 65.

Utrecht, Delegate from, 15 ; Address from University, 56.

V.

Victoria, Delegates from, 17.

Vienna, Address from Imperial Academy of, 31 .

W.

Wales, Univerity of, Delegate from, 19 ; Address from, 94.

Warsaw, Delegate from, 15 ; Address from University, 61 .

Washington, Delegates from, 17.

Address from Carnegie Insti-

tution, 79.
Address from National Academy of Sciences, 79 .

Address from Smithsonian Institution, 80.

, Address from

Address from Washington Academy of Sciences, 80.

Westminster Abbey, 3, 5, 22. Abey, 3, 5, 22.

Windsor, Garden Party at, 3, 23.

Wisconsin University, Delegate from, 17 ; Address from, 77.

Y.

Yale University, Delegate from, 17.

$\mathrm{Z}$.

Zoological Society, Delegate from, 20 ; Address from, 113 .

Zürich, Delegate from, 16; Address from Federal Technical High School, 69. 


$$
\ldots
$$





